\title{
Use of an entomopathogenic, endophytic Metarhizium brunneum isolate (Cb15III) to manage wireworm and Colorado potato beetle
}

\author{
Dissertation \\ zur Erlangung des Doktorgrades \\ der Fakultät für Agrarwissenschaften \\ der Georg-August-Universität Göttingen
}

vorgelegt von:

Laurenz Hettlage

geboren am 01.08.1987 in Münster, Deutschland

Göttingen, 05.2018 
D 7

1. Referent: $\quad$ Prof. Dr. rer. nat. habil. Stefan Vidal

2. Korreferent: Prof. Dr. rer. nat. Anant Patel

Tag der mündlichen Prüfung: 19.09.2018 


\section{Table of contents}

Table of contents

Summary

General introduction

Objectives

Chapter 1 Isolation and identification of a novel endophytic Metarhizium brunneum strain from Central Germany with potential activity against potato pests

Abstract

Introduction

Material and Method

Results

Discussion

Conclusion

Acknowledgements

References

Chapter 2 An endophytic Metarhizium brunneum isolate Cb15III active against the Colorado potato beetle

Abstract

Introduction

Material and Method

Results

Discussion

Conclusion

Acknowledgements 
Chapter 3 Encapsulated Metarhizium brunneum mycelium: a novel approach to managing wireworms in field with an endophytic $M$. brunneum strain Cb15III?

Abstract

Introduction

Material and Method

Results

Discussion

Conclusion

Acknowledgements

General discussion

Isolation and identification of Metarhizium spp. strains

Endophytic M. brunneum against $C P B$

Encapsulated mycelium against wireworms

References (General introduction and discussion)

Publications 


\section{Summary}

Potatoes (Solanum tuberosum, L.) are one of the most important crops worldwide and beside of rice, wheat and maize of an essential importance for the nourishment of the world population. However, potato plants are sensitive to a broad range of pests and pathogens and cultivation without a proper plant protection management can be difficult or impossible. Over the past decade, quality issues caused by wireworm (Agriotes spp.) tuber feeding became more and more relevant. Due to the soil born character of this pest species complex management is far more complicated, particularly because efficient protection agents are missing. Moreover, well managed pests like the Colorado potato beetle (Leptinotarsa decemlineata, SAY) developed resistances against often used insecticides e.g. pyrethroids. The development of new biological control agents against these and other pests is therefore of high importance, to overcome disadvantages of chemically synthetic plant protection products, which can be highly efficient but with indeterminate environmental effects.

Metarhizium brunneum $\mathrm{PETCH}$ is known to comprise many different isolates each specialized to one or more insect hosts. This makes M. brunneum a promising biological agent against several, relevant agricultural pests. However, field-scale, spray applications are difficult, not only because of a high sensitivity against UVradiation and limited efficacy under arid conditions but also a low competitive competence against nematodes or microorganism like bacteria or other fungi can reduce the activity of $M$. brunneum in field. An option to protect the fungus from environmental influences and exploit its entomopathogenic nature is to introduce the fungus into crop plants as an endophyte to build up a systemic protection against pests. As a consequence, $M$. brunneum isolates must be entomopathogenic to target organisms, endophytic in the specific crop plant and an industrial propagation and formulation should be possible.

To outline how a novel biological control agent is introduced to modern, biological plant protection management, this dissertation is structured in three chapters and focused on finding a new M. brunneum isolate, which can be systemically used to control potato pests. 
1. Chapter: To identify a broad acting endophytic entomopathogen, M. brunneum isolates from soil samples were collected and tested against a model organism (Tenebrio molitor L.), important potato pests and inoculated into potato tubers.

- General pathogenicity test: Seven M. brunneum isolates were tested against the larvae of $T$. molitor due to the known high sensitivity against entomopathogenic fungi. Two isolates were identified as highly pathogenic with mortalities up to $100 \%$ within 7 days after inoculation.

- Pathogenicity test against Agriotes spp.: The two most promising isolates (Cb15III and Gc2II) from the "general pathogenicity test" were tested against the larvae of Agriotes sputator (L.), A. obscurus (L.) and A. lineatus (L.). Isolate Cb15III was able to significantly reduce the number of vital $A$. obscurus and $A$. lineatus larvae compared to control groups within a time span of 70 days.

- Pathogenicity test against CPB: The M. brunneum isolate Cb15III was tested against the larval and adult stages of the CPB. $100 \%$ of the inoculated larvae died within 21 days and $80 \%$ of those showed a characteristic M. brunneum mycosis. Adult CPB beetles were not susceptible to the M. brunneum treatment.

- Endophytism test in potato: M. brunneum $\mathrm{Cb} 15 \mathrm{III}$ was tested for its endophytic potential to colonize potato tuber tissue. Therefore, 20 potato varieties were selected and M. brunneum Cb15III was inoculated into tubers. Re-isolation of M. brunneum from new developed shoots was successful, however with very low re-isolation rates.

2. Chapter: Potato tubers were inoculated with the M. brunneum isolate $\mathrm{Cb} 15 \mathrm{III}$ and used to evaluate the effects of colonized plants on the development of CPB. For the inoculation, dipping and injection methods were tested under greenhouse conditions and the more promising injection method was evaluated in two field experiments in southern Lower Saxony.

It was shown that larval development was influenced by the endophyte and significantly less beetle emerged from treated plants in the greenhouse experiment. In the field experiments the number of laid CPB eggs, $L_{1}-L_{3}$ and $L_{4}$ larvae was significantly reduced when tubers inoculated with $M$. brunneum. 
3. Chapter: To improve technical feasibility of field scale applications, M. brunneum Cb15III mycelium was imbed in a biopolymer matrix and formulated into dry microcapsules. Capsules with varying formulation adjuvants were tested in field in two consecutive years. Field trials were set up following the EPPO guideline for wireworms. Treatments were applied as spot applications beneath each tuber to enhance mycelium growth into the tuber tissue. Quantity and quality of potato yield was assessed and wireworm holes counted during harvest to assess quality losses. None of the tested treatments reduced the damage caused by wireworms; also no effects on plant grow or yield were observed. 


\section{General introduction}

Potato, Solanum tuberosum L., is an economically important staple crop cultivated across the world. With a total yield of 376.83 million tons in 2016, it is beside of maize, wheat and rice the most produced crop worldwide (FAO 2016). However, it is also one of the most susceptible crops in arable crop rotations. Potato plants are not only infested by several pathogens (e.g. Phytophthora infestans) but also by a large number of pests threatening yield and quality (Kapsa 2008). In conventional farming systems, pests and pathogens are controlled and managed with chemically synthetic plant protection agents (Kapsa 2008).To protect growing plants from pathogens and pests, fungicides are applied in intervals of $7-10$ days during growing season plus 1 - 2 herbicide and $2-4$ insecticide applications (Kapsa 2008; Cooke et al. 2011). This high input of chemical agents with partially unknown effects on ecosystems (Matson et al. 1997; Stoate et al. 2001; Kremen et al. 2002) is leading to an increased public demand for naturally produced foodstuff. Consequently, the worldwide organically farmed land increased from 11.0 ( $0.3 \%$ of overall agricultural land) to 57.8 (1.2\%) million hectares in the years 1999 to 2016 (Willer and Lernoud 2018)

In organic farming systems, chemically synthetic agents are not permitted. Alternatively, copper compounds can be applied against pathogens and biologicals (e.g. neem, Bacillus thuringiensis or spinosad) against pests (Anonymous 2008). Nevertheless, pathogens and pests are a tremendous challenge in organic farming, which is reflected in average yield varying between 39.8 and 22.9 t/ha in conventional and organic potato farming, respectively (Pawelzik and Möller 2014). Beside of the pathogens $P$. infestans and Rhizoctonia solani, wireworms, the larvae of click beetles (Agriotes spp., Coleoptera: Elateridae) (French and White 1965), and the Colorado potato beetle (CPB), Leptinotarsa decemlineata SAY (Coleoptera: Chrysomelidae), are some of the most devastating threats to potatoes (French and White 1965; Hare 1990; Vernon and van Herk 2013).

Adults and larvae of the CPB are a serious foliar pest in potato and widely spread in North America and Europe (Hare 1990; Grapputo et al. 2005; Kapsa 2008). In spring, female CPB deposit up to 4000 eggs in clusters of 20-60 eggs on the surface of host plant foliage (Hare 1990). Hatched larvae can defoliate more than $100 \mathrm{~cm}^{2}$ of leaf surface within 4 larval stages until they burrow into soil for pupation (Ferro et al. 1985; Hare 1990). A new CPB generation can emerge within 14 days after pupation and lay 
new eggs after maturation feeding (Hare 1990). An emergence of two or more generations in one year can lead to full defoliation of potato plant and therefore significant yield losses (Zehnder and Evanylo 1988). CPB have a high adaptability and evolved resistances to nearly all available insecticidal classes used over the past decades (Roush et al. 1990; Mota-Sanchez et al. 2006; Alyokhin et al. 2008). In organic farming CPB are attempted to be managed with the biologicals Bacillus thuringiensis and/ or neem extracts (Trisyono and Whalon 1999; Kryukov et al. 2009; Yaroslavtseva et al. 2017). In the field, efficacies of both agents are limited as neem extracts are mainly just effective against the first larval stages and CPB have evolved resistances against Bt-products. As a consequence, CPB adults and their late instars impair an efficient pest management in field (Whalon et al. 1993; Trisyono and Whalon 1999; Crowder et al. 2005; Premachandra et al. 2005). Without a prospective, sufficient pest management, CPB will threat organic potato production and cause defoliation and yield losses (Zehnder and Evanylo 1988; Kapsa 2008; Ertürk 2017).

A no less major threat to potatoes are wireworms, which are among the most important soil dwelling pests in potato causing substantial problems throughout the northern hemisphere (Parker and Howard 2001; Vernon et al. 2008). In May and June, female click beetle lay their eggs singly or in small clusters just below the soil. Thereby, weed or grass covered soil is preferred to protect eggs from desiccation (Parker and Howard 2001). Larvae hatch within 13 to 45 days after oviposition depending on temperature (Furlan 1998). Larval development is slow and can take up to five years or more with several larval stages, which are mainly dependent on soil moisture, temperature and food source (Furlan 1998; Parker and Howard 2001; Vernon and van Herk 2013). Mature click beetles hibernate in their pupation cells before emerging from soil in next year spring (Parker and Howard 2001). Larval stages are feeding on roots and decomposing plant material but can also cause severe damage to potato tubers. Wireworm damage is not causing yield losses but impair tuber quality (Vernon and van Herk 2013). Even slight wireworm damages can render harvest unmarketable, especially with coinciding drycore symptoms (Parker and Howard 2001; Keiser et al. 2012). Agriotes lineatus, $A$. obscurus, $A$. sputator and in some regions $A$. ustulatus are the most abundant and destructive wireworm species in European agriculture (Ritter and Richter 2013) Since the 1990s, these species reappeared as serious potato pests and problems exacerbated within the last years. Reasons are among other a cessation of non-specific insecticides such as organochlorides, organophosphates and 
carbamates,(Parker and Howard 2001) a transformation of permanent grassland to arable land and a reduction of soil tillage (Parker and Howard 2001; Vernon and van Herk 2013). Additionally, a proper pest management in Europe is difficult, not only due to the sheltered habitat of wireworms in soil but also a lack of permitted insecticides. Therefore, not just organic farmers have to use partially effective, non-chemical alternatives, such as an intensification of soil tillage to desiccate eggs, larvae and pupae or an incorporation of cruciferous plants (e.g. Brassica juncea) into soil (Furlan et al. 2010). It was also shown that an incorporation of entomopathogenic fungi into the soil can potentially manage wireworms (Reddy et al. 2014; Eckard et al. 2014; Rogge et al. 2017; Brandl et al. 2017; Razinger et al. 2018). Nevertheless, there is no agent on market protecting potato tubers sufficiently from wireworm damage, thus novel control agents and strategies to control wireworms and CPB are urgently needed. Finding and development of one single biological control agent that protects potatoes from wireworm tunneling and CPB defoliation would be highly beneficial for organic farmers.

Entomopathogenic fungi (EFP) are promising candidates in biological control and their potential to control pests was reviewed in several articles (Hajek and St. Leger 1994; Shah and Pell 2003; Hajek et al. 2007; Zehnder et al. 2007; Faria and Wraight 2007). Furthermore, studies revealed that wireworms as well as CPB are susceptible to an infection with EPF of the families Metarhizium spp. and Beauveria spp. (Wraight and Ramos 2002; Kabaluk and Ericsson 2007; Kryukov et al. 2009, 2014; Akbarian 2012; Tyurin et al. 2016; Yaroslavtseva et al. 2017). Wireworms are more susceptible to an infection with Metarhizium than with Beauveria (Kabaluk et al. 2007; Kabaluk and Ericsson 2007; Ritter and Richter 2013; Eckard et al. 2014; Razinger et al. 2018), whereas CPB can be infected by both fungal families (Wraight and Ramos 2002; Kryukov et al. 2009; Akbarian 2012; Tyurin et al. 2016). Therefore, Metarhizium spp. and in particular Metarhizium brunneum PETCH (Ascomycota: Hypocreales: Clavicipitaceae) seems to be appropriate to control both potato pests.

Technical applications of Metarhizium spp. on field scale are, however, difficult. Aerial applied conidia are sensitive to changes in relative air humidity, temperature and UVradiation (Hywel-Jones and Gillespie 1990; Hallsworth and Magan 1999; Lovett and St. Leger 2014). In addition, unformulated EPF degrade over time and can be outpaced by antagonistic organisms when artificially introduced into soil (Scheepmaker and Butt 2010; Pilz et al. 2011) 
The discovery that EPF are also endophytes in plants revealed new opportunities in biological plant protection (Quesada-Moraga et al. 2014; Vidal and Jaber 2015; Moonjely et al. 2016). EPF, colonizing plants, can affect insect pests (Batta 2013; Contreras et al. 2014; Muvea et al. 2014; Mantzoukas et al. 2015) and have, furthermore, multiple beneficial effects on host plants such as growth promotion (Khan et al. 2012), nutrient uptake (Behie et al. 2012), salt stress mitigation (Khan et al. 2012) and protection against plant pathogens (Sasan and Bidochka 2012). Recently published studies indicated that $M$. brunneum can be established in potatoes as an endophyte (Ríos-Moreno et al. 2016; Krell et al. 2018b). Thus, an endophytic M. brunneum strain can be a promising way to control wireworms and CPB without exposing M. brunneum to environmental influence (Ownley et al. 2010). However, the mode of action in this complex plant - entomopathogen - insect - system is still unknown and data on insects infected by an endophytic, entomopathogenic fungus are rare. 


\section{Objectives}

In this study, novel endophytic Metarhizium spp. strains were isolated from soil samples and identified. Promising strains were evaluated for their potential to protect potatoes from wireworm and CPB damage in laboratory, greenhouse and field scale.

1. Isolation and identification of a novel Metarhizium spp. strain that possess requirements to protect potato plants endophytically. Therefore, strains were tested to be:

a. Virulent to the wireworm species $A$. lineatus, $A$. sputator and $A$. obscurus

b. Virulent to CPB larvae and/ or beetles

c. Able to colonize potato plant tissue endophytically

2. Evaluation of an endophytic control approach to manage CPB on field scale.

a. Do potato plants colonized by M. brunneum influence the development of CPB?

b. Does an endophytic $M$. brunneum changes plants preference of adult CPB?

C. Can an endophytically applied $M$. brunneum strain protect potato plants on field scale?

3. Evaluation of technically encapsulated M. brunneum mycelium on field scale and its potential to manage wireworms.

a. Is M. brunneum able to colonize potato plants in field and do formulations affect endophytism?

b. Can technical applications reduce wireworm damage on tubers?

c. Is M. brunneum persistent in field soil during growing season? 


\section{Chapter 1}

Isolation and identification of a novel endophytic Metarhizium brunneum strain from Central Germany with potential activity against potato pests
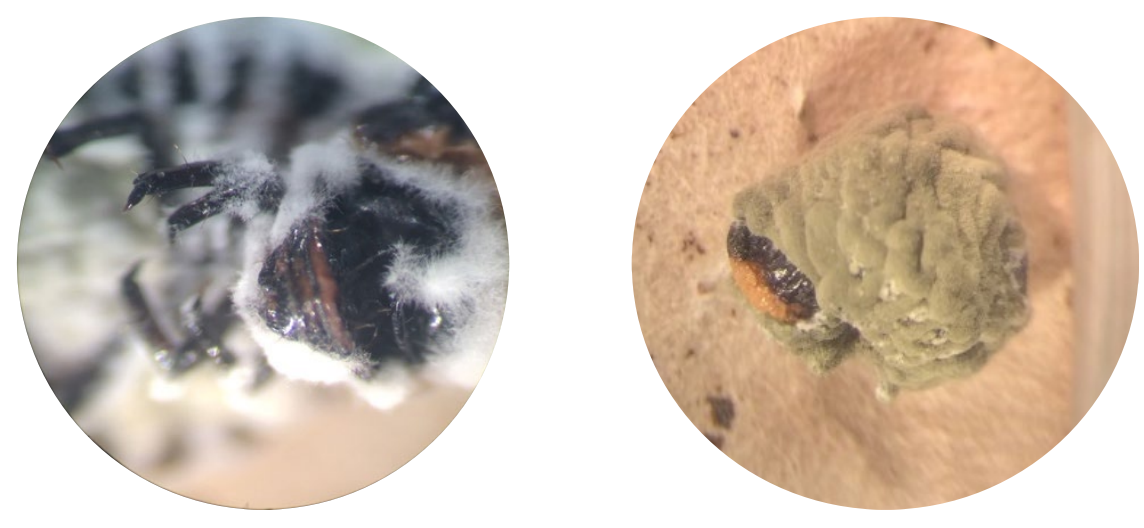

Authors: Laurenz Hettlage*, Daria-Jasmin Haunschild, Malte Ansgar Stöppler, Stefan Vidal

${ }^{*}$ Corresponding author 
Chapter 1 Isolation and identification of a novel endophytic $M$. brunneum strain from Central Germany with potential activity against potato pests

Isolation and identification of a novel endophytic Metarhizium brunneum strain from Central Germany with potential activity against potato pests

L. Hettlage ${ }^{1}$, D.-J. Haunschild ${ }^{1}$, M. A. Stöppler ${ }^{1}$, S. Vidal ${ }^{1}$

${ }^{1}$ Georg-August University, Department of Crop Sciences, Agricultural Entomology, Grisebachstr. 6, 37077 Göttingen, Germany,

Phone: +49 (0) 551-39 33732, E-mail: laurenz.hettlage@agr.uni-goettingen.de

\section{Abstract}

Potato (Solanum tuberosum, L.) crops are vulnerable to a broad range of pests and pathogens. In particular organic farmers are challenged to protect their crops from infestations and therefore crop losses. Beside of pathogens, wireworms (Agriotes spp., Coleoptera: Elateridae) and the Colorado potato beetle (CPB), Leptinotarsa decemlineata SAY (Coleoptera: Chrysomelidae) are hardly manageable pests in organic potato farming. CPB evolved resistances against nearly all insecticidal agents available and wireworm are well protected in their below ground habitats. Endophytic, entomopathogenic fungi, such as Metarhiziumbrunneum PETCH (Ascomycota: Hypocreales: Clavicipitaceae), can have the potential to build up a systemic protection against pests. It is known that Metarhizium brunneum can infect wireworms or CPB, though no solely strain is descripted infecting both. In this study M. brunneum strains were isolated from soil probes, identified and tested for their ability to infect wireworms and CPB. The most promising strain was inoculated into potato tubers and re-isolated from newly developed shoots to unveil their endophytic potential. In this study, the M. brunneum strain Cb15III was observed to be the most promising candidate to protect potato crops from wireworms and CPB. The strain revealed $\mathrm{LT}_{50}$ values of $21 \pm 7.75,16 \pm 1.55$ and 18 days \pm 15.02 for the wireworm species $A$. lineatus, $A$. obscurus and $A$. sputator, respectively. For CPB larvae a LT50 value of 10 days \pm 0.78 were observed. CPB adults were not affected by a $M$. brunneum Cb15III treatment. M. brunneum Cb15III was re-isolated from shoots after tubers have been inoculated, albeit re-isolation rates were very low. This study demonstrated the possibility to isolate novel entomopathogenic fungi from local habitats and unveil their potential as biological control agents against potato pests.

Keywords: Metarhizium brunneum, Colorado potato beetle, wireworms, potato, endophyte 
Chapter 1 Isolation and identification of a novel endophytic $M$. brunneum strain from Central Germany with potential activity against potato pests

\section{Introduction}

Plant protection management in modern agriculture is based on chemically synthetic agents to protect crops from pests and pathogens. However, increasing public demand for naturally produced foodstuff is putting agriculture under pressure to reduce application of insecticides. Consequently, organic farming systems are getting more and more prominent, hence worldwide organically farmed land increased from 11.0 ( $0.3 \%$ of overall agricultural land) to 57.8 (1.2\%) million hectares in the years 1999 to 2016 (Willer and Lernoud 2018). But organic farmers are facing a broad range of pests and diseases, since a lack of fast and predictable acting insecticidal agents is making organically cultivated crops vulnerable to yield losses due to severe pest infestations (Oerke 2006). Some biological control agents acting as effectively as chemically synthetic insecticide, such as spinosad (Salgado 1998; Sparks et al. 2001), can also be as devastating to non-target organisms (Biondi et al. 2012). Alternatively, farmers can apply products based on the bacterium Bacillus thuringiensis. The active ingredients of these products are proteins produced by $B$. thuringiensis and which toxically acting to the digested system of herbivore insects without harming pollinators (Slaney et al. 1992; Schnepf et al. 1998; Wang et al. 2008; Dai et al. 2016). However, insect resistances to Bt-toxins are reported which lowering the efficacy of these products (Whalon et al. 1993; Crowder et al. 2005). The botanical neem is a widely used alternative to manage pests. The efficacy is lower compared to spinosad or Btproducts and the active ingredient azadirachtin is mainly active against early larval stages (Trisyono and Whalon 1999; Premachandra et al. 2005)

Especially in potato crops, the lack of highly effective biological insecticides is a challenge. Pest infestation can be of significant relevance to tuber yield and quality (Kapsa 2008). The potato plant, Solanum tuberosum L., is attacked above and below ground by nematodes (Williamson and Hussey 1996), aphids (Landis et al. 1972), wireworms (Agriotes spp., Coleoptera: Elateridae) (French and White 1965), and the Colorado potato beetle (CPB), Leptinotarsa decemlineata SAY (Coleoptera: Chrysomelidae). Management of these pests in organic potato crops is today limited to: cultivation of less susceptible crop varieties (Johnson et al. 2008), crop rotation (Kratochvil et al. 2004; Lamondia 2006) or natural insecticides (Schnepf et al. 1998; Copping and Duke 2007). 
In addition, applications of entomopathogens showed sufficient efficacies against potato pests. Laznik et al. (2010) showed that entomopathogenic nematodes, Steinernema feltiae, can successfully be applied as a foliar treatment against CPB. Larvae of the CPB were also susceptible to the EPF Metarhizium anisopliae, Cordyceps militaris and Beauveria bassiana under laboratory conditions (Akbarian 2012; Kryukov et al. 2014).

Eckard et al. (2014) demonstrated that three Metarhizium brunneum PETCH (Ascomycota: Hypocreales: Clavicipitaceae) strains, BIPESCO 5, V1002 and ART 2825, were able to infect and kill the three most abundant and destructive wireworm species Agriotes lineatus (Coleoptera: Elateridae), A. obscurus and A. sputator (Ritter and Richter 2013). Under laboratory conditions, the M. brunneum strain ART 2825 showed $\mathrm{LT}_{50}$ values between $14 \pm 5.4$ ( $A$. obscurus) and $21 \pm 4.5$ days (A. lineatus), A. sputator $L_{50}$ values could not be defined in this study because of a mortality less than 50 \% (Eckard et al. 2014). Brandl et al. (2017) revealed that the M. brunneum strain ART2825 is capable to reduce tuber damage induced by wireworms under field conditions, when applied in the sowing furrow as formulated capsules. These results indicate that EPF are generally capable of infecting a wide range of insects, but each strain can be closely associated with its specific hosts. However, it seems possible that one EPF strain can also infect other arthropod species such as ticks, for although the M. brunneum strain F52 is virulent against wireworms it can also infect Asian longhorned beetle, Anoplophora glabripennis, as well as Ixodes scapularis nymphs (Bharadwaj and Stafford 2011; Behle et al. 2013; Goble et al. 2015). The knowledge that one M. brunneum strain can infect various arthropod families could be exploited to manage various pests of the same crop. It is reported that wireworms as well as CPB are susceptible to an infection with EPF but there is no study showing that one strain is able to infect both pests on a sufficient level (Kabaluk and Ericsson 2007; Tyurin et al. 2016). It would be highly beneficial for organic farmers to have one single agent protecting potato crops from pest infestation.

Therefore, this study aims to demonstrate the possibility of isolating EPF from local habitats and exploit their virulence against wireworms and CPB. Furthermore, the EPF is tested for its ability to endophytically colonize potato plants. Results will allow the evaluation of a combined management of above and belowground pests with an entomopathogenic, endophytic fungus. 
Chapter 1 Isolation and identification of a novel endophytic $M$. brunneum strain from Central Germany with potential activity against potato pests

\section{Material and Method}

\section{Isolation and identification of Metarhizium strains}

Metarhizium spp. strains used in the following experiments were isolated from soil samples taken in south Lower Saxony near the village Boesinghausen (N 51 $34^{\prime}$ '00"; O $\left.10^{\circ} 3^{\prime} 36^{\prime \prime}\right)$. Sampling was conducted following the protocol of Schneider et al. (2012). The first sample site was arable land (labeled as C) with a field size of $20,000 \mathrm{~m}^{2}$. It was cultivated with winter wheat, barley or oilseed rape as part of a crop rotation and was managed according to conventional farming standards. The second sample site was a semi-natural, permanent grassland (labeled as $\mathrm{G}$ ) with a size of $5,000 \mathrm{~m}^{2}$. Soil was not cultivated for at least seven years and grassland was harvested twice a year. In each sample site four transects ( $a, b, c$ and d) were defined with a distance of $10 \mathrm{~m}$ to each other and a length of $100 \mathrm{~m}$. Twenty soil cores of $1.8 \mathrm{~cm}$ diameter and $15 \mathrm{~cm}$ depth were collect within each transect $(1-20)$ with a spacing of $5 \mathrm{~m}$ from each other. Plant debris was removed and samples were collected in plastic bags. Samples were stored in the laboratory over night at room temperature to avoid condensation.

Metarhizium spp. propagules were isolated following the protocol of Brandl et al. (2017). Soil samples were homogenized and sieved though a mesh ( $\varnothing 5 \mathrm{~mm}$, RETSCH $\mathrm{GmbH}$, Haan, Germany). Subsamples of $5 \mathrm{~g}$ were transferred to a $50 \mathrm{ml}$ centrifugation tube (Carl Roth $\mathrm{GmbH} \&$ Co. KG, Karlsruhe, Germany) and suspended with $25 \mathrm{ml}$ sterile $0.1 \%(w / v)$ Tween ${ }^{\circledR} 80$ solution (Carl Roth $\mathrm{GmbH} \&$ Co. KG, Karlsruhe, Germany). Tubes were inverted every 30 min over a time span of $3.5 \mathrm{~h}$ to release fungal propagules from the soil matrix in the suspension (Goettel and Douglas Inglis 1997). $100 \mu$ of the $10^{0}, 10^{-1}$ or $10^{-2}$ dilutions of the supernatant were spread on semiselective media (Strasser et al. 1996), respectively. Plates were incubated in the dark at $25^{\circ} \mathrm{C}$ for 7 days. Separately grown, fungal colonies from the highest dilution were transferred to fresh semi-selective media with a cork borer. If colonies established on media with the highest dilution, colonies from the next higher dilution were taken. After 14 days incubation, colonies were identified as Metarhizium spp. based on morphological criteria ((i) conidiogenesis in dense hymenia, (ii) branching conidiophores, (iii) clavate/cylindrical conidia, (iiii) conidia chains) relevant for the genus level (Humber 2012). 
Chapter 1 Isolation and identification of a novel endophytic $M$. brunneum strain from Central Germany with potential activity against potato pests

Identification down to species level was conducted at the workgroup of Dr. Jürg Enkerli (ISS Agroscope, Zürich, Switzerland) with multiplex microsatellite markers (Mayerhofer et al. 2015). All further tested strains revealed to be strains of Metarhizium brunneum (Jürg Enkerli, personal communication).

\section{Fungal preparation}

All strains were cultured on potato-extract-dextrose-agar (PDA) (Carl Roth $\mathrm{GmbH}$ \& Co. KG, Karlsruhe, Germany) in the dark in a climatic cabinet (Biologischer Klimaschrank WB 750, mytron Bio- und Solartechnik $\mathrm{GmbH}$, Heilbad Heiligenstadt, Germany) at $25^{\circ} \mathrm{C}$ and $70 \%$ relative humidity $(\mathrm{RH})$. Conidia suspensions were freshly prepared for each experiment with 2 - 3 weeks old M. brunneum cultures. Aero conidia for suspensions were harvested by flooding cultures with $0.1 \%(v / v)$ Tween ${ }^{\circledR} 80$ and gently scratching of mycelia (including spores) from the PDA media surface. Conidia/mycelium suspension was transferred to a $400 \mathrm{ml}$ glass beaker and stirred at $700 \mathrm{rpm}$ on a magnetic stirred in a total volume of $200 \mathrm{ml}$ to detach conidia from mycelia. Mycelium debris was removed by filtering the suspension through a sterile metal sieve (mesh opening: $1 \mathrm{~mm}$ ). Conidia were determined via counting using a hemocytometer (Thoma chamber, Paul Marienfeld GmbH \& Co. KG, LaudaKönigshofen, Germany) (Goettel and Douglas Inglis 1997). Spore vitality was evaluated in Petri plates on PDA incubated for $36 \mathrm{~h}$ at $25^{\circ} \mathrm{C}$, with vitality rates always above $92 \%$. Conidia concentration was adjusted to $1 \times 10^{7}$ by adding $0.1 \%$ Tween $^{\circledR} 80$ solution before using in experiments.

\section{General Metarhizium brunneum pathogenicity test}

Tenebrio molitor L. (Coleoptera: Tenebrionidae) larvae were used to conduct the general pathogenicity test because of their known sensitivity against entomopathogenic fungi such as M. brunneum (Lee et al. 2014). Six Metarhizium brunneum strains from soil probes were used for the experiment, three from grassland samples (Gb5I, Gc2II and Gb9II) and three from crop field samples (Ca8II, Ca16 and Cb15). Additionally, the M. brunneum strain ART 2825 was used as a reference due to its known pathogenicity against the larvae of Agriotes spp. (Eckard et al. 2014; Brandl et al. 2017). 
For each treatment, five plastic trays $(10 \mathrm{~cm} \times 7.5 \mathrm{~cm} \times 5 \mathrm{~cm}$, Nette Papier $\mathrm{GmbH}$, Göttingen, Germany) were filled with $150 \mathrm{ml}$ of a soil (Fruhstorfer Einheitserde Typ P, HAWITA Gruppe $\mathrm{GmbH}$, Vechta, Germany) vermiculite $(2-8 \mathrm{~mm})$ mixture in a ratio of $5: 1$ and watered with $15 \mathrm{ml}$ autoclaved tap water. Five $\mathrm{ml}$ spore suspension $\left(1 \times 10^{7}\right.$ aerial conidia/ $\left.\mathrm{ml}\right)$ was pipetted on soils surface of each plastic tray. The control was treated with $5 \mathrm{ml} 0.1 \%(\mathrm{v} / \mathrm{v})$ Tween $^{\circledR} 80$ (Carl Roth $\mathrm{GmbH}+$ Co. KG, Karlsruhe, Germany). Plastic trays were sealed with an appropriate lid $(10 \mathrm{~cm} \times 7.5 \mathrm{~cm}$, Nette Papier GmbH, Göttingen, Germany) and manually shaken to for 30 seconds. Four, 20 mm long T. molitor larvae (Zoo-Busch GmbH, Göttingen, Germany) were add to each plastic tray and afterwards manually shaken again for 5 seconds. The lid was perforated with a needle $(\varnothing 1 \mathrm{~mm})$ to allow air exchange. Treatments were stored in a climatic cabinet (Biologischer Klimaschrank WB 750, mytron Bio- und Solartechnik $\mathrm{GmbH}$, Heilbad Heiligenstadt, Germany) at $22^{\circ} \mathrm{C} \pm 1$ and $70 \% \pm 5$ relative humidity and randomly distributed at one rack level. The number of vital larvae was examined after 5, 8, 11, 14, 17 and 20 days after inoculation (dpi). Dead larvae were immersed in $2 \%(\mathrm{v} / \mathrm{v})$ sodium hypochlorite and $70 \%(\mathrm{v} / \mathrm{v})$ ethanol for 2 minutes, respectively and then rinsed three times in autoclaved tap water. $100 \mu \mathrm{l}$ of the last watering step was plated on PDA-Media and incubated for 4 days at $25^{\circ} \mathrm{C}$ to prove the success of the surface sterilization. Surface sterilized larvae were individually transferred to sterile Petri dishes ( $\varnothing 60 \mathrm{~mm}$, with vents, Sarstedt AG \& Co. KG, Nümbrecht, Germany) lined with autoclaved filter paper ( $\varnothing 50 \mathrm{~mm}$, Munktell \& Filtrak $\mathrm{GmbH}$, Bärenstein, Germany) and moistened with $200 \mu \mathrm{l}$ autoclaved tap water. Petri dishes were sealed with laboratory film (Parafilm ${ }^{\circledR}$ M, Bemis Company Inc., Neenah, USA) and incubated at $25^{\circ} \mathrm{C}$ for 14 days or until a characteristic M. brunneum mycosis became visible. Additionally, mycelium and spores were examined under a light microscope (200 x magnification, $\mathrm{BH} 2-\mathrm{HLSH}$, Olympus Corporation, Tokyo, Japan) to prove M. brunneum outgrow from the cadaver.

\section{Pathogenicity test against wireworms}

The strains Gc2II and Cb15III revealed to be the most aggressive from each habitat, permanent grassland and field. Consequently, these strains were tested against larvae of the Agriotes species $A$. lineatus, $A$. obscurus and $A$. sputator from a wireworm rearing. The pathogenicity test was conducted in $50 \mathrm{ml}$ centrifuge tubes $(115 \times 28 \mathrm{~mm}$, 
Sarstedt AG \& Co. KG, Nümbrecht, Germany) filled with soil (Fruhstorfer Einheitserde Typ P, HAWITA Gruppe GmbH, Vechta, Germany) as described by Brandl et al. (2017). Centrifuge tubes were filled with $40 \mathrm{ml}$ soil and mixed with $5 \mathrm{ml}$ spore suspension $\left(1 \times 10^{7}\right.$ aero conidia / $\mathrm{ml}$ ) of the M. brunneum strains Cb15III or Gc2II. A control was conducted with $5 \mathrm{ml} 0.1 \%(\mathrm{v} / \mathrm{v})$ Tween ${ }^{\circledR} 80$. One wireworm (length $1.2-1.7 \mathrm{~cm}$ ) was placed in each tube and a carrot slice (ca. $2 \times 2 \times 0.7 \mathrm{~cm}$ ) was served as a food source. Each treatment was replicated ten times per wireworm species. Tubes were stored in the climatic cabinet at $22^{\circ} \mathrm{C} \pm 1$ and $70 \% \pm 5 \mathrm{RH}$ and randomly distributed across rack levels. Wireworms were monitored weekly over a period of 12 weeks. Dead larvae were removed, surface sterilized and transferred to sterile Petri dishes as described for $T$. molitor larvae. Soil moisture was kept between $20-25 \%$ and moistened with sterile tap water if needed. Carrot slices were replaced, if heavy feeding damage or mold was observed.

\section{Pathogenicity test against Leptinotarsa decemlineata}

The M. brunneum strain Cb15III was tested in a pathogenicity test against Leptinotarsa decemlineata larvae and adults was conducted in sterile Petri dishes (ø $60 \mathrm{~mm})$. Second instar larvae and newly hatched adults were individually placed in a Petri dish lined with autoclaved filter paper ( $\varnothing 50 \mathrm{~mm}$ ). Larvae and adults were doused with $400 \mu \mathrm{l}$ of a spore suspension $\left(1 \times 10^{7}\right.$ aero conidia / ml) or $400 \mu \mathrm{l} 0.1 \%(\mathrm{v} / \mathrm{v})$ Tween $^{\circledR}$ 80 as a control. A potato leave (var. Belana, ca. $40 \times 40 \mathrm{~mm}$ ) was added as food source to each Petri dish. All treatments were stored randomly distributed in a climatic cabinet at $22^{\circ} \mathrm{C} \pm 1,70 \% \pm 5 \mathrm{RH}$ and $16 \mathrm{~h}$ light/ $8 \mathrm{~h}$ dark. Petri dishes were monitored daily over a period of 4 weeks. Every second day, potato leaves were replaced and filter papers were moistened with $200 \mu$ sterile tap water. Dead larvae and adult beetle were removed from Petri dishes, surface sterilized and placed in new sterile Petri dishes to observe mycelium outgrowth as described T. molitor larvae.

\section{Endophyte test in potato tuber}

To prove the ability of the M. brunneum strain $\mathrm{Cb} 15 \mathrm{Il}$ to grow endophytically in potato plants, tubers form 20 potato varieties (Bioland Hof Jeebel Biogartenversand OHG, Salzwedel, Germany) were inoculated with a spore suspensions and re-isolated from newly developed shoots (Table 1). Equal sized tubers (ca. $40 \mathrm{~g}$ ) from all varieties were 
Chapter 1 Isolation and identification of a novel endophytic $M$. brunneum strain from Central Germany with potential activity against potato pests

washed with tap water and surface sterilized. Therefore, tubers were immersed in $7 \%$ (v/v) sodium hypochlorite and $70 \%(\mathrm{v} / \mathrm{v})$ ethanol for 2 minutes, respectively and then rinsed three times in autoclaved tap water. $100 \mu \mathrm{l}$ of the last watering step was plated on PDA-Media and incubated for four days at $25^{\circ} \mathrm{C}$ to prove the success of the surface sterilization. Ten tubers of each variety were inoculated with $10 \mu \mathrm{l}$ of a spore suspension $\left(1 \times 10^{7}\right.$ aero conidia / ml) or $0.1 \%(\mathrm{v} / \mathrm{v})$ Tween ${ }^{\circledR} 80$ using a microliter syringe (Hamilton Company, Reno, USA). The spore suspension as well as $0.1 \%$ Tween $^{\circledR} 80$ was injected into the middle of tubers. The injection wound was cleaned and sterilized with a $70 \%(\mathrm{v} / \mathrm{v})$ ethanol soaked, sterile paper tissue to avoid unwanted vital $M$. brunneum spores on the surface. Tubers were placed in plastic boxes (6.5 x $17.5 \times 11.5 \mathrm{~cm}$, Nette Papier GmbH, Göttingen, Germany) cleaned with 70 \% ethanol and sealed with an appropriate plastic lid. Boxes were stored in the dark in a climate cabinet at $22^{\circ} \mathrm{C} \pm 1$ and $70 \% \pm 5 \mathrm{RH}$ until new developed potato shoots reached a length of $40 \mathrm{~mm}$. Three shoots of each tuber were cut off with a sterile scalpel and sectioned in three equal parts in a sterile laminar flow cabinet. Sectioned shoots were placed on semi-selective media and in incubated in the dark at $25^{\circ} \mathrm{C}$ for four weeks. Growing mycelium and spores were examined under a microscope to verify $M$. brunneum outgrowth.

Table 1 Potato varieties used in the experiment

\section{Potato varieties}

(Bioland Hof Jeebel Biogartenversand OHG, Salzwedel, Germany)

\begin{tabular}{llll}
\hline Adretta & Augusta & Cassablanca & Marabel \\
Agila & Belana & Ditta & Nicola \\
Agria & Bellinda & Gala & Quarta \\
Annabelle & Bintje & Granola & Orla \\
Annalena & Campina & Linda & Solist \\
\hline
\end{tabular}

\section{Statistical analysis}

All values are given as means \pm standard errors $(\mathrm{SE})$, unless otherwise stated.

T. molitor larval vitality was calculated by comparing the number of vital larvae with the number of attached larvae in each treatment. 


$$
\% \text { vitality }=\left(1-\frac{\text { no. dead larvae }}{\text { no. attached larvae }}\right) * 100
$$

Mycosis was estimated for each treatment by comparing the number of mycosed T. molitor larvae compared to the total number of dead larvae.

$$
\% \text { mycosis }=\frac{\text { no. mycosed larvae }}{\text { no. dead larvae }} * 100
$$

Vitality was analyzed by nonparametric Kruskal-Wallis ANOVA followed by a Dunnetttest (M. brunneum treatments compared to "Control") $(\alpha=0.05)$. Differences in mycosis rates were statistically compared with a $2 \times 2$ table Fisher's exact test $(\alpha=0.05)$ (Fisher 1922).

Agriotes spp. as well as CPB survival was analyzed with Kaplan-Meier survival analysis (log-rank test) (Kaplan and Meier 1958). Dead larvae were referred to an "event", whereas vital larvae were "censored" within the log-rank test procedure. Significant differences between treatments were detected with the Holm-Sidak pairwise test $(\alpha=0.05)$.

Tuber germination was analyzed for each potato variation with Mann-Whitney-U test ( $\alpha=0.05$ ) by comparing the bygone time until shoots reached a size of $40 \mathrm{~mm}$. Percentages of germinated tubers as well as fungal re-isolation rates per treatment and variation were analyzed with a $2 \times 2$ table Fisher's exact test $(\alpha=0.05)$, respectively. Re-isolation rates of $M$. brunneum as well as for other fungi from potato shoots were calculated by comparing the number of shoots with fungal outgrowth to the germinated, plated shoots.

$$
\% \text { re }- \text { isolated }=\frac{\text { no. fungi growing from shoots }}{\text { no. plated shoots }} * 100
$$

All statistical analyses were carried out with the software STATISTICA, version 13 (StatSoft Inc., Tulsa, OK, USA). Kaplan-Meier survival analysis was done with SigmaPlot, version 11.0 (Analytical Software, Tallahasee, FI, USA). 
Chapter 1 Isolation and identification of a novel endophytic $M$. brunneum strain from Central Germany with potential activity against potato pests

\section{Results}

\section{Identification of Metarhizium strains}

Microsatellite analysis identified all soil-isolated colonies as Metarhizium brunneum and the number of base pairs within microsatellites indicated that most of the isolated colonies originated from different strains (data not shown). Hierarchical clusterization of strains revealed a close relationship of the strains Cb15III, Ca16 and Gc5I to the known M. brunneum strains BIPESCO 5, ARSEF 5198 and Ma714 (Figure 1).

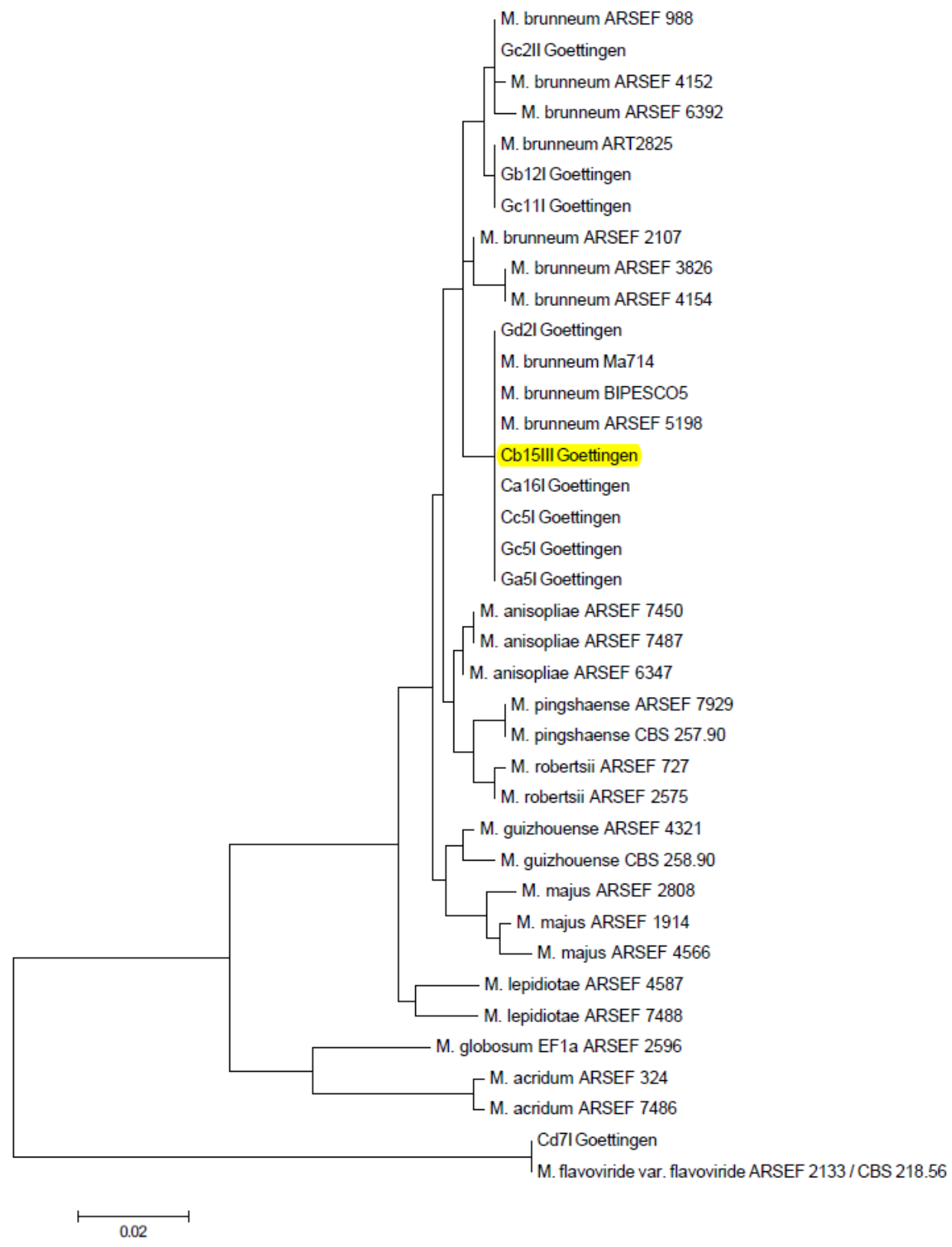

Figure 1 Hierarchical clustering of soil-isolated Metarhizum strains from Göttingen including the in this study tested strains Gc2II, Cb15III, Ca16I and Gc5I) (Jürg Enkerli, Personal communication) 
Chapter 1 Isolation and identification of a novel endophytic M. brunneum strain from Central Germany with potential activity against potato pests

\section{General Metarhizium brunneum pathogenicity test}

Dead Tenebrio molitor larvae were found five days past inoculation (dpi). After seven days, Metarhizium brunneum treatments affected the number of vital larvae significantly (Kruskal-Wallis ANOVA: $\mathrm{H}_{7,40}=29.96, \mathrm{p}<0.0001$ ). All strains from arable land, Ca16 $(30.00 \% \pm 9.35)(p<0.001)$, Ca8II $(10.00 \% \pm 6.12)(p<0.0001)$ and Cb15III $(0.00 \% \pm 0.00) \quad(p<0.00001)$, and one strain from grassland, Gc5I $(25.00 \% \pm 19.36)(p<0.001)$ significantly reduced the number of vital larvae compared to the "Control" $(85.00 \% \pm 6.12)$ within the first week after inoculation (Figure 2). Strain Gc2II (35.00\% \pm 12.75$)$ significantly reduced the number of vital larvae within $11 \mathrm{dpi}$ $(p<0.01)$. The well-studied M. brunneum strain ART $2825(14.00 \% \pm 10.00)$ reduced the number of vital T. molitor larvae significantly at $18 \mathrm{dpi}(p<0.5)$. The Strain Gb9ll was not able to show significant effects on the larval vitality till experiment terminated. Mycosis rates were always above $60 \%$ for all $M$. brunneum treatments but did not exceed $90 \%$. No statistically significant differences were found in-between treatments $(2 \times 2$ table Fisher's exact test $(\alpha=0.05))$ (Figure 3$)$. Most larvae showed symptoms of mycosis when treated with Gc2ll (16 out of 20 dead larvae) and fewest when treated with Gb9ll (8 out of 11 dead larvae).

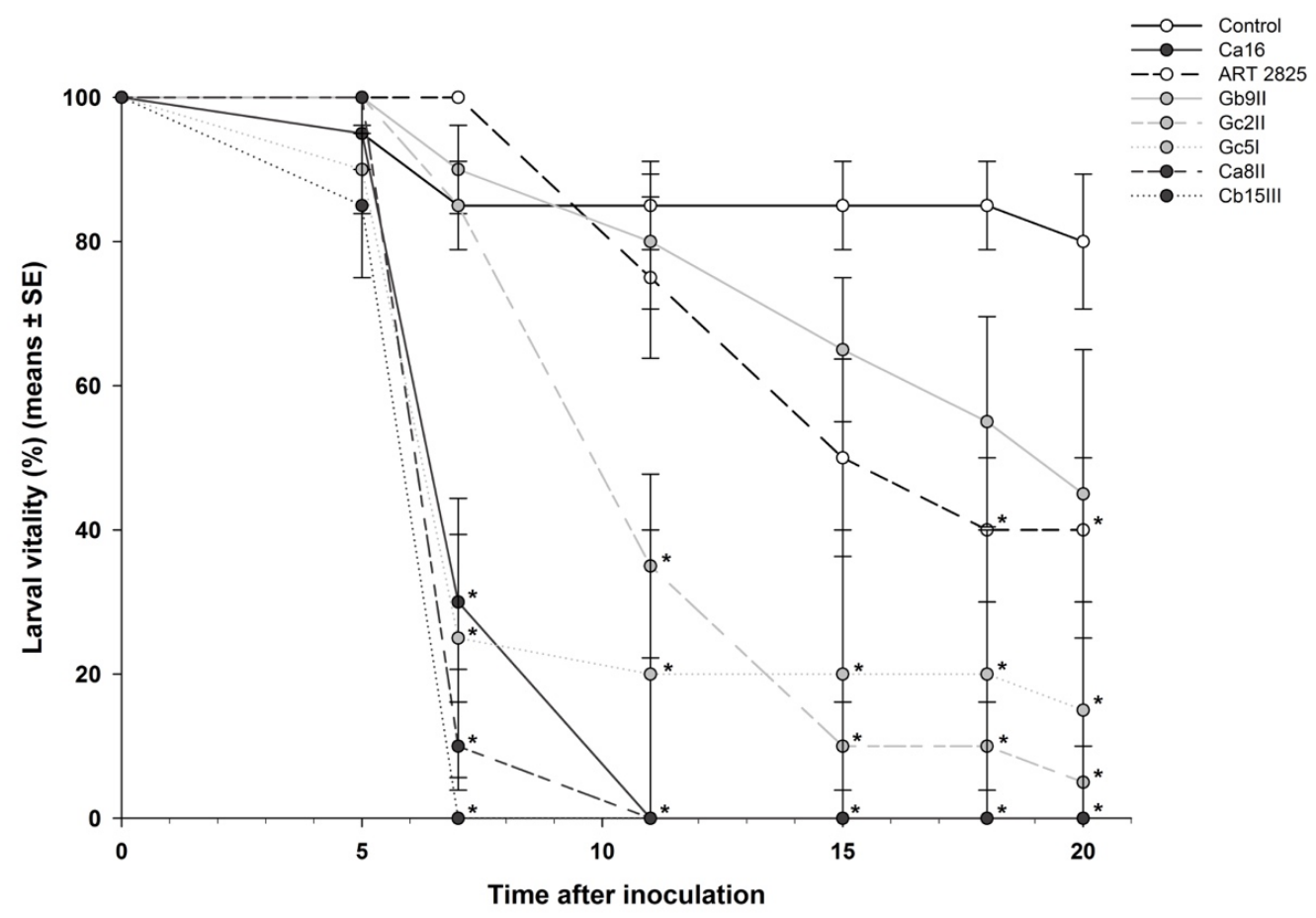

Figure 2 Larval mortality in \% (mean \pm standard error (SE)) in day past inoculation (dpi) after treated with the M. brunneum strains Gb5I, Gc2II, Gb9II, Ca8II, Ca16, Cb15III and ART 2825. Asterisks $\left(^{*}\right)$ indicate significant differences between $M$. brunneum treatments and the "Control" (Kruskal-Wallis ANOVA followed by Dunnett-test $(\alpha=0.05)$ ). 


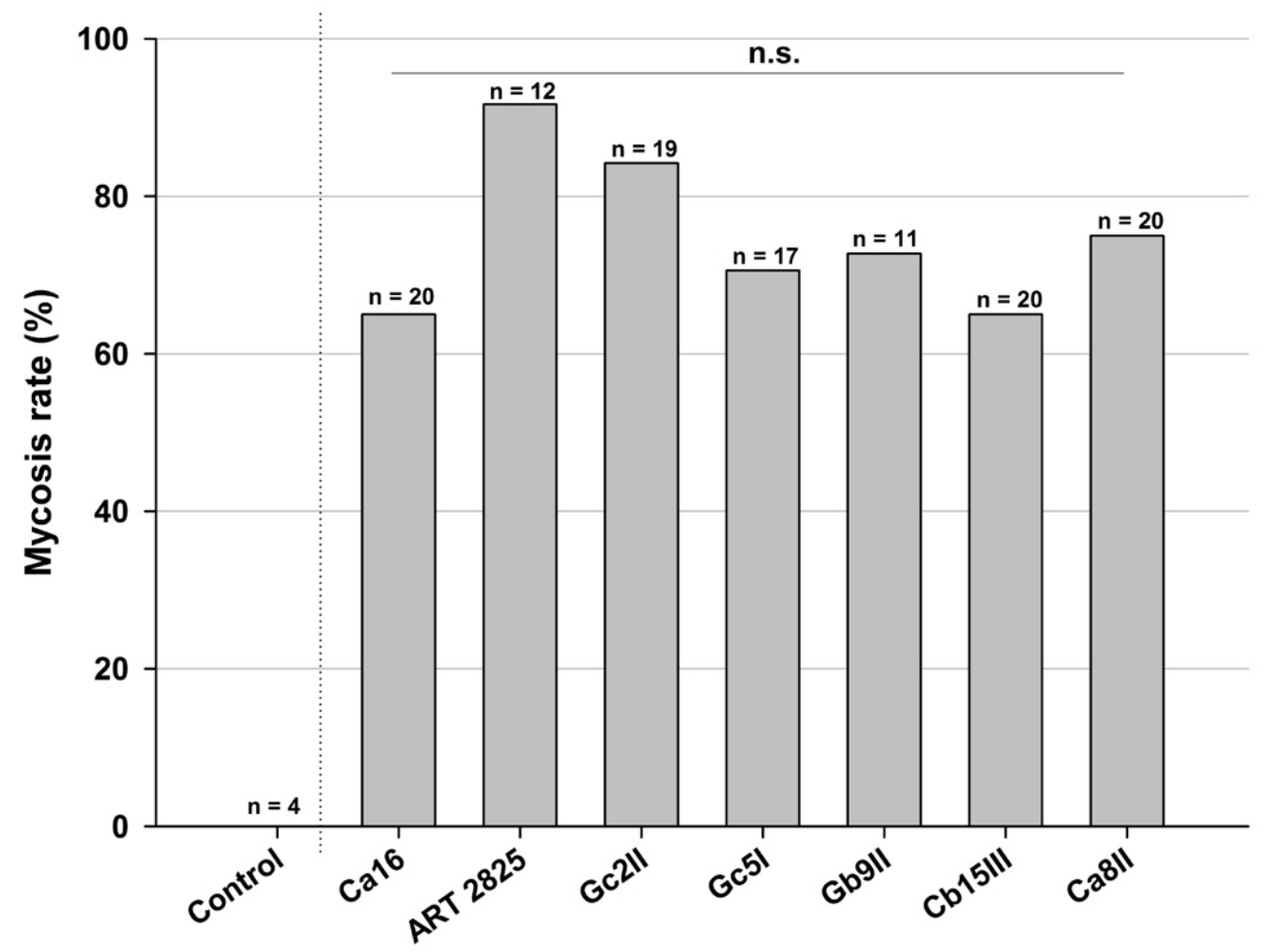

Treatments

Figure 3 Larval mycosis rates (\%) after treated with the M. brunneum strains Gb5I, Gc2II, Gb9II, Ca8II, Ca16, Cb15III and ART 2825. " $n$ " indicates the number of dead larvae. "No significant differences revealed within the M. brunneum treatments $(2 \times 2$ table Fisher's exact test $(\alpha=0.05))$.

\section{Pathogenicity against wireworms}

Survival rates were significantly affected when treated with the $M$. brunneum strains Gc2 and Cb15Il for the three tested Agriotes species A. lineatus ( $\chi^{2}=6.79$; DF $=2$, $\mathrm{p}<0.05)$, A. obscurus $\left(\chi^{2}=17.81\right.$; DF $\left.=2, \mathrm{p}<0.001\right)$ and $A$. sputator $\left(\chi^{2}=10.10 ; \mathrm{DF}=\right.$ $2, \mathrm{p}<0.01)$. The strain $\mathrm{Cb} 15 \mathrm{III}$ was able to significantly shorten the survival of $A$. obscurus $(p<0.001)$ and $A$. sputator $(p<0.001)$ larvae compared to control larvae. However, $A$. lineatus larvae treated with $\mathrm{Cb} 15 \mathrm{III}$ did not show a significant different survival curve than control larvae $(p=0.051)$, even though survival time was halved. Cb15III was able to reduce the number of all species larvae by more than $50 \%$ with a $\mathrm{LT}_{50}$ (median $\pm \mathrm{SE}$ ) of $21 \pm 7.75$ (A. lineatus), $16 \pm 1.55$ (A. obscurus) and $18 \pm 15.02$ (A. sputator). The M. brunneum strain Gc2ll reduced larval survival merely for A. sputator larvae significantly $(p<0.05)$ with a LT50 of $50 \pm 17.39$ (Table 2 ). 
Chapter 1 Isolation and identification of a novel endophytic M. brunneum strain from Central Germany with potential activity against potato pests

Table $2 \mathrm{LT}_{50}$ in days (Median \pm standard error (SE) and $95 \%$ upper and lower confidence intervals $(\mathrm{Cl})$ ), mortality and mycosis rates (both in \%) of Agriotes lineatus, $A$. obscurus and $A$. sputator after inoculation with M. brunneum (strain: Cb15III and Gc2II) (Kaplan-Meier survival analysis (log-rank test)); small letter indicates significant differences between treatments of Agriotes species (Holm-Sidak pairwise tests $(\alpha=0.05)$ ).

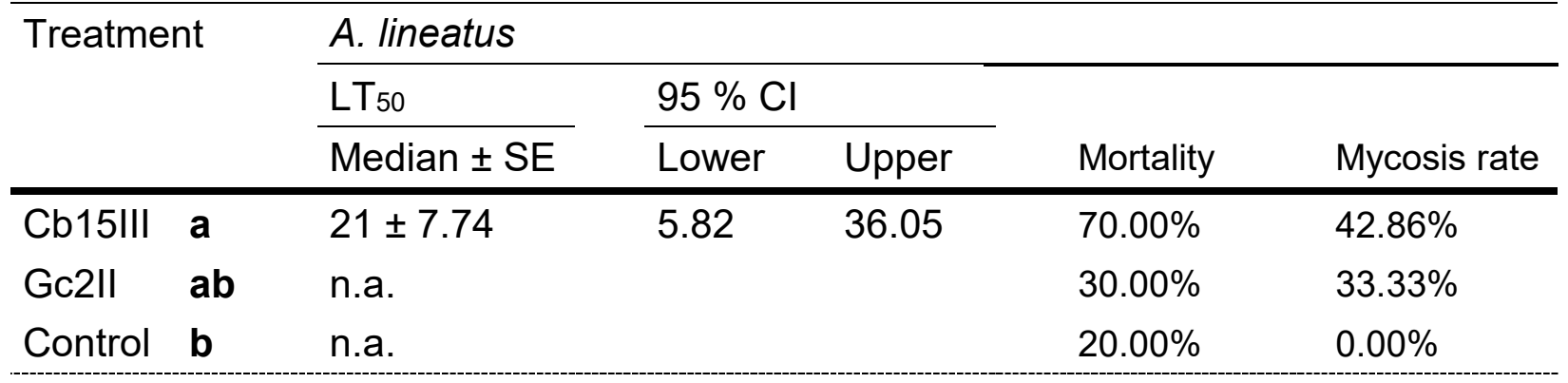

\begin{tabular}{|c|c|c|c|c|c|c|}
\hline & & \multicolumn{5}{|l|}{ A. obscurus } \\
\hline & & \multirow{2}{*}{$\begin{array}{l}\mathrm{LT}_{50} \\
\text { Median } \pm \mathrm{SE}\end{array}$} & \multicolumn{2}{|c|}{$95 \% \mathrm{Cl}$} & \multirow[b]{2}{*}{ Mortality } & \multirow[b]{2}{*}{ Mycosis rate } \\
\hline & & & Lower & Upper & & \\
\hline Cb15III & a & $16 \pm 1.55$ & 11.85 & 46.95 & $90.00 \%$ & $87.50 \%$ \\
\hline Gc2II & b & n.a. & & & $30.00 \%$ & $50.00 \%$ \\
\hline Control & $\mathbf{b}$ & n.a. & & & $20.00 \%$ & $0.00 \%$ \\
\hline
\end{tabular}

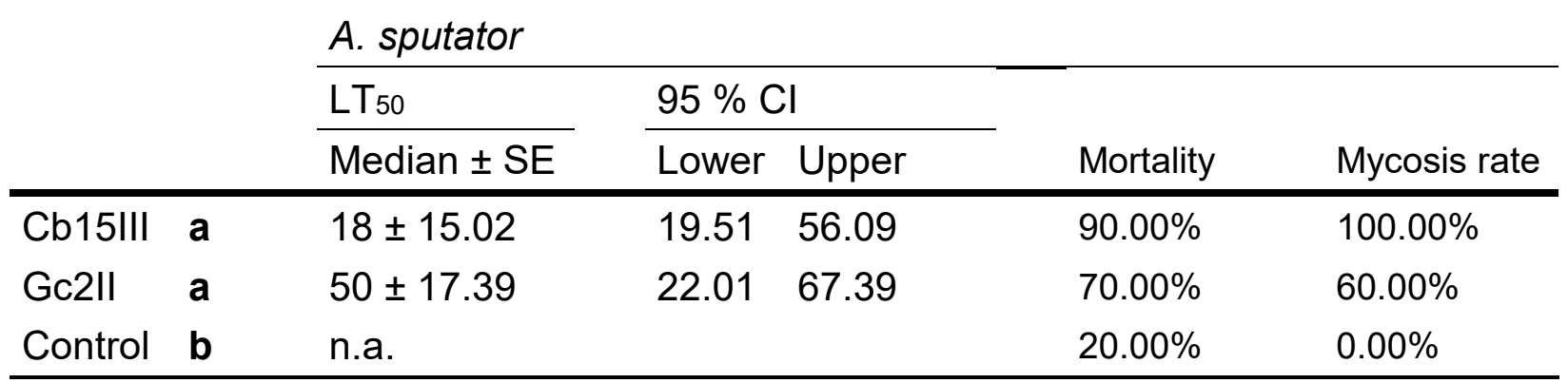

n.a. not available

\section{Pathogenicity against Colorado potato beetle}

CPB larvae treated with the M. brunneum strain Cb15III had a significantly shortened survival $\left(\chi^{2}=8.65\right.$; DF $\left.=1, \mathrm{p}<0.01\right)$. All Cb15III treated larvae died within $21 \mathrm{dpi}$ with a $\mathrm{LT}_{50}$ value (median $\pm \mathrm{SE}$ ) of 10 days \pm 0.78 (Figure 4). After $21 \mathrm{dpi}, 70 \%$ of control larvae were still alive and started pupation. All pupae developed into adult beetles 10 to 14 days later. All but one CPB larvae did develop a mycosis within seven days after death.

When adult beetles treated with $\mathrm{Cb} 15 \mathrm{III}$ or $0.1 \%$ Tween ${ }^{\circ} 80$ neither symptoms of fungus infestation nor effects on vitality were observed within the 60 days of the experiment. 


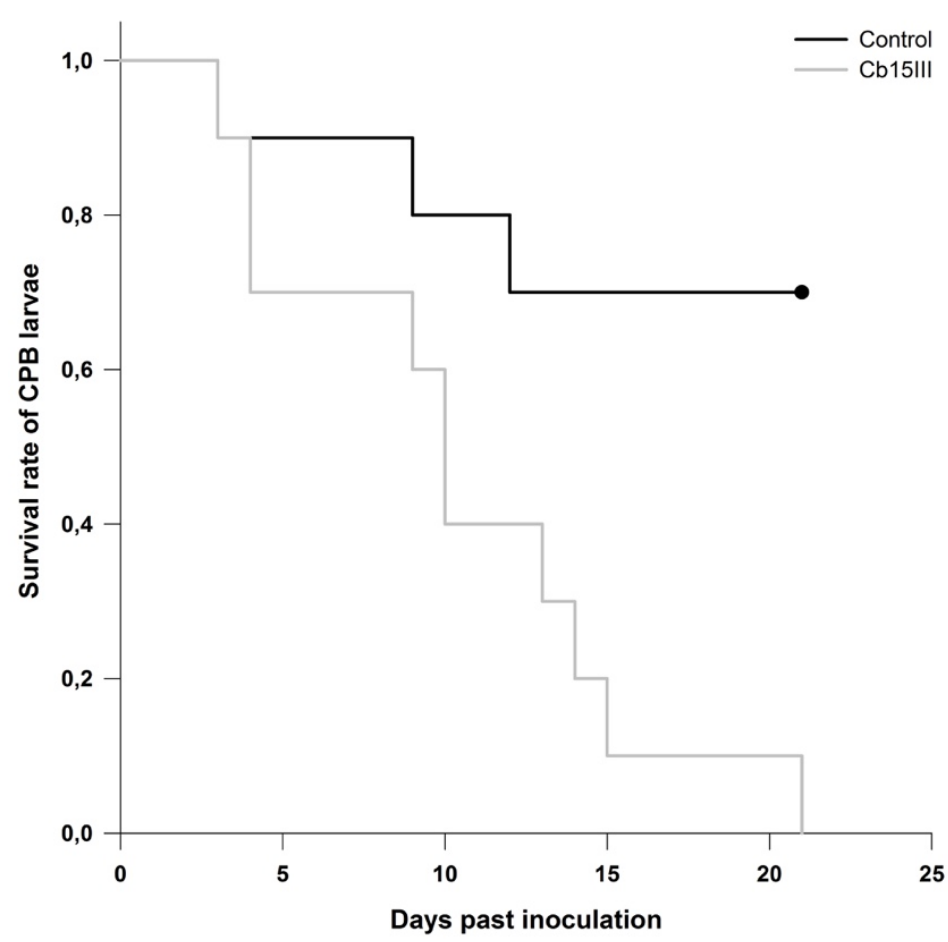

Figure 4 Survival curves of CPB larvae and treated with $M$. brunneum Cb15III or 0.1 Tween ${ }^{\circledR}$ 80. Survival of inoculated larvae was significantly reduced compared to the control (LogRank test: $\left(\chi^{2}=8.65 ; \mathrm{DF}=1, \mathrm{p}<0.01\right)$.

\section{Endophyte test in potato tuber}

Potato tubers developed shoots $(4 \mathrm{~mm}$ ) with a germination rate between $70 \%$ and 100 $\%$ throughout all varieties and treatments. However, treatments of the varieties "Belana" and "Marabel" as well as the control treatments of "Annabelle" and "Cassablance" had a lower germination rate of $60 \%$ or fewer. An inoculation with M. brunneum $\mathrm{Cb} 15 \mathrm{III}$ had a statistically significant positive effect only on the germination rate of the variety "Cassablanca" $(2 \times 2$ table Fisher's exact test, $p<0.05)$. Germination time was significantly negative affected by $\mathrm{Cb} 15 \mathrm{III}$ inoculation within the varieties "Orla" (Mann-Whitney U test, $z=-1.84, p<0.05$ ) and "Cassablanca" (MannWhitney $U$ test, $z=-1.96, p<0.05)$. M. brunneum re-isolation rates on semi selective media were poor and for most potato varieties no M. brunneum outgrow was proven. M. brunneum was successfully re-isolated from one shoot of the varieties "Linda", "Gala", "Ditta" and "Marabel", respectively. In most cases other fungi, predominantly Penicillium spp. and Gliocladium spp., were isolated from potato shoots. The outgrowth of "unwanted" fungi reached up to $100 \%$ in several treatments (Table 3 ). The variety "Belana" was the only variety without any fungal outgrowth, neither M. brunneum nor Penicillium spp., Gliocladium spp. or other fungi evolved from plated shoots. 
Table 3 Tuber germination (\%) and time in days (mean \pm standard error (SE)) bygone until shoots reached a size of $40 \mathrm{~mm}$. Re-isolation rate (\%) of $M$. brunneum and other fungi from shoots on semi-selective media. Asterisks $\left(^{*}\right)$ indicate significant differences between treatments within potato varieties (Mann-Whitney-U test $\alpha=0.05$ ). Small letters indicate significant differences between treatments within varieties $(2 \times 2$ table Fisher's exact test $\alpha=$ 0.05).

\begin{tabular}{|c|c|c|c|c|c|}
\hline \multirow[t]{2}{*}{ Variety } & \multirow[t]{2}{*}{ Treatment } & \multicolumn{2}{|c|}{ Germination } & \multicolumn{2}{|c|}{ Fungal re-isolation (\%) } \\
\hline & & Mean (\%) & Mean $(\mathrm{dpi}) \pm \mathrm{SE}$ & M. brunneum & Other \\
\hline Nicola & $\begin{array}{l}\text { Control } \\
\text { Cb15III }\end{array}$ & $\begin{array}{l}100 \\
100\end{array}$ & $\begin{array}{l}22.8 \pm 1.3 \\
22.2 \pm 1.2\end{array}$ & $\begin{array}{l}0 \\
0\end{array}$ & $\begin{array}{l}10 \\
30\end{array}$ \\
\hline Annabelle & $\begin{array}{l}\text { Control } \\
\text { Cb15III }\end{array}$ & $\begin{array}{l}60 \\
70\end{array}$ & $\begin{array}{l}38.5 \pm 4.3 \\
37.3 \pm 4.0\end{array}$ & $\begin{array}{l}0 \\
0\end{array}$ & $\begin{array}{l}100 \\
71\end{array}$ \\
\hline Orla & $\begin{array}{l}\text { Control } \\
\text { Cb15III }\end{array}$ & $\begin{array}{l}80 \\
80\end{array}$ & $\begin{array}{l}24.0 \pm 2.0 \text { * } \\
32.5 \pm 3.2 \text { * }\end{array}$ & $\begin{array}{l}0 \\
0\end{array}$ & $\begin{array}{l}50 \\
88\end{array}$ \\
\hline Quarta & $\begin{array}{l}\text { Control } \\
\text { Cb15III }\end{array}$ & $\begin{array}{l}80 \\
90\end{array}$ & $\begin{array}{l}32.3 \pm 0.5 \\
31.7 \pm 1.0\end{array}$ & $\begin{array}{l}0 \\
0\end{array}$ & $\begin{array}{l}100 \\
67\end{array}$ \\
\hline Cassablanca & $\begin{array}{l}\text { Control } \\
\text { Cb15III }\end{array}$ & $\begin{array}{l}20 \mathrm{a} \\
80 \mathrm{~b}\end{array}$ & $\begin{array}{l}26.0 \pm 0.0^{*} \\
33.8 \pm 0.8 \text { * }\end{array}$ & $\begin{array}{l}0 \\
0\end{array}$ & $\begin{array}{l}50 \\
88\end{array}$ \\
\hline Granola & $\begin{array}{l}\text { Control } \\
\text { Cb15III }\end{array}$ & $\begin{array}{l}100 \\
100\end{array}$ & $\begin{array}{l}32.3 \pm 2.4 \\
28.1 \pm 1.5\end{array}$ & $\begin{array}{l}0 \\
0\end{array}$ & $\begin{array}{l}30 \\
60\end{array}$ \\
\hline Agria & $\begin{array}{l}\text { Control } \\
\text { Cb15III }\end{array}$ & $\begin{array}{l}100 \\
100\end{array}$ & $\begin{array}{l}32.2 \pm 3.2 \\
31.3 \pm 3.4\end{array}$ & $\begin{array}{l}0 \\
0\end{array}$ & $\begin{array}{l}20 \\
10\end{array}$ \\
\hline Agila & $\begin{array}{l}\text { Control } \\
\text { Cb15III }\end{array}$ & $\begin{array}{l}100 \\
100\end{array}$ & $\begin{array}{l}43.4 \pm 3.2 \\
47.9 \pm 1.4\end{array}$ & $\begin{array}{l}0 \\
0\end{array}$ & $\begin{array}{l}60 \\
60\end{array}$ \\
\hline Campina & $\begin{array}{l}\text { Control } \\
\text { Cb15III }\end{array}$ & $\begin{array}{l}100 \\
80\end{array}$ & $\begin{array}{l}45.1 \pm 2.2 \\
41.5 \pm 3.1\end{array}$ & $\begin{array}{l}0 \\
0\end{array}$ & $\begin{array}{l}70 \\
88\end{array}$ \\
\hline Annalena & $\begin{array}{l}\text { Control } \\
\text { Cb15III }\end{array}$ & $\begin{array}{l}50 \\
50\end{array}$ & $\begin{array}{l}49.6 \pm 0.2 \\
46.6 \pm 2.9\end{array}$ & $\begin{array}{l}0 \\
0\end{array}$ & $\begin{array}{l}60 \\
80\end{array}$ \\
\hline Adretta & $\begin{array}{l}\text { Control } \\
\text { Cb15III }\end{array}$ & $\begin{array}{l}100 \\
90\end{array}$ & $\begin{array}{l}26.3 \pm 0.7 \\
27.2 \pm 2.2\end{array}$ & $\begin{array}{l}0 \\
0\end{array}$ & $\begin{array}{l}60 \\
100\end{array}$ \\
\hline Bintje & $\begin{array}{l}\text { Control } \\
\text { Cb15III }\end{array}$ & $\begin{array}{l}100 \\
100\end{array}$ & $\begin{array}{l}25.7 \pm 2.3 \\
20.9 \pm 1.4\end{array}$ & $\begin{array}{l}0 \\
0\end{array}$ & $\begin{array}{l}40 \\
50\end{array}$ \\
\hline Linda & $\begin{array}{l}\text { Control } \\
\text { Cb15III }\end{array}$ & $\begin{array}{l}100 \\
100\end{array}$ & $\begin{array}{l}25.2 \pm 1.3 \\
22.8 \pm 0.8\end{array}$ & $\begin{array}{l}0 \\
10\end{array}$ & $\begin{array}{l}10 \\
50\end{array}$ \\
\hline Gala & $\begin{array}{l}\text { Control } \\
\text { Cb15III }\end{array}$ & $\begin{array}{l}100 \\
90\end{array}$ & $\begin{array}{l}28.6 \pm 2.0 \\
27.1 \pm 1.7\end{array}$ & $\begin{array}{l}0 \\
11\end{array}$ & $\begin{array}{l}20 \\
22\end{array}$ \\
\hline Ditta & $\begin{array}{l}\text { Control } \\
\text { Cb15III }\end{array}$ & $\begin{array}{l}100 \\
90\end{array}$ & $\begin{array}{l}24.4 \pm 1.2 \\
25.6 \pm 1.4\end{array}$ & $\begin{array}{l}0 \\
11\end{array}$ & $\begin{array}{l}40 \\
11\end{array}$ \\
\hline Bellinda & $\begin{array}{l}\text { Control } \\
\text { Cb15III }\end{array}$ & $\begin{array}{l}90 \\
60\end{array}$ & $\begin{array}{l}34.7 \pm 0.9 \\
36.0 \pm 0.0\end{array}$ & $\begin{array}{l}0 \\
0\end{array}$ & $\begin{array}{l}22 \\
33\end{array}$ \\
\hline Belana & $\begin{array}{l}\text { Control } \\
\text { Cb15III }\end{array}$ & $\begin{array}{l}40 \\
50\end{array}$ & $\begin{array}{l}36.0 \pm 0.0 \\
36.0 \pm 0.0\end{array}$ & $\begin{array}{l}0 \\
0\end{array}$ & $\begin{array}{l}0 \\
0\end{array}$ \\
\hline Solist & $\begin{array}{l}\text { Control } \\
\text { Cb15III }\end{array}$ & $\begin{array}{l}70 \\
60\end{array}$ & $\begin{array}{l}29.3 \pm 2.4 \\
28.3 \pm 2.6\end{array}$ & $\begin{array}{l}0 \\
0\end{array}$ & $\begin{array}{l}43 \\
67\end{array}$ \\
\hline Augusta & $\begin{array}{l}\text { Control } \\
\text { Cb15III }\end{array}$ & $\begin{array}{l}100 \\
70\end{array}$ & $\begin{array}{l}30.4 \pm 1.8 \\
28.4 \pm 2.2\end{array}$ & $\begin{array}{l}0 \\
0\end{array}$ & $\begin{array}{l}80 \\
71\end{array}$ \\
\hline Marabel & $\begin{array}{l}\text { Control } \\
\text { Cb15III }\end{array}$ & $\begin{array}{l}60 \\
40\end{array}$ & $\begin{array}{l}28.3 \pm 2.6 \\
28.0 \pm 4.0\end{array}$ & $\begin{array}{l}0 \\
25\end{array}$ & $\begin{array}{l}83 \\
75\end{array}$ \\
\hline
\end{tabular}


Chapter 1 Isolation and identification of a novel endophytic $M$. brunneum strain from Central Germany with potential activity against potato pests

\section{Discussion}

All tested Metarhizium brunneum strains, isolated from soil samples, were able to infect and kill T. molitor larvae. However, differences between strains were tremendous, particular in regard to sample location. All strains isolated from arable land were able to kill $100 \%$ of the larvae within a maximum of eleven days, whereas larvae treated with grassland strains showed mortality rates between 55 and $95 \%$ after 20 days. It is likely that the sample location have effects on certain fungal features affecting the virulence to insects. Bidochka et al. (2001), for instance, revealed that M. anisopliae strains isolated from forested or agricultural habitats differ in their cold and heat activity. Accordingly, strains from agricultural habitats are more active at high temperatures (growth activity at $37^{\circ} \mathrm{C}$ ) and more tolerant to UV-radiation compared to isolated strains from forested habitats, which are more likely to grow at low temperatures (grow activity at $8^{\circ} \mathrm{C}$ ). Furthermore, Bidochka et al. (1998) found $M$. anisopliae more frequently in agricultural habitats than in natural habitats contrary to B. bassiana, regardless of soil type or $\mathrm{pH}$. This indicates that $M$. anisopliae is well adapted to agricultural used land, thus it seems logical that also the closely related fungus $M$. brunneum developed similar adaptations to these habitats and the predominant insect fauna (Driver et al. 2000).

Within grassland habitats the soil matrix, plant and microbial community as well as the presence of hosts can be stable over years or decades. Bruck (2009) reviewed that within particular habitats plant communities can drive a selection pressure on EPF to select for those capable persisting within the rhizosphere in the time gap between two insect hosts. This leads to an interaction between insect hosts, EPF and plants. Within this system EPF are among others able to transfer nitrogen to plants and receive carbohydrates instead (Behie et al. 2012, 2017; Behie and Bidochka 2014). The specificity of this system could lead to a reduced virulence of EPF isolated from grassland (Humber 2008). On the other hand, M. brunneum strains from agricultural habitats could have developed higher virulence due to a constantly changing environment. Tillage and crop rotation is changing the soil environment several times a year thus conidia of EPF are relocated and dispersed within the soil matrix. The insect fauna is not as diverse as in other habitats (Schneider et al. 2012) and natural selection could pressure EPF to select those able to generally infecting insects rapidly when available. Additionally, higher UV-light exposure could lead to mutations creating 
more virulent strains (Zhao et al. 2016). These habitat influenced factors could explain differences in virulence against $T$. molitor larvae, which were also observed for wireworms. The coincidentally high virulence of the strain $\mathrm{Cb} 15 \mathrm{III}$ and the lower virulence of the strain Gc2ll against T. molitor larvae and wireworms also confirms results of Bharadwaj and Stafford (2011) who have utilized T. molitor larvae as a functional bioassay to test the pathogenicity against pests. This makes T. molitor larvae an easily available and manageable insect for fast acting bioassays to test a great number of EPF strains for their potential to kill wireworms or other pests. In this study, the M. brunneum strain Cb15III was able to kill all three tested wireworm species with $\mathrm{LT}_{50}$ values between 21 ( $A$. lineatus) and $18 \mathrm{dpi}(A$. obscurus). These findings are in accordance with $\mathrm{LT}_{50}$ values quoted by Eckard et al. (2014) for the Agriotes lineatus (21 dpi) and obscurus (14 dpi) dipped in a M. brunneum strain ART2825 spore suspension. However, strain Cb15III seems to be more virulent to $A$. sputator than strain ART2825. This is especially true in regard to the larval inoculation method indicating that dipped larvae could get more likely in contact to a higher, more homogenous number of spores than larvae placed in inoculated soil. This was also discussed by Brandl et al. (2017), who pointed out higher LT50 values for Agriotes species exposed to M. brunneum inoculated field soil. This makes strain Cb15III one of the most virulent strain tested against the three economically most important and destructive wireworm species (Ritter and Richter 2013). The hierarchical clustering of the in this study isolated strains revealed a close relation between the M. brunneum strains Cb15III and BIPESCO5 (Figure 1). However, the M. brunneum strain BIPESCO5 was unable to kill more than $50 \%$ of the tested wireworms (Eckard et al. 2014), suggesting that a close genetic relationship is not appropriate to predict fungal virulence. This is also true for the strains $\mathrm{Cb} 15 \mathrm{III}$ and Gc5I, latter less aggressive against T. molitor larvae (Figure 2).

In addition, the virulence against $T$. molitor larvae and wireworms, strain Cb15III was found to be additionally virulent against CPB larvae. This is the first study showing evidences that a M. brunneum strain is virulent against two of the most important potato pests. The high susceptibility of CBP larvae against the M. brunneum strain Cb15III observed in the experiments is supporting this thesis.

The observed virulence of the strain Cb15III against CBP larvae is in accordance with data from Tyurin et al.(2016) showing up to $100 \%$ fourth instar larval mortality 13 dpi. Strain Cb15III was only effective against the larval stage of CPB but not against adults, 
Chapter 1 Isolation and identification of a novel endophytic $M$. brunneum strain from Central Germany with potential activity against potato pests

indicating that early CPB stages are more susceptible than later stages. Tolerance of adult CPB against $M$. brunneum strain Cb15III could result from different cuticle textures between adults and larvae. St.Leger et al. (1989) revealed that $M$. anisopliae conidia germinates when in contact with a hard surface (e.g. cuticle), thereof appressoria can only develop under specific conditions, influenced among other by cuticle lipids composition. As a consequence, treatments against CPB with $M$. brunneum strain Cb15III should focus on the management of larval stages.

The tuber inoculation method, evaluated in this study, is a novel way of introducing M. brunneum conidia inside plant tissue. This technique allows conclusions about the endophytic qualities of a fungus regardless of its plant penetration abilities. Crosscontamination of the re-isolation process by inoculum can be excluded because of the surface cleaning step after inoculation. The re-isolation rate of $M$. brunneum strain Cb15III from newly developed potato shoots was very low and an outgrowth was only observed in four samples. More often other fungi, such as Penicillium spp. or Gliocladium spp., developed mycelium outgrowth from plant tissue. These fungi are known for their fast development and could have overgrown the previously inoculated strain Cb15III (Goettel and Douglas Inglis 1997). Furthermore, potato tubers have a rich and divers microbial and fungal community which can be antagonistic to newly inoculated fungi (Fiers et al. 2010; Pageni et al. 2013, 2014). Explaining that in most cases M. brunneum strain Cb15III was not re-isolated. Nevertheless, strain Cb15III proved its general ability to establish within potato tuber tissue which was also shown by Krell et al. (2018). 
Chapter 1 Isolation and identification of a novel endophytic $M$. brunneum strain from Central Germany with potential activity against potato pests

\section{Conclusion}

This study demonstrated that entomopathogenic $M$. brunneum strains can be isolated from any agricultural used land and exploit as potential biological control agents. $M$. brunneum strains isolated from arable soil were more virulent under the conducted conditions. T. molitor larvae revealed to be a potent bioassay probe to test $M$. brunneum strains in regard to their ability to infect other insect pests, in particular wireworms and CPB. It was shown that the M. brunneum strain Cb15III is not only virulent against the most devastating pests in potato production but also able to colonize potato plants and tubers. However, further studies must be conducted to reveal the potential of the $M$. brunneum strain $\mathrm{Cb} 15 \mathrm{III}$ as an systemically acting biological control agent.

\section{Acknowledgements}

We would like to thank Biance Tappe and Marie Nörthemann for their technical assistance and Dr. Jürg Enkerli (ISS Agroscope, Zürich, Switzerland) for identification fungal strains. This research was funded by the German Federal Environmental Foundation (DBU), Germany.

\section{References}

Akbarian J (2012) Pathogenicity of some isolates of Beauveria bassiana (Bals.) Vuill. and Metarhizium anisopliae (Metsch.) Sorokin on 2nd and 4th larval instars of Colorado potato beetle, Leptinotarsa decemlineata (Say) (Col.: Chrysomelidae), under laboratory conditions. African J Microbiol Res 6:6407-6413. doi: 10.5897/AJMR12.1112

Behie SW, Bidochka MJ (2014) Nutrient transfer in plant-fungal symbioses. Trends Plant Sci 19:734-740. doi: 10.1016/j.tplants.2014.06.007

Behie SW, Moreira CC, Sementchoukova I, et al (2017) Carbon translocation from a plant to an insect-pathogenic endophytic fungus. Nat Commun 8:1-5. doi: 10.1038/ncomms 14245

Behie SW, Zelisko PM, Bidochka MJ (2012) Endophytic Insect-Parasitic Fungi Translocate Nitrogen Directly from Insects to Plants. Science (80- ) 336:15761577. doi: 10.1126/science.1222289 
Chapter 1 Isolation and identification of a novel endophytic $M$. brunneum strain from Central Germany with potential activity against potato pests

Behle RW, Jackson MA, Flor-Weiler LB (2013) Efficacy of a Granular Formulation Containing <l>Metarhizium brunneum</l> F52 (Hypocreales: Clavicipitaceae) Microsclerotia Against Nymphs of $<|>|$ xodes scapularis $</ \mid>$ (Acari: Ixoididae). J Econ Entomol 106:57-63. doi: 10.1603/EC12226

Bharadwaj A, Stafford KC (2011) Potential of Tenebrio molitor (Coleoptera: Tenebrionidae) as a Bioassay Probe for Metarhizium brunneum (Hypocreales: Clavicipitaceae) Activity Against Ixodes scapularis (Acari: Ixodidae). J Econ Entomol 104:2095-2098. doi: 10.1603/EC11170

Bidochka MJ, Kamp AM, Lavender TM, et al (2001) Habitat association in two genetic groups of the insect-pathogenic fungus Metarhizium anisopliae: uncovering cryptic species? Appl Environ Microbiol 67:1335-1342. doi: 10.1128/AEM.67.3.1335

Bidochka MJ, Kasperski JE, Wild GA (1998) Occurrence of the entomopathogenic fungi Metarhizium anisopliae and Beauveria bassiana in soils from temperate and near-northern habitats. Can J Bot 76:1198-1204. doi: 10.1139/b98-115

Biondi A, Mommaerts V, Smagghe G, et al (2012) The non-target impact of spinosyns on beneficial arthropods. Pest Manag Sci 68:1523-1536. doi: 10.1002/ps.3396

Brandl MA, Schumann M, Przyklenk M, et al (2017) Wireworm damage reduction in potatoes with an attract-and-kill strategy using Metarhizium brunneum. J Pest Sci (2004) 90:479-493. doi: 10.1007/s10340-016-0824-x

Bruck DJ (2009) Fungal entomopathogens in the rhizosphere. In: The Ecology of Fungal Entomopathogens. Springer Netherlands, Dordrecht, pp 103-112

Copping LG, Duke SO (2007) Natural products that have been used commercially as crop protection agents. Pest Manag Sci 63:524-554. doi: 10.1002/ps.1378

Crowder DW, Onstad DW, Gray ME, et al (2005) Analysis of the Dynamics of Adaptation to Transgenic Corn and Crop Rotation by Western Corn Rootworm (Coleoptera: Chrysomelidae) Using a Daily Time-Step Model. J Econ Entomol 98:534-551. doi: 10.1603/0022-0493-98.2.534

Dai P-L, Jia H-R, Geng L-L, Diao Q-Y (2016) Bt Toxin Cry1le Causes No Negative Effects on Survival, Pollen Consumption, or Olfactory Learning in Worker Honey Bees (Hymenoptera: Apidae). J Econ Entomol 109:1028-1033. doi: 10.1093/jee/tow088

Driver F, Milner RJ, Trueman JWH (2000) A taxonomic revision of Metarhizium based on a phylogenetic analysis of rDNA sequence data. Mycol Res 104:134-150. doi: $10.1017 / S 0953756299001756$ 
Chapter 1 Isolation and identification of a novel endophytic $M$. brunneum strain from Central Germany with potential activity against potato pests

Eckard S, Ansari MA, Bacher S, et al (2014) Virulence of in vivo and in vitro produced conidia of Metarhizium brunneum strains for control of wireworms. Crop Prot 64:137-142. doi: 10.1016/j.cropro.2014.06.017

Fiers M, Chatot C, Edel-Hermann V, et al (2010) Diversity of microorganisms associated with atypical superficial blemishes of potato tubers and pathogenicity assessment. Eur J Plant Pathol 128:353-371. doi: 10.1007/s10658-010-9657-2

Fisher RA (1922) On the Interpretation of $\times 2$ from Contingency Tables, and the Calculation of P. J R Stat Soc 85:87. doi: 10.2307/2340521

French N, White JH (1965) OBSERVATIONS ON WIREWORM POPULATIONS CAUSING DAMAgE TO WARE POTATOES. Plant Pathol 14:41-43. doi: 10.1111/j.1365-3059.1965.tb00620.x

Goble TA, Hajek AE, Jackson MA, Gardescu S (2015) Microsclerotia of Metarhizium brunneum F52 Applied in Hydromulch for Control of Asian Longhorned Beetles (Coleoptera: Cerambycidae). J Econ Entomol 108:433-443. doi: 10.1093/jee/tov013

Goettel MS, Douglas Inglis G (1997) Fungi. In: Lacey LA (ed) Manual of Techniques in Insect Pathology. Elsevier, London, UK, pp 213-249

Humber RA (2012) Identification of entomopathogenic fungi. In: Lacey LA (ed) Manual of Techniques in Invertebrate Pathology, Second Edi. Academic Press, London, UK, pp 151-187

Humber RA (2008) Evolution of entomopathogenicity in fungi. J Invertebr Pathol 98:262-266. doi: 10.1016/j.jip.2008.02.017

Johnson SN, Anderson EA, Dawson G, Griffiths DW (2008) Varietal susceptibility of potatoes to wireworm herbivory. Agric For Entomol 10:167-174. doi: 10.1111/j.1461-9563.2008.00372.x

Kabaluk JT, Ericsson JD (2007) Environmental and behavioral constraints on the infection of wireworms by Metarhizium anisopliae. Environ Entomol 36:1415-20. doi: 10.1603/0046-225X(2007)36[1415:EABCOT]2.0.CO;2

Kaplan EL, Meier P (1958) Nonparametric Estimation from Incomplete Observations. J Am Stat Assoc 53:457. doi: 10.2307/2281868

Kapsa JS (2008) Important threats in potato production and integrated pathogen/pest management. Potato Res 51:385-401. doi: 10.1007/s11540-008-9114-1

Kratochvil RJ, Sardanelli S, Everts K, Gallagher E (2004) Evaluation of Crop Rotation and Other Cultural Practices for Management of Root-Knot and Lesion 
Chapter 1 Isolation and identification of a novel endophytic $M$. brunneum strain from Central Germany with potential activity against potato pests

Nematodes. Agron J 96:1419. doi: 10.2134/agronj2004.1419

Krell V, Jakobs-Schoenwandt D, Vidal S, Patel A V. (2018) Cellulase enhances endophytism of encapsulated Metarhizium brunneum in potato plants. Fungal Biol 122:373-378. doi: 10.1016/j.funbio.2018.03.002

Kryukov VY, Yaroslavtseva ON, Dubovskiy IM, et al (2014) Insecticidal and immunosuppressive effect of ascomycete Cordyceps militaris on the larvae of the Colorado potato beetle Leptinotarsa decemlineata. Biol Bull 41:276-283. doi: $10.1134 / \mathrm{S} 1062359014020046$

Lamondia JA (2006) Management of lesion nematodes and potato early dying with rotation crops. J Nematol 38:442-8

Landis BJ, Powell DM, Fox L (1972) Populations of aphids on named varieties of Irish potatoes. Am Potato J 49:63-69. doi: 10.1007/BF02862817

Laznik Ž, Tóth T, Lakatos T, et al (2010) Control of the Colorado potato beetle (Leptinotarsa decemlineata [Say]) on potato under field conditions: a comparison of the efficacy of foliar application of two strains of Steinernema feltiae (Filipjev) and spraying with thiametoxam. J Plant Dis Prot 117:129-135. doi: 10.1007/BF03356348

Lee SJ, Kim SH, Nai YS, et al (2014) Management of entomopathogenic fungi in cultures of Tenebrio molitor (Coleoptera: Tenebrionidae). Entomol Res 44:236243. doi: 10.1111/1748-5967.12068

Mayerhofer J, Lutz A, Widmer F, et al (2015) Multiplexed microsatellite markers for seven Metarhizium species. J Invertebr Pathol 132:132-134. doi: 10.1016/j.jip.2015.09.006

Oerke E-C (2006) Crop losses to pests. J Agric Sci 144:31. doi: 10.1017/S0021859605005708

Pageni BB, Lupwayi NZ, Akter Z, et al (2014) Plant growth-promoting and phytopathogen-antagonistic properties of bacterial endophytes from potato ( Solanum tuberosum L.) cropping systems. Can J Plant Sci 94:835-844. doi: 10.4141/cjps2013-356

Pageni BB, Lupwayi NZ, Larney FJ, et al (2013) Populations, diversity and identities of bacterial endophytes in potato ( Solanum tuberosum L.) cropping systems. Can J Plant Sci 93:1125-1142. doi: 10.4141/cjps2013-166

Premachandra DWTS, Borgemeister C, Poehling H-M (2005) Effects of Neem and Spinosad on Ceratothripoides claratris (Thysanoptera: Thripidae), an Important 
Chapter 1 Isolation and identification of a novel endophytic $M$. brunneum strain from Central Germany with potential activity against potato pests

Vegetable Pest in Thailand, Under Laboratory and Greenhouse Conditions. J Econ Entomol 98:438-448. doi: 10.1603/0022-0493-98.2.438

Ritter C, Richter E (2013) Control methods and monitoring of Agriotes wireworms (Coleoptera: Elateridae). J Plant Dis Prot 120:4-15. doi: 10.1007/BF03356448

Salgado VL (1998) Studies on the Mode of Action of Spinosad: Insect Symptoms and

Physiological Correlates. Pestic Biochem Physiol 60:91-102. doi: 10.1006/pest.1998.2332

Schneider S, Widmer F, Jacot K, et al (2012) Spatial distribution of Metarhizium clade 1 in agricultural landscapes with arable land and different semi-natural habitats. Appl Soil Ecol 52:20-28. doi: 10.1016/j.apsoil.2011.10.007

Schnepf E, Crickmore N, Van Rie J, et al (1998) Bacillus thuringiensis and its pesticidal crystal proteins. Microbiol Mol Biol Rev 62:775-806. doi: 1092-2172

Slaney AC, Robbins HL, English L (1992) Mode of action of Bacillus thuringiensis toxin CryllIA: An analysis of toxicity in Leptinotarsa decemlineata (Say) and Diabrotica undecimpunctata howardi Barber. Insect Biochem Mol Biol 22:9-18. doi: 10.1016/0965-1748(92)90094-U

Sparks TC, Crouse GD, Durst G (2001) Natural products as insecticides: the biology, biochemistry and quantitative structure-activity relationships of spinosyns and spinosoids. Pest Manag Sci 57:896-905. doi: 10.1002/ps.358

St.Leger RJ, Butt TM, Goettel MS, et al (1989) Production in vitro of Appressoria by the Entomopathogenic Fungus Metarhizium anisopliae. Exp Mycol 13:274-288. doi: 10.1016/0147-5975(89)90049-2

Strasser H, Forer A, Schinner F (1996) Development of media for the selective isolation and maintenance of virulence of Beauveria brongniartii. In: Jackson TA, Glare TR (eds) Proceedings of the 3rd International Workshop on Microbial Control of Soil Dwelling Pests. Lincoln, New Zealand, pp 125-130

Trisyono A, Whalon ME (1999) Toxicity of Neem Applied Alone and in Combinations with Bacillus thuringiensis to Colorado Potato Beetle (Coleoptera: Chrysomelidae). J Econ Entomol 92:1281-1288. doi: 10.1093/jee/92.6.1281

Tyurin M V., Kryukov VY, Yaroslavtseva ON, et al (2016) Comparative analysis of immune responses in Colorado potato beetle larvae during development of mycoses caused by Metarhizium robertsii, M. brunneum, and M. pemphigi. J Evol Biochem Physiol 52:252-260. doi: 10.1134/S002209301603008X

Wang G, Zhang J, Song F, et al (2008) Recombinant Bacillus thuringiensis strain 
Chapter 1 Isolation and identification of a novel endophytic $M$. brunneum strain from Central Germany with potential activity against potato pests

shows high insecticidal activity against Plutella xylostella and Leptinotarsa decemlineata without affecting nontarget species in the field. J Appl Microbiol 105:1536-1543. doi: 10.1111/j.1365-2672.2008.03866.x

Whalon ME, Miller DL, Hollingworth RM, et al (1993) Selection of a Colorado Potato Beetle (Coleoptera: Chrysomelidae) Strain Resistant to Bacillus thuringiensis. J Econ Entomol 86:226-233. doi: 10.1093/jee/86.2.226

Willer H, Lernoud J (2018) The World of Organic Agriculture. Statistics and Emerging Trends 2018. In: Willer H, Lernoud J (eds) Research Institute of Organic Agriculture (FiBL), Frick, and IFOAM - Organics International, Bonn. Bonn

Williamson VM, Hussey RS (1996) Nematode Pathogenesis and Resistance in Plants. Plant Cell 8:1735. doi: $10.2307 / 3870226$

Zhao J, Yao R, Wei Y, et al (2016) Screening of Metarhizium anisopliae UV-induced mutants for faster growth yields a hyper-virulent isolate with greater UV and thermal tolerances. Appl Microbiol Biotechnol 100:9217-9228. doi: 10.1007/s00253-016-7746-7 


\section{Chapter 2}

An endophytic Metarhizium brunneum isolate Cb15III active against the Colorado potato beetle
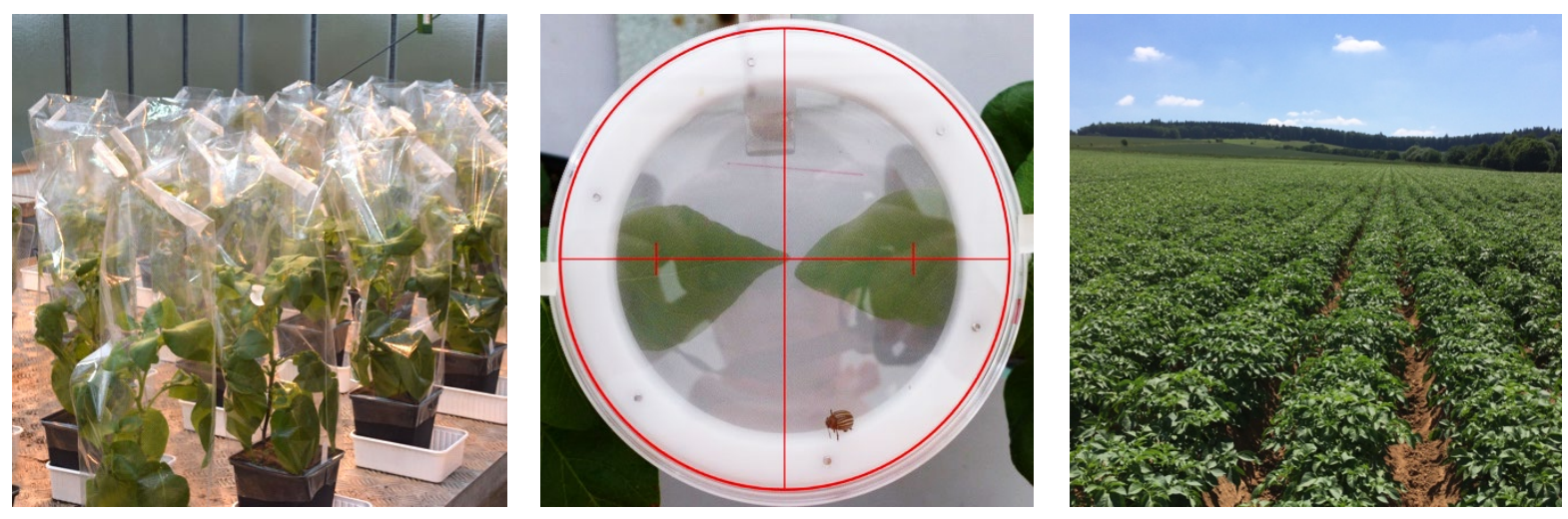

Authors: Laurenz Hettlage*, Maria-Elisabeth Fischer, Stefan Vidal

${ }^{*}$ Corresponding author 


\title{
An endophytic Metarhizium brunneum isolate $\mathrm{Cb} 15 \mathrm{III}$ active against the Colorado potato beetle
}

\author{
L. Hettlage ${ }^{1}$, M.-E. Fischer ${ }^{1}$, S. Vidal ${ }^{1}$
}

${ }^{1}$ Georg-August University, Department of Crop Sciences, Agricultural Entomology, Grisebachstr. 6, 37077 Göttingen, Germany,

Phone: +49 (0) 551-39 33732, E-mail: laurenz.hettlage@agr.uni-goettingen.de

\section{Abstract}

The Colorado potato beetle (CPB), Leptinotarsa decemlineata SAY (Coleoptera: Chrysomelidae), is among the most important foliage pest in potato. In years with mass emergence, beetles and larvae can fully defoliate potato plants and cause tremendous yield losses. Throughout the last decades CPB were managed with chemically synthetic insecticides, such as carbamates, organophosphates or pyrethroids. The extensive use of insecticides combined with a high adaptability of CPB led to evolved resistances to nearly all applied insecticidal agents. Novel protection agents and strategies are needed to overcome insecticide resistances and expand the range of biological control agents. Entomopathogenic fungi are known to be virulent to several important agricultural pests and the occurrence of resistances against fungal antagonists is unlikely. In this study, the endophytic, entomopathogenic fungus Metarhizium brunneum PETCH (Ascomycota: Hypocreales: Clavicipitaceae) Cb15III was tested in laboratory (choice test), greenhouse (non-choice test) and field experiments to evaluate the potential to manage CPB. In the greenhouse experiment, adult emergence was reduced by $33 \%$ when larvae fed on $M$. brunneum inoculated plants. Furthermore, adult tibia length was slightly shortened in M. brunneum treatments compared to control beetles. In field, CPB oviposition was significantly reduced when seed tubers inoculated with M. brunneum Cb15III compared to untreated seed tubers. Due to the reduced oviposition also $L_{1}-L_{3}$ larvae were significantly reduced by the treatment. However, assumed deterrent effects of M. brunneum Cb15III colonized plants could not be verified in the laboratory choice experiment. This study revealed that an endophytic M. brunneum $\mathrm{Cb} 15 \mathrm{III}$ has the potential to protect potato plant, though the complex interaction between plant, entomopathogen and pest is still not understood.

Keywords: Metarhizium brunneum, Colorado potato beetle, potato, endophyte 


\section{Introduction}

The Colorado potato beetle (CPB), Leptinotarsa decemlineata SAY (Coleoptera: Chrysomelidae), is a serious pest in potato crops throughout the northern hemisphere (Hare 1990; Grapputo et al. 2005; Kapsa 2008). Larvae and adults are foliar pests and predominately feeding in potato plants, Solanum tuberosum L., but are also capable to feed on other Solanacea (Hare 1990). Adult beetles overwinter in soil and can stay there for up to two years, which makes the prediction of CPB emergence difficult (Hare 1990). During their lifetime, the larval stages and adult beetles can eat more than $100 \mathrm{~cm}^{2}$ of leaf surface (Ferro et al. 1985). Full defoliation of potato crops with an huge impact on tuber yield can occur in years with two or more CPB generations (Zehnder and Evanylo 1988). Over the past decades larvae and adult beetles has been mainly managed with chemically synthetic insecticides, thus CPB developed resistances against nearly all available insecticidal classes (Roush et al. 1990; Mota-Sanchez et al. 2006; Alyokhin et al. 2008). Alternatively, CPB have been managed with natural products based on the bacterium Bacillus thuringiensis (Kryukov et al. 2009; Yaroslavtseva et al. 2017). The active ingredient of these products are proteins produced by $B$. thuringiensis, toxic to the digested system of CPB (Schnepf et al. 1998). A combined application of Bt and the botanical extract neem can increase the efficacy against CPB larvae (Trisyono and Whalon 1999). However, efficacy in field is limited. Neem extracts are mainly effective against the first larval stages and loss of sensitivity against Bt-products is lowering efficacy of neem and Bt-products in field. As a consequence, CPB adults and their late instars impair an efficient pest management in field (Whalon et al. 1993; Trisyono and Whalon 1999; Crowder et al. 2005; Premachandra et al. 2005). In years with a high infestation, CPB are hardly manageable with biological control agents. Full defoliation and yield losses can be a consequence (Zehnder and Evanylo 1988; Kapsa 2008; Ertürk 2017). Therefore, new management strategies in organic farming systems are required.

Entomopathogenic fungi (EPF) can have the potential to close the gap in biological CPB management. Several studies revealed that CPB were susceptible to several EPF such as: Metarhizium anisopliae, Metarhizium robertsii, Cordyceps militaris and Beauveria bassiana (KRYUKOV ET AL. 2009, 2014; AKBARIAN 2012; TYURIN ET AL. 2016; YAROSLAVTSEVA ET AL. 2017). Foliar application on field scale seems to be difficult due to an high sensitivity of EPF to humidity, temperature and UV-radiation (Hywel-Jones 
and Gillespie 1990; Hallsworth and Magan 1999; Lovett and St. Leger 2014). However, studies have shown effects of the EPF $B$. bassiana on the emergence of first generation adult beetles (Wraight and Ramos 2002). A promising way of controlling CPB with EPF without direct expose of EPF to environmental influence, is to establish EPF in the plant as an endophyte (Ownley et al. 2010). Barelli et al. (2016) reviewed that species of the genera Metarhizium and Beauveria, known as entomopathogens, are pathogenic to insects and endophytically colonize plant tissue. Several studies revealed that plants colonized with EPF affecting insect pests (Batta 2013; Contreras et al. 2014; Muvea et al. 2014; Mantzoukas et al. 2015). Furthermore, EPF can have multiple beneficial effects such as plant growth promotion (Khan et al. 2012), increased nutrient uptake (Behie et al. 2012), salt stress mitigation (Khan et al. 2012) and protection against plant pathogens (Sasan and Bidochka 2012).

Ríos-Moreno et al. (2016) showed that Metarhizium brunneum PETCH (Ascomycota: Hypocreales: Clavicipitaceae) is able to colonize all parts of potato plants, which makes this species a promising candidate for further studies. M. brunneum was described as antagonist of CPB larvae by Tyurin et al. (2016) and own data suggest a high virulence of the M. brunneum strain Cb15III against CPB larvae (Hettlage, unpublished). It was also shown that mycelium of this strain is able to colonize potato tubers (Krell et al. 2018).

This makes strain $\mathrm{Cb} 15 \mathrm{III}$ a promising candidate to protect potato plants systemically from CPB infestation. However, the mode of action in this complex plant entomopathogen - insect - system is unclear and needs to be studied.

The aim of this study is to figure out the potential of an endophytically applied M. brunneum strain $\mathrm{Cb} 15 \mathrm{III}$ to control the CPB. Therefore, a non-choice greenhouse experiment, a choice experiment and a field trial at two locations in Lower Saxony were conducted. 


\section{Material and Method}

\section{Source and preparation of Metarhizium brunneum}

In all experiments, M. brunneum isolate $\mathrm{Cb} 15 \mathrm{III}$ was used. It was cultured on potatoextract-dextrose-agar (PDA) (Carl Roth $\mathrm{GmbH} \&$ Co. KG, Karlsruhe, Germany) in the dark in a climatic cabinet (Biologischer Klimaschrank WB 750, mytron Bio- und Solartechnik $\mathrm{GmbH}$, Heilbad Heiligenstadt, Germany) at $25^{\circ} \mathrm{C}$ and $70 \%$ relative humidity $(\mathrm{RH})$. Conidia suspensions were freshly prepared for each experiment from $2-3$ weeks old $M$ brunneum cultures. Aero conidia for suspensions were harvested by flooding cultures with $0.1 \%(\mathrm{v} / \mathrm{v})$ Tween $^{\circledR} 80$ and gently scratching of mycelia (including spores) from the PDA media surface. Conidia/ mycelium suspension was transferred to a $400 \mathrm{ml}$ glass beaker and stirred at $700 \mathrm{rpm}$ on a magnetic stirred in a total volume of $200 \mathrm{ml}$ to detach conidia from mycelia. Mycelium debris was removed by filtering the suspension through a sterile metal sieve (mesh opening: $1 \mathrm{~mm}$ ). Conidia were determined via counting using a hemocytometer (Thoma chamber, Paul Marienfeld GmbH \& Co. KG, Lauda-Königshofen, Germany) (Goettel and Douglas Inglis 1997). Spore vitality was evaluated in Petri dishes on PDA incubated for $36 \mathrm{~h}$ at $25^{\circ} \mathrm{C}$, with vitality rates always above $92 \%$. Conidia concentration was adjusted to $1 \times 10^{7}$ aero conidia/ml suspension by adding $0.1 \%$ Tween ${ }^{\circledR} 80$ solution before using in experiments.

\section{Source and handling of Colorado potato beetle}

A Colorado potato beetle rearing was built up from collected adults from a nearby potato field. Larvae and adults were fed weekly with 14 weeks old potato plants. Depending on the following experiment the potato variety Bintje or Belana was used for the rearing to allow $\mathrm{CPB}$ accustom to the food source used in experiments.

\section{Greenhouse experiment}

Potato tubers (var. Bintje, Ellenberg's Kartoffelvielfalt $\mathrm{GbR}$, Barum, Germany) with an average size of $7 \times 4 \mathrm{~cm}$ and a germinal shoot size of $10 \pm 2 \mathrm{~mm}$ were immersed in $200 \mathrm{ml}$ aero conidia suspension (“Cb15III") or $0.1 \%$ Tween® 80 (“Tween") for $5 \mathrm{~s}$. Moist tubers were singly placed in plant pots $(13 \times 13 \times 13 \mathrm{~cm})$ half filled with a soilsubstrate (Einheitserde T25, HAWITA Gruppe GmbH, Vechta, Germany) sand mix 
with a ratio of $3: 2$. Pots were filled up with the soil mix, gently compressed with a wooden soil-squeezing-device $(12.5 \times 12.5 \mathrm{~cm})$ and watered until soil was watersoaked. In an untreated control, tubers were directly placed in the soil mix without previous dipping ("control"). Each treatment was replicated twelve times and pots placed randomly distributed in a greenhouse $\left(23^{\circ} \mathrm{C} \pm 2,65 \% \mathrm{RH}\right)$. After germination, $\mathrm{BBCH}$ stages were evaluated daily until $\mathrm{BBCH} 19$ (Hack et al. 1993). All but the highest shoots were removed at $\mathrm{BBCH} 13$ to allow equal plant growth throughout plants/ treatments. Removed shoots were collected in plastic bags and stored at $5^{\circ} \mathrm{C}$ for a later M. brunneum re-isolation and molecular analysis. After all plants reached $\mathrm{BBCH}$ 19 , four neonate CPB larvae were transferred to a rolled-up filter paper $(\varnothing 70 \mathrm{~mm}$, Macherey-Nagel GmbH \& Co. KG, Düren, Germany) with a brush and placed on each potato plant. Plants were covered with a perforated plastic bag $(25 \times 50 \mathrm{~cm}$ polypropylene, Nette Papier $\mathrm{GmbH}$, Göttingen, Germany) to prevent larvae from escaping. After all larvae buried themselves for pupation the aboveground plant material was cut off and dried for dry matter determination. Pots with plastic bags kept in the greenhouse until all adults hatched. Hatched CPB adults were removed daily and tibia length of the most posterior left leg was measured under a stereo microscope (10 x magnifications, Stemi 305 trino, Carl Zeiss Microscopy GmbH, Jena, Germany).

\section{M. brunneum re-isolation and molecular detection (nested-PCR)}

All cut off potato plants were surface sterilized by successive immersion in $2 \%(\mathrm{v} / \mathrm{v})$ sodium hypochlorite solution ( $2 \mathrm{~min}), 70 \%(\mathrm{v} / \mathrm{v})$ ethanol $(2 \mathrm{~min})$ and three rinses in sterile water. $100 \mu \mathrm{l}$ of the last watering step was plated on PDA-Media and incubated for 4 days at $25^{\circ} \mathrm{C}$ to prove the success of the surface sterilization. The first and third true leaves of each plant were detached with a scalpel, sterilized by immersing in $70 \%$ $(\mathrm{v} / \mathrm{v})$ ethanol and scorching in a flame. Three leave disc $(\varnothing 10 \mathrm{~mm})$ from each leave were removed with a sterile cork borer and placed on semi-selective media (Strasser et al. 1996) in a $9 \mathrm{~cm}$ Petri dish and incubated at $25^{\circ} \mathrm{C}$ for 14 days

Five surface sterilized shoots from each treatment were lyophilized (VaCo 5, Zirbus technology $\mathrm{GmbH}$, Bad Grund (Harz), Germany) for $72 \mathrm{~h}$. DNA was extracted according to the cetyltrimethylammonium bromide (CTAB) protocol described by Brandfass and Karlovsky (2008). Extraction performance was tested via gel electrophoresis in a $0.8 \%(\mathrm{w} / \mathrm{v})$ agarose gel (Biozym Scientific $\mathrm{GmbH}$, Hessisch Oldendorf,Germany) running at $60 \vee$ for $60 \mathrm{~min}$. Double-stranded DNA was stained in 
ethidium bromide solution ( $2 \mathrm{mg} / \mathrm{L}$ ) for $15 \mathrm{~min}$ finally rinsed with demineralized water for $10 \mathrm{~min}$. Gel was documented with a digital imaging system.

The primers used for amplification were 'Ma 1763' (forward primer: 5'-CCAACTCCCAACCCCTGTGAAT) and 'Ma 2079' (reverse primer: 5'-AAAACCAGCCTCGCCGAT) specific for Metarhizium clade 1 (Schneider et al. 2012). A volume of $14 \mu$ was used for PCR amplification consisting of $0.3 \mu \mathrm{l}$ 'Ma 1763' (10 $\mu \mathrm{M}$, Thermo Fisher Scientific Inc., Waltham, USA), $0.3 \mu \mathrm{l}$ 'Ma 2079' (10 $\mu \mathrm{M}$, Thermo Fisher Scientific Inc., USA), $0.09 \mu \mathrm{l}$ BIOTaq DNA polymerase ( $5 \mathrm{U} / \mu \mathrm{l}$, Bioline $\mathrm{GmbH}$, Luckenwalde, Germany), $1.2 \mu \mathrm{l}$ dNTP (Bioline $\mathrm{GmbH}$, Luckenwalde, Germany), $0.3 \mu \mathrm{l} \mathrm{MgCl} 2(50 \mathrm{mM}), 1.5 \mu \mathrm{l}$ reaction buffer (10 x, Bioline $\mathrm{GmbH}$, Luckenwalde, Germany), $10.31 \mu \mathrm{l}$ sterile purified water and $1 \mu \mathrm{l}$ of the DNA extract. The PCR was performed in PCR cycler (PEQLAB Biotechnologie $\mathrm{GmbH}$, Erlangen, Germany) according to the following protocol: Initial denaturation for $1 \mathrm{~min}$ at $94^{\circ} \mathrm{C}$ followed by 35 cycles with $30 \mathrm{~s}$ at $94^{\circ} \mathrm{C}, 30 \mathrm{~s}$ at $63^{\circ} \mathrm{C}$ and $30 \mathrm{~s}$ at $68^{\circ} \mathrm{C}$. The final elongation was performed for $5 \mathrm{~min}$ at $68^{\circ} \mathrm{C}$.

A second nested-PCR amplification was performed under the same conditions as in the initial PCR but with the nested-primers MetarhL1 (forward primer: 5'-ATCTCTTGGTTCTGGCATCG) and MetarhR1 (reverse primer: 5'-CCCAACACCAAGTCCACAG) (Thermo Fisher Scientific Inc., Waltham, USA). Nested PCR performance was tested via gel electrophoresis in a $2.0 \%(\mathrm{w} / \mathrm{v})$ agarose gel (Biozym Scientific $\mathrm{GmbH}$, Hessisch Oldendorf,Germany) running at $60 \mathrm{~V}$ for $60 \mathrm{~min}$. Gel was documented with a digital imaging system. 


\section{Choice test}

To test the choice behavior of adult CPB, an 'arena' was constructed, which allowed testing the attractiveness of two differently treated potato plants (Schütz et al. 1997). The 'arena' is made of two TC dish bottom parts ( $\varnothing 150 \mathrm{~mm}$, Sarstedt AG \& Co. KG, Nürnbrecht, Germany) and two screwed self-turned polytetrafluoroethylene (PTFE) rings with a gauze net in-between. The TC dishes perfectly fit on the PTFE ring, whereas one dish has two opposing cauterized notches through which leaves can be placed in the 'arena' without cutting them of the plant (Figure 5).
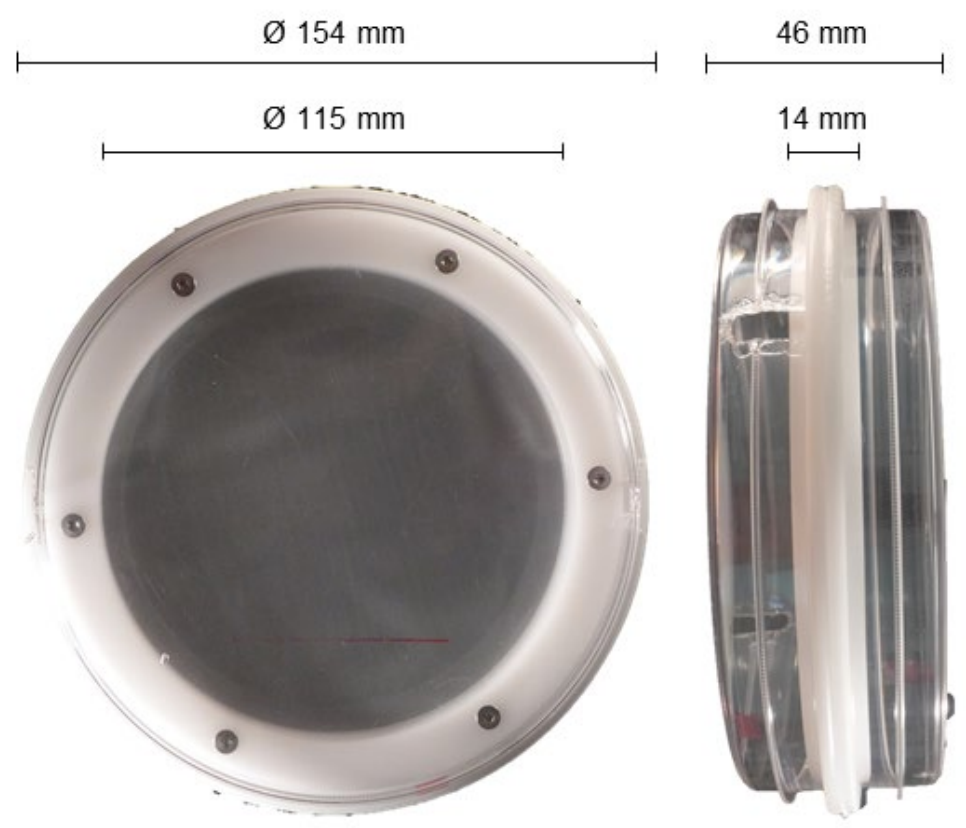

Figure 5 Front and side view of the self-made 'arena' made of two TC dish bottom parts and two screwed self-turned PTFE rings with a gauze net in-between. The gauze prevents insects from feeding on leaves placed in the bottom part of the 'arena'. However, this part can be removed to extend the volatiles-choice test by a food-choice test.

Three treatments were set up and pairwise tested against each other with a total of ten replications. Pre-germinated potato tubers (var. Belana) (BBCH 03) were either inoculated with $10 \mu \mathrm{l}$ of a M. brunneum strain $\mathrm{Cb} 15 \mathrm{III}$ spore suspension $\left(1 \times 10^{7}\right.$ aero conidia/ ml suspension) ('Cb15III), a $0.1 \%$ (v/v) Tween ${ }^{\circledR} 80$ solution ('Tween Control') or not treated at all ('Control'). Spore suspension and Tween ${ }^{\circledR} 80$ solution were injected into tubers with a microliter syringe (10 $\mu \mathrm{l}$, \# 701, Hamilton Company, Reno, USA). All tubers were washed with tap water and injection wounds were cleaned and sterilized with $70 \%(\mathrm{v} / \mathrm{v})$ ethanol. Tubers were singly placed in plant pots $(13 \times 13 \times 13 \mathrm{~cm})$ half filled with a soil-substrate (Einheitserde T25, HAWITA Gruppe $\mathrm{GmbH}$, Vechta, Germany) sand mix with a ratio of $3: 2$. Pots were filled up with the soil mix, gently 
compressed with a wooden soil-squeezing-device $(12.5 \times 12.5 \mathrm{~cm})$, watered until soil was water-soaked and randomly distributed stored in a greenhouse cabin $\left(23^{\circ} \mathrm{C} \pm 2\right.$, $65 \% \mathrm{RH})$. The choice experiment was conducted after all plants reached stage $\mathrm{BBCH}$ 17. Plants were randomly selected and pairwise arranged in a darkened room $\left(20^{\circ} \mathrm{C}\right.$ $\pm 1,65 \% \mathrm{RH}$ ) to avoid beetles get distracted from bright light. Two equal sized potato leaves from two differently treated plants were inserted in the bottom part of the height leveled 'arena' and fixed with cotton wool. The PTFE ring was attached to the bottom part and a $24 \mathrm{~h}$ starving adult CPB is placed in the middle of the gauze. 'arena' was sealed with the top dish. Photos from the 'arena' (top view) were taken after $1 \mathrm{~h}, 2 \mathrm{~h}$, $3 \mathrm{~h}$ and $15 \mathrm{~h}$ to detect CPB preference, which was determined by measuring the distances between beetle's scutellum and the set centers of the two leaves. Leaf centers were defined as the points, $40 \mathrm{~mm}$ left and right from the intersection point of the two centerlines (Figure 6). After $15 \mathrm{~h}$, the gauze was removed and the CPB were placed in-between the two potato leaves. Leaf damage was evaluated after five hours feeding time. Damaged leaf area was determined by comparing images taken before and after beetle attachment (Figure 7).

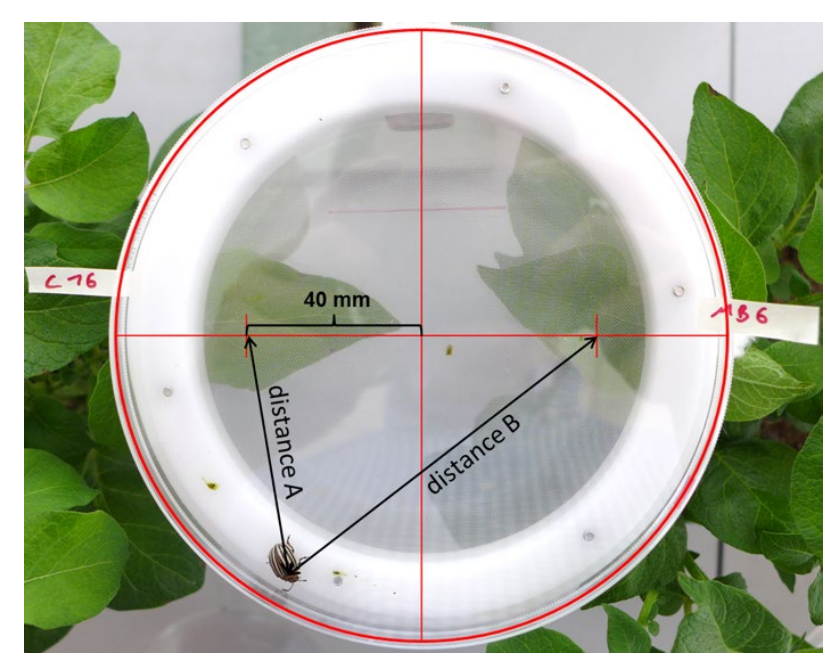

Figure 6 Distance $[\mathrm{mm}]$ from leaf centers of the leaf $A$ and $B$ to the $C P B$ scutellum.
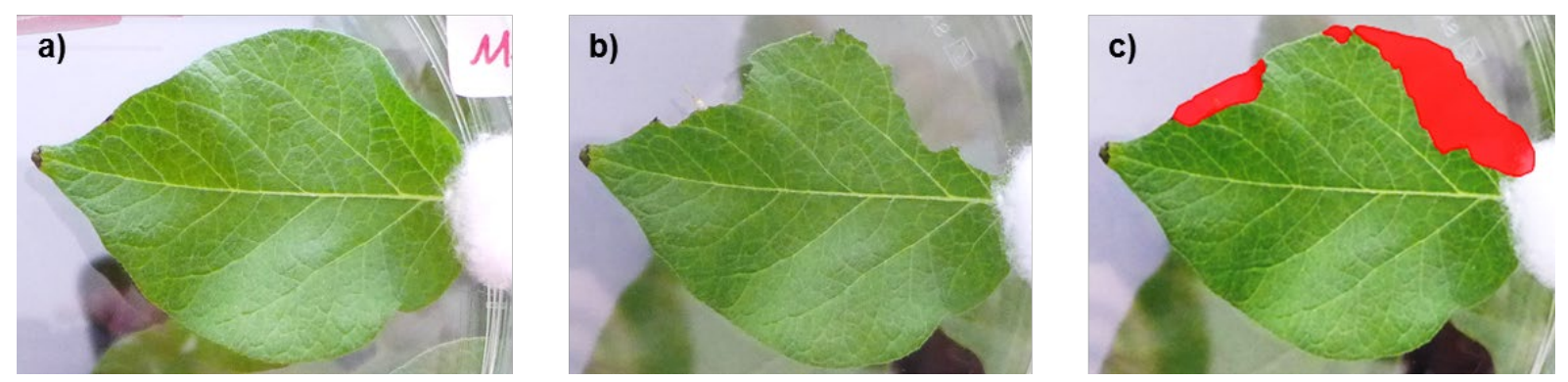

Figure 7 Procedure to determine CPB damaged leaf area. Undamaged leaves a) were compared with damaged leaves $\mathbf{b}$ ) and the missing area was colored and measured $\mathbf{c}$ ) with ImageJ software. 


\section{Field trial}

\section{Field sites}

Trials were conducted in 2017 within two organic cultivated potato fields in south Lower Saxony. Field 1 was surrounded by bushes, vegetable fields and allotment gardens. Field 2 was situated within wheat fields with punctual arranged bushes. Both locations were chosen because of a predicted high pest pressure due to the fact that potato cultivation is a fixed part in crop rotation in this specific landscape and CPBs can immigrate from surrounded areas. Fields were cultivated according to the requirements of the organic field associations and good agricultural practice. Weather data was recorded by the weather station Göttingen (Station 1691, Deutscher Wetterdienst, DWD, Offenbach, Germany).

Table 4 Characteristics of two field sites in Lower Saxony, Germany in 2017 and details of potato field sites including cultivar and treatments (Control: untreated potato rows; Cb15III: M. brunneum (strain: Cb15III) injected into potato tubers)

\begin{tabular}{|c|c|c|}
\hline Study year & 2017 & \\
\hline Field code & 1 & 2 \\
\hline Location & Etzenborn & Bischhausen \\
\hline Coordinates & $\begin{array}{l}\text { N } 51^{\circ} 27^{\prime} 29.591^{\prime \prime} \\
\text { E } 10^{\circ} 9^{\prime} 42.947^{\prime \prime}\end{array}$ & $\begin{array}{l}\text { N 51ㅇ } 26^{\prime} 8.803^{\prime \prime} \\
\text { E } 10^{\circ} 5^{\prime} 42.201^{\prime \prime}\end{array}$ \\
\hline Elevation (m) & 237 & 328 \\
\hline $\begin{array}{l}\text { Temperature }\left({ }^{\circ} \mathrm{C}\right) \\
\text { Mean year } \\
\text { April/ May } \\
\text { July/ Aug./ Sep. }\end{array}$ & $\begin{array}{l}9.9 \\
7.3 / 14.4 \\
18.1 / 17.6 / 13.0\end{array}$ & $\begin{array}{l}9.9 \\
7.3 / 14.4 \\
18.1 / 17.6 / 13.0\end{array}$ \\
\hline $\begin{array}{l}\text { Rainfall (mm) } \\
\text { Sum year } \\
\text { April/ May } \\
\text { July/ Aug./ Sep. } \\
\text { Trial size (ha) }\end{array}$ & $\begin{array}{l}776.6 \\
27.3 / 28.8 \\
202.1 / 87.2 / 40.5 \\
0.034\end{array}$ & $\begin{array}{l}776.6 \\
27.3 / 28.8 \\
202.1 / 87.2 / 40.5 \\
0.034\end{array}$ \\
\hline Field size (ha) & 3.89 & 0.54 \\
\hline Soil type & Sandy loam & Sandy loam \\
\hline Cultivar & Belana & Belana \\
\hline $\begin{array}{l}\text { Tuber pre- } \\
\text { treatment }\end{array}$ & Warming & Warming \\
\hline Previous crop & Cereal & Cereal \\
\hline Irrigation & No & No \\
\hline Row-spacing (m) & 0,75 & 0,75 \\
\hline Tuber-spacing (m) & 0.30 & 0.30 \\
\hline $\begin{array}{l}\text { Planting (BBCH } \\
01)\end{array}$ & 10. Apr. & 10. Apr. \\
\hline $\begin{array}{l}\text { Harvest (BBCH } \\
99)\end{array}$ & 4. Sep. & 4. Sep. \\
\hline Plot size $\left(m^{2}\right)$ & 21 & 21 \\
\hline Blocks & 8 & 8 \\
\hline
\end{tabular}




\section{Experimental design}

To test the effects of an endophytic, entomopathogenic M. brunneum isolate Cb15III on field scale, two treatments were set up at two locations with eight replications, respectively. Plots were set up in a complete randomized block design. Individual plots had a length of $7 \mathrm{~m}$ and a width of $3 \mathrm{~m}$ (equivalent to 4 potato dams à $0,75 \mathrm{~m}$ ), respectively. Treatments were applied one day after surrounded potatoes planted by the farmer. CPB eggs, 1. - 3. instar larvae, 4. instar larvae, adult beetles and plant damage were evaluated following the EPPO guideline PP 1/12 (4) for the evaluation of insecticides against Leptinotarsa decemlineata (EPPO 2008). Evaluation started when beetles started to lay eggs. Ten randomly selected potato plants from the two center rows of each plot were labeled with a red ribbon and consequently evaluated every week until potatoes were harvested.

\section{Treatment preparation and application}

Pre-germinated seed potatoes (var. Belana) (BBCH 03) (Hack et al. 1993) were either treated with M. brunneum strain $\mathrm{Cb} 15 \mathrm{III}$ aero conidia ('Cb15III') or not treated at all ('Control'). Tubers in the 'Cb15III' treatment were inoculated with a $10 \mu \mathrm{l}$ spore suspension $\left(1 \times 10^{7}\right.$ aero conidia / $\left.\mathrm{ml}\right)$ using a microliter syringe $(10 \mu \mathrm{l}$, \# 701, Hamilton Company, Reno, USA) and applying the spore suspension into tuber center. The inoculation area was cleaned from sand and dirt with a paper tissue. Unwanted attached conidia spurting out from the injection point were removed with $70 \%(\mathrm{v} / \mathrm{v})$ ethanol. In the middle of April, the farmer planted seed potatoes at both locations, potatoes were not planted in the experimental plots but rows were preform for a latter hand application. Preformed dams were opened the next day with a two-wheel tractor combined with plowshare (Honda F560 \& F220, Honda Motor Europe Ltd., Berkshire, England) and treated tubers were placed in the dams with a distance of $30 \mathrm{~cm}$ to each other. Dams were covered with soil again by the use of the two-wheel tractor.

\section{Destruxins and solanine determination}

Tubers were harvested at the beginning of July (ca. BBCH 45) for a destruxins and $\alpha$-Solanine extraction and determination. Four randomly chosen plants from each plot were dug up, bagged plant by plant and stored in the dark at $5^{\circ} \mathrm{C}$ in a cooled storage room. Four tubers from each plot, one from each plant, were poled to one 
sample. Destruxins and solanine were extracted from tubers following the protocol of Carpio et al. (2016) step by step. Identification and quantification of destruxins and solanine was implemented by the workgroup of Prof. Karlsovsky (Molecular Phytopathology and Mycotoxin Research, Georg-August University, Göttingen, Germany).

\section{Yield}

In August, potato tubers were manually harvested (BBCH 99, Hack et al. 1993) from each plot. Therefore, the two central potato dams were opened with the two-wheel tractor on a length of $3 \mathrm{~m}$. All tubers in an area of $1.5 \mathrm{~m}$ (= two rows at a length of $1 \mathrm{~m}$ ) were harvested from plots center in order to determine the potato yield.

\section{Statistical analysis}

Values are given as mean \pm standard error (SE), unless otherwise stated. All statistical analyses were carried out with the software STATISTICA, version 13 (StatSoft Inc., Tulsa, OK, USA).

\section{Greenhouse experiment}

Data was tested for normal distribution and variances homogeneity using Shapiro-Wilk test and Levene's-test, respectively. Where appropriate, data was square-root $(0.5+x)$ transformed and compared with one-way ANOVA. Adult emergence was calculated by comparing the number of emerged adults and the number of prior attached neonate larvae per plant. The emergence over time was analyzed with an RM-ANOVA

$$
\% \text { emerged adults }=\frac{\text { no. emerged adults }}{\text { no. attached neonate larvae }} * 100
$$

\section{Choice experiment}

Distances between adults and leaves measured, $1 \mathrm{~h}, 2 \mathrm{~h}, 3 \mathrm{~h}$ or $15 \mathrm{~h}$ after adult attachment, were analyzed with a paired sample t-test. Previously, data was tested for normal distribution and variances homogeneity. Non-normal distributed data have been analyzed with Wilcoxon-test for paired samples $(\alpha=0.05)$. 


\section{Field trial}

Eggs and $L_{1}-L_{3}$ larvae counted per plant within plots were combined to number of Eggs or $L_{1}-L_{3}$ larvae per plot (= ten plants). Data was square root $(0.5+x)$ transformed to reach normal distribution and variances homogeneity. RM-ANOVA followed by Student's t-test $(\alpha=0.05)$ was used to analyze data over time and for each evaluation date. $L_{4}$ larvae and adults were not analyzed due to low counts in the fields. Potato yield in tons per hectare was calculated by extrapolating the actually harvested yield in kilograms per $1.5 \mathrm{~m}^{2}$ (per plot).

$$
\left[\frac{\mathrm{t}}{\text { ha }}\right] \text { potato yield }=\frac{\mathrm{x} \mathrm{kg} *\left(10,000 / 1.5 \mathrm{~m}^{2}\right)}{1000}
$$

Yield and solanine concentrations were tested for normal distribution and variances homogeneity using Shapiro-Wilk test and Levene's-test, respectively and compared with Student's t-test $(\alpha=0.05)$. 


\section{Results}

\section{Greenhouse experiment}

Treatments did not have a statistically significant effect on adult emergence (RMANOVA $\left._{(26,42)}=1,273, p=0,238\right)$, however emergence in $M$. brunneum strain Cb15III treated plants was slightly delayed and reduced. Highest adult emergence was observed in the 'Untreated Control' $(91.67 \% \pm 3.56) 54$ days after neonate larvae were attached to plants. Fewest adults emerged in the 'Cb15III' treatment $(68.75 \% \pm 9.79)$ (Figure 8). In the 'Untreated Control' $50 \%$ adults emerged after 33 to 34 days, in the 'Cb15III' treatment after 35 to 36 days.

Tibia length of CPB adults was slightly shortened when larvae fed on 'Cb15III' plants (2.90 $\mathrm{mm} \pm 0.06$ ) compared to the 'Untreated Control' ( $3.03 \mathrm{~mm} \pm 0.03$ ) but statistical analysis did not reveal significant effects of the treatments to tibia length (ANOVA $\left.F_{(2,32)}=2.104, p=0.139\right)$ (Figure 8).

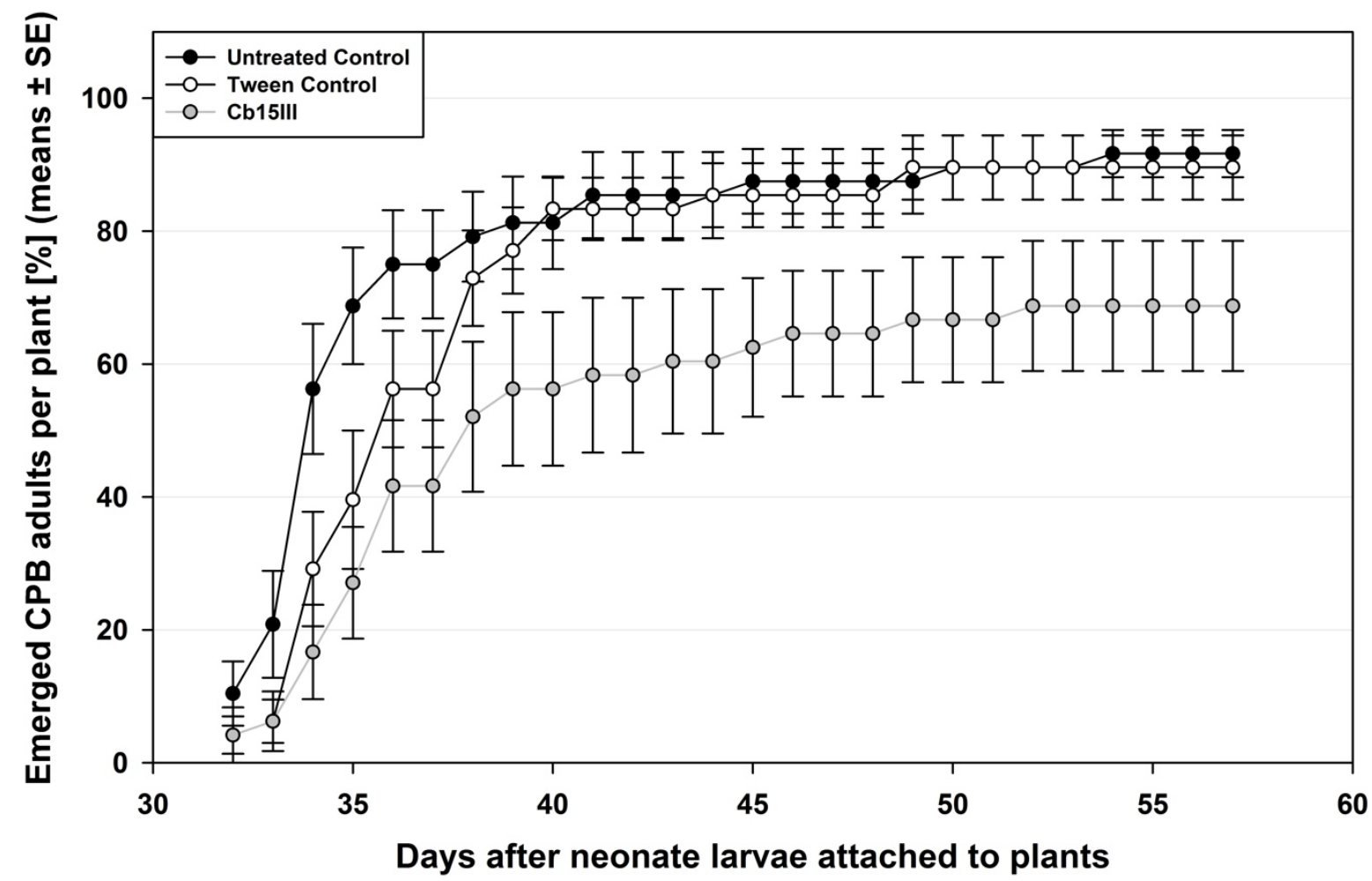

Figure 8 Adult CPB emergence [\%] (means \pm standard errors (SE)) in days after neonate larvae were attached to potato plants. RM-ANOVA $F_{(26,42)}=1,273, p=0,238 ; n=12$. 


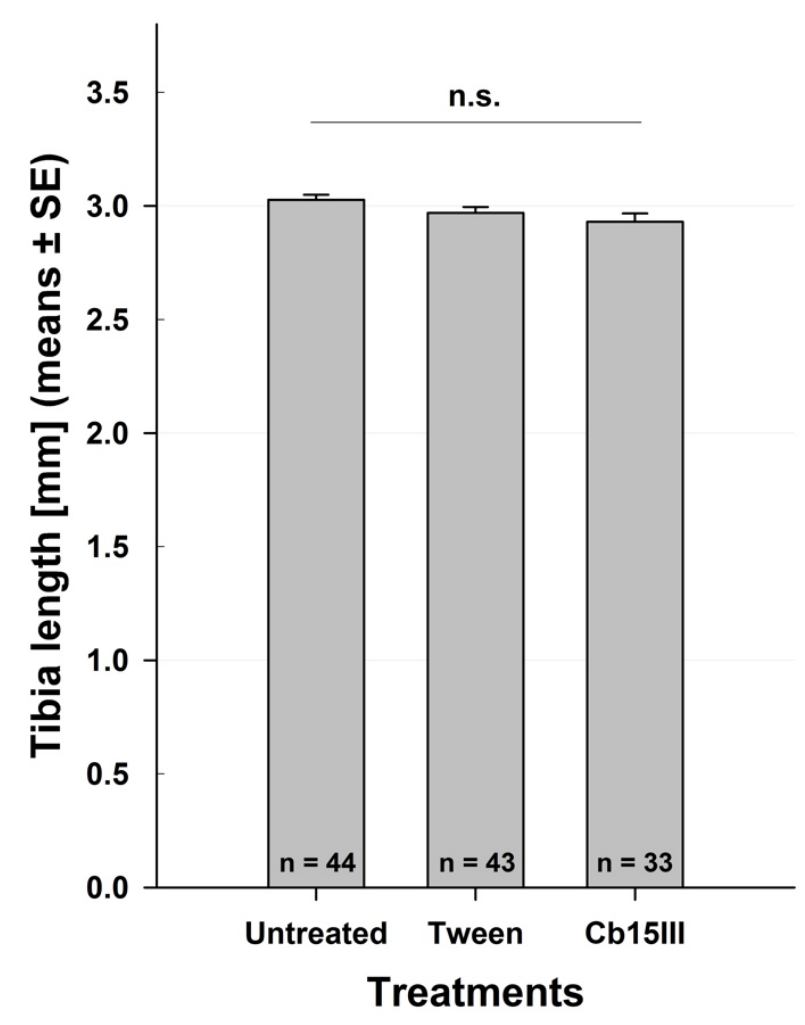

Figure 9 Adult CPB's tibia length [mm] (means \pm standard errors (SE)) of the most posterior left leg. ANOVA $F_{(2,32)}=2.104, p=0.139$. $n$ varies due to varying beetle emergence in-between treatments.

Treatments with $0.1 \%$ Tween $\circledast 80$ or M. brunneum strain Cb15III did neither shown statically significant effects on tuber fresh weight (FW) (ANOVA $\left.F_{(2,33)}=2.193, p=0,128\right)$ or quantity (ANOVA $F_{(2,33)}=0.112$, $p=0,894)$ nor on plant dry matter (DM) (ANOVA $\mathrm{F}_{(2,33)}=0.069$, $p=0,934$ ) or damage (ANOVA $F(2,33)=1.406, \quad p=0,259)$. Highest plant damage was observerd for 'Control' plants $(34.63 \% \pm 1.57)$ but also the highest tuber FW (102.96 $\mathrm{g} \pm 0.70$ ). Plants with fewest damage were observerd in 'Cb15III' treatment $(26.95 \% \pm 4.27)$ (Table 5). Fungal reisolation was not successful and no fungal outgrowth from leaf discs was observed. Nested-PCR DNA amplificants were found in all treatments. Metarhizium spp. was detected in two out of five samples in the 'Untreated Control' and in three out of five samples in the treatments 'Tween Control' and 'Cb15II', respectively.

Table 5 Above (plant damage [\%] and plants dry matter [g] (DM)) and below ground ( tuber fresh weight $[\mathrm{g}](\mathrm{FW})$ and tuber quantitiy) plant parameters (means \pm standard errors (SE)) treated plants treated M. brunneum strain Cb15III (Cb15III), 0.1 \% Tween ${ }^{\circledR} 80$ (Tween Control) or not treated at all (Untreated Control). No statistical significant differences were found within treatments for above ground plant damage [\%] ( $\left.\operatorname{ANOVA~}_{(2,33)}=1.406, p=0,259\right)$ and DM [g] (ANOVA $\left.F_{(2,33)}=0.069, p=0,934\right)$ or tuber FW [g] (ANOVA $\left.F_{(2,33)}=2.193, p=0,128\right)$ and quantity (ANOVA $\left.F_{(2,33)}=0.112, p=0,894\right)$.

\begin{tabular}{|c|c|c|c|c|}
\hline \multirow[t]{3}{*}{ Treatment } & \multicolumn{4}{|c|}{ Plant parameters (means $\pm \mathrm{SE}$ ) } \\
\hline & \multicolumn{2}{|l|}{ Above ground } & \multicolumn{2}{|l|}{ Tuber } \\
\hline & Damage [\%] & DM [g] & Total FW [g] & Quantity \\
\hline Untreated Control & $34.63 \pm 1.57$ & $2.12 \pm 0.07$ & $102.96 \pm 2.98$ & $9.33 \pm 0.70$ \\
\hline Tween Control & $34.09 \pm 4.30$ & $2.19 \pm 0.19$ & $93.11 \pm 1.97$ & $9.50 \pm 1.04$ \\
\hline Cb15III & $26.95 \pm 4.27$ & $2.12 \pm 0.16$ & $97.36 \pm 4.54$ & $8.92 \pm 0.92$ \\
\hline
\end{tabular}




\section{Choice test}

a)

Tween Control

Control

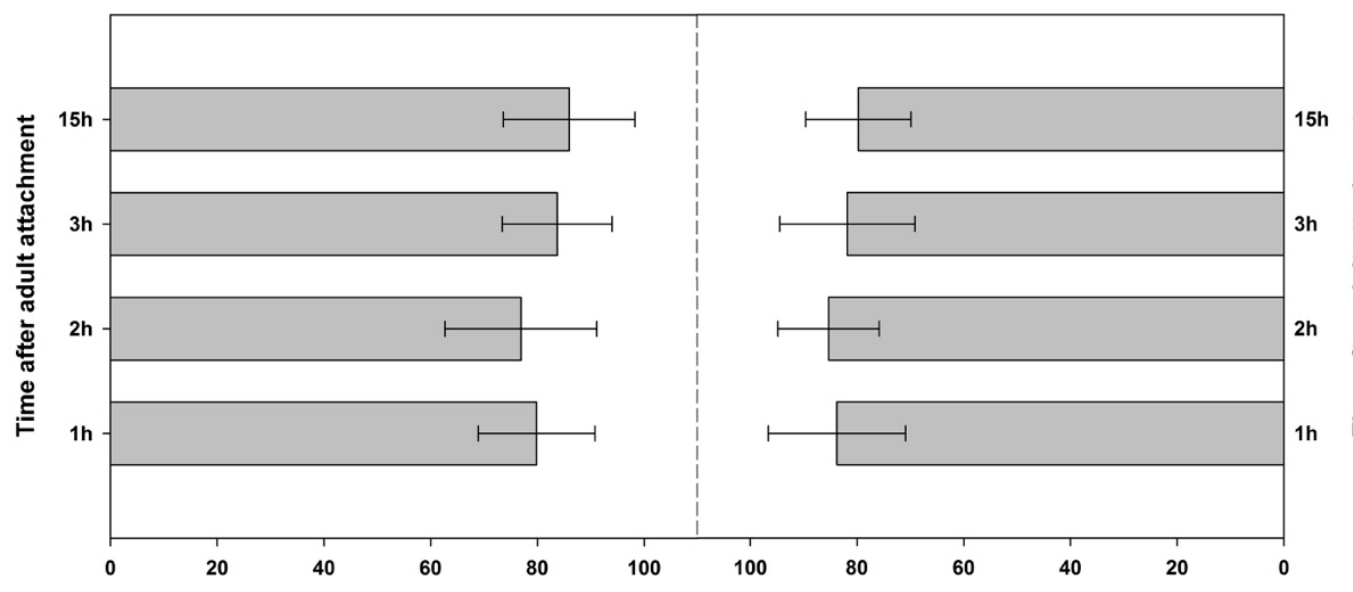

CPB distance [mm] from 'Cb15III' leaves (left) or 'Tween Control' leaves (right) (means \pm SE)

b)

Cb15III

Tween Control

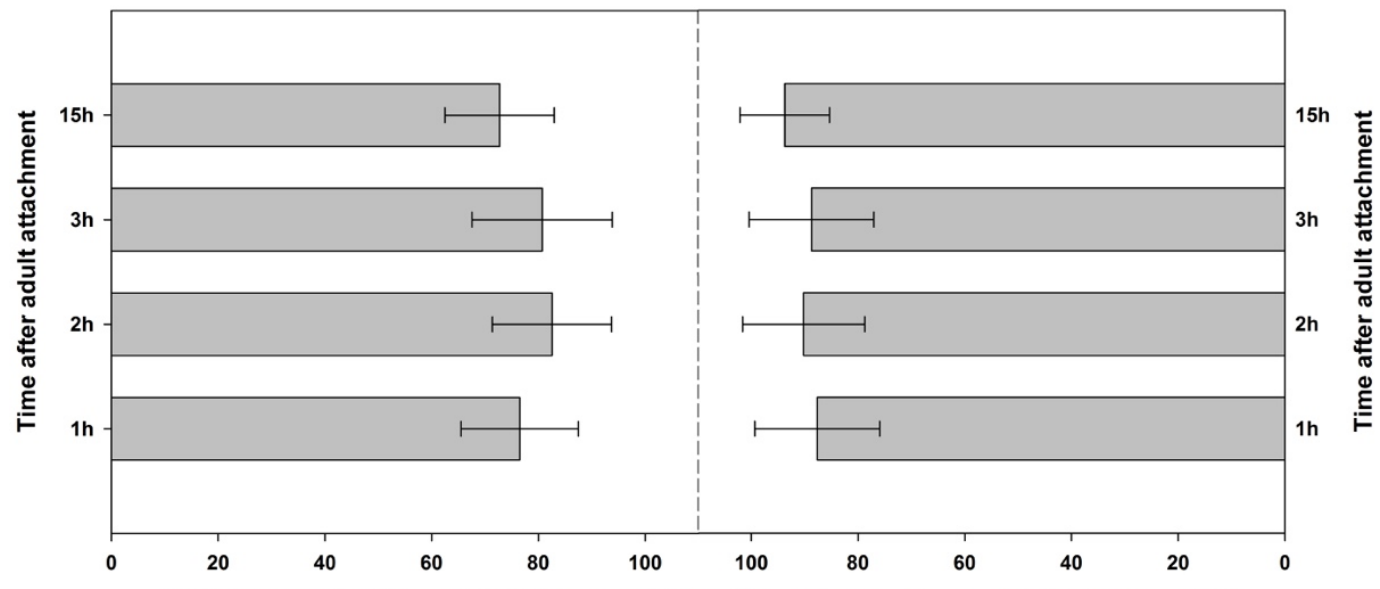

CPB distance [mm] from 'Cb15III' leaves (left) or 'Tween Control' leaves (right) (means $\pm \mathrm{SE}$ )

c)

Cb15III

Control

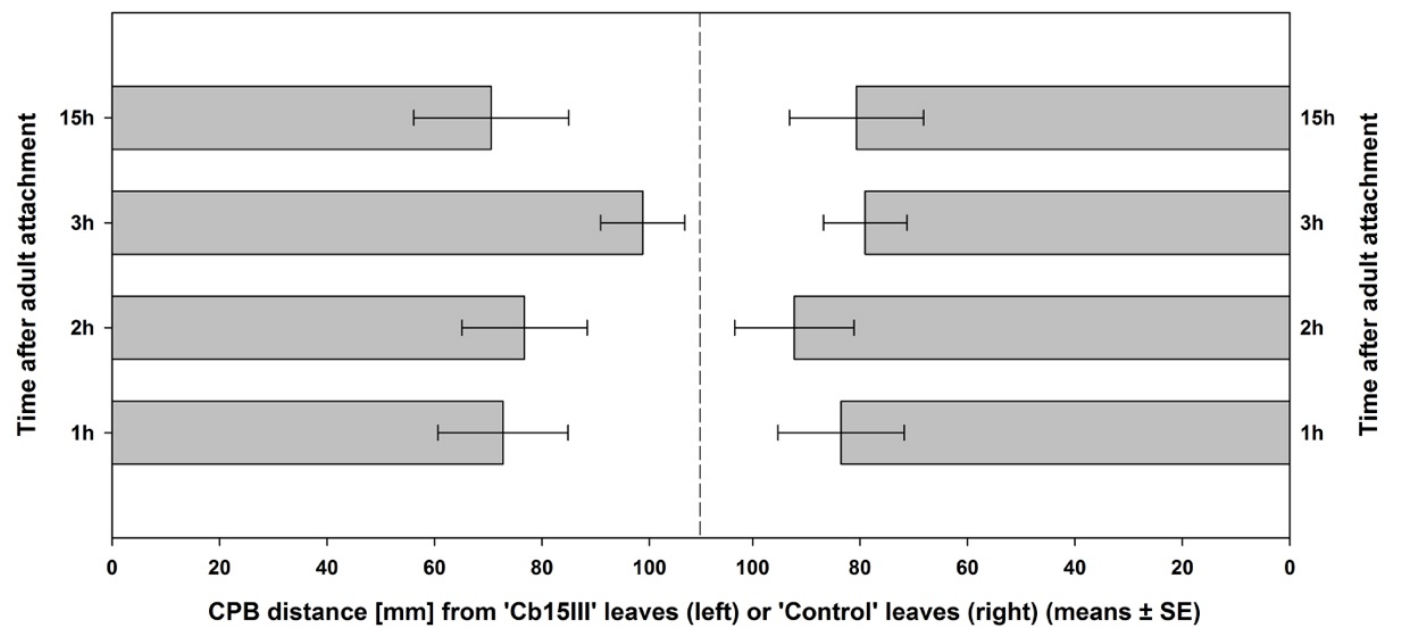

Figure 10 Distances [mm] between CPB adults and the two leaves from treated potato plants within 'arenas' (means \pm standard errors (SE)), after $1 \mathrm{~h}, 2 \mathrm{~h}, 3 \mathrm{~h}$ and $15 \mathrm{~h}$. No statistical significant differences were found within pairs and time (paired sample t-test: $\alpha=0.05$ ). 
There are no statistically significant indications that adult CPB preferred one or more treatments within the 'arena'-choice test (paired sample t-test: $\alpha=0.05$ ) (Figure 10). However, data suggests that the 'Cb15III' treatment were slightly more attractive to beetles than the 'Control'. Thus the closest distance between a treated leaf and beetles was measured for 'Cb15III' after $1 \mathrm{~h}(72.75 \mathrm{~mm} \pm 12.12)$ and $15 \mathrm{~h}(70.54 \mathrm{~mm} \pm 14.40)$ when compared to 'Control' (Figure $10 \mathrm{c}$ ). Similar distances for the 'Cb15III' treated plants were measured after $1 \mathrm{~h}(76.46 \mathrm{~mm} \pm 10.98)$ and $15 \mathrm{~h}(72.74 \mathrm{~mm} \pm 10.24)$ when compared to the 'Tween Control' (Figure $10 \mathrm{~b}$ ). No beetle preference was observed when 'Control' was compared to 'Tween Control' (Figure $10 \mathrm{a}$ ).

After the gauze had been removed from 'arenas', beetles could crawl to potato leaves and feed on them. A statistically significant preference of the beetles for one of the treatments could not be revealed (Wilcoxon-test for paired samples: $\alpha=0.05$ ). Leaves from plants treated with strain Cb15III $\left(38.88 \mathrm{~mm}^{2} \pm 19.42\right.$ and $\left.58.15 \mathrm{~mm}^{2} \pm 28.88\right)$ were slightly more damaged than the respectively compared treatments 'Control' $\left(31.09 \mathrm{~mm}^{2} \pm 13.39\right)$ or 'Tween Control' $\left(48.78 \mathrm{~mm}^{2} \pm 22.73\right.$ ) (Figure 11). However, variances within treatments were too high to reveal statistically significant differences.

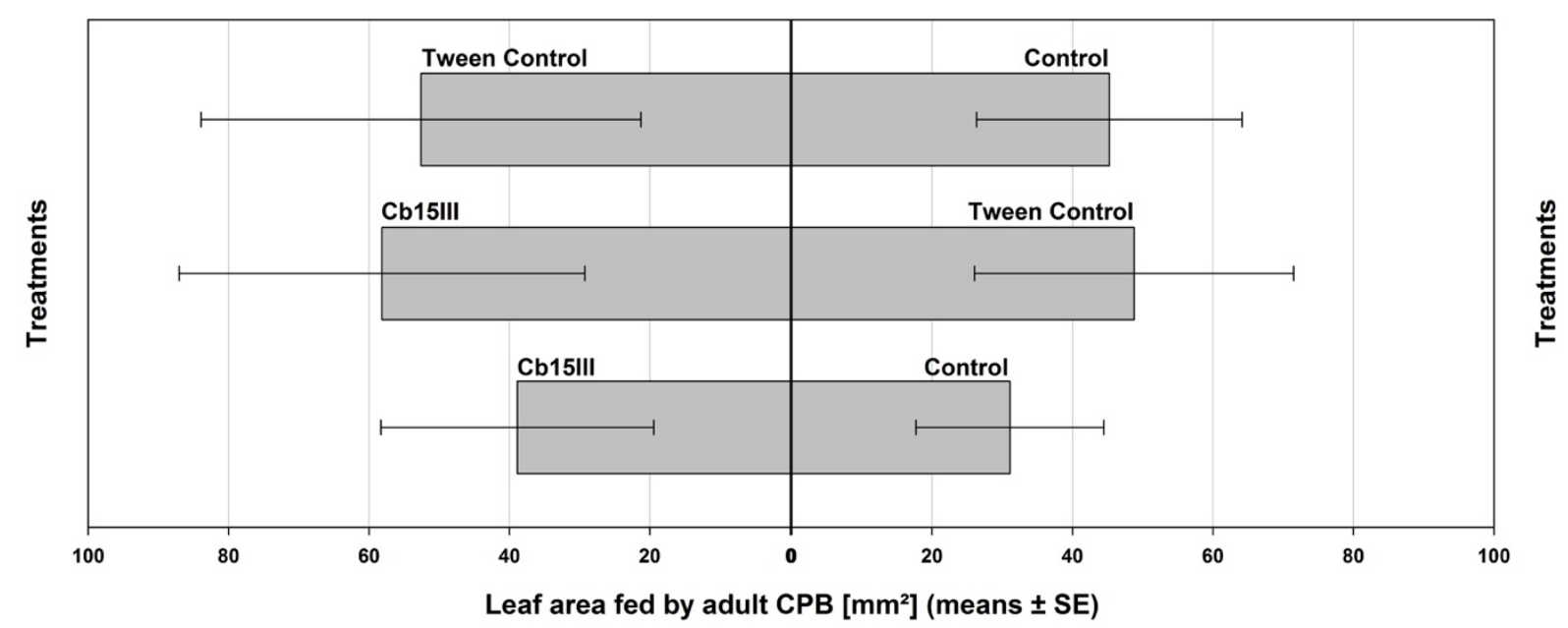

Figure 11 Leaf area $\left[\mathrm{mm}^{2}\right]$ fed by adult CPB in "arenas' after removing gauze (means \pm standard errors (SE)). Treatments were pairwise tested to each other. No statistical significant differences were found within pairs (Wilcoxon-test for paired samples: $\alpha=0.05$ ). 


\section{Field experiment}

First eggs, $L_{1}-L_{3}$ larvae and adult CPB were found in field 1 and field 2 from the 14.06.17 and 21.06.17 onwards, respectively. CPB infestation was higher in field 1 than in field 2. During the evaluation period, oviposition in field 1 was significantly higher in the 'Control' than in 'Cb15III' treated plots (RM-ANOVA $F_{(5,10)}=9.233$, $p<0.01)$. Equal observations were made for hatched $L_{1}-L_{3}$ larvae (RM-ANOVA $\left.F_{(5,10)}=11.523, p<0.001\right)$ (Figure $\left.\left.12 a\right) \& b\right)$ ). Significantly more eggs were found in the field 1 'Control' within the first three evaluation dates: 14.6. (t-test $t=4.392$, $\mathrm{DF}=14, \mathrm{p}<0.001$ ), 21.6. (t-test $\mathrm{t}=4.734$, $\mathrm{DF}=14, \mathrm{p}<0.001$ ) and 28.6.17 (t-test $t=2.288, D F=14, p<0.05)($ Figure $12 a)) . L_{1}-L_{3}$ larvae were found in field 1 significantly more often in the 'Control' than in 'Cb15IIl' from the 21.6.17 (t-test $\alpha=0.05)$ on but not on 14.6.17 (t-test $t=1.254, D F=14, p=0.230)$.

Field 1
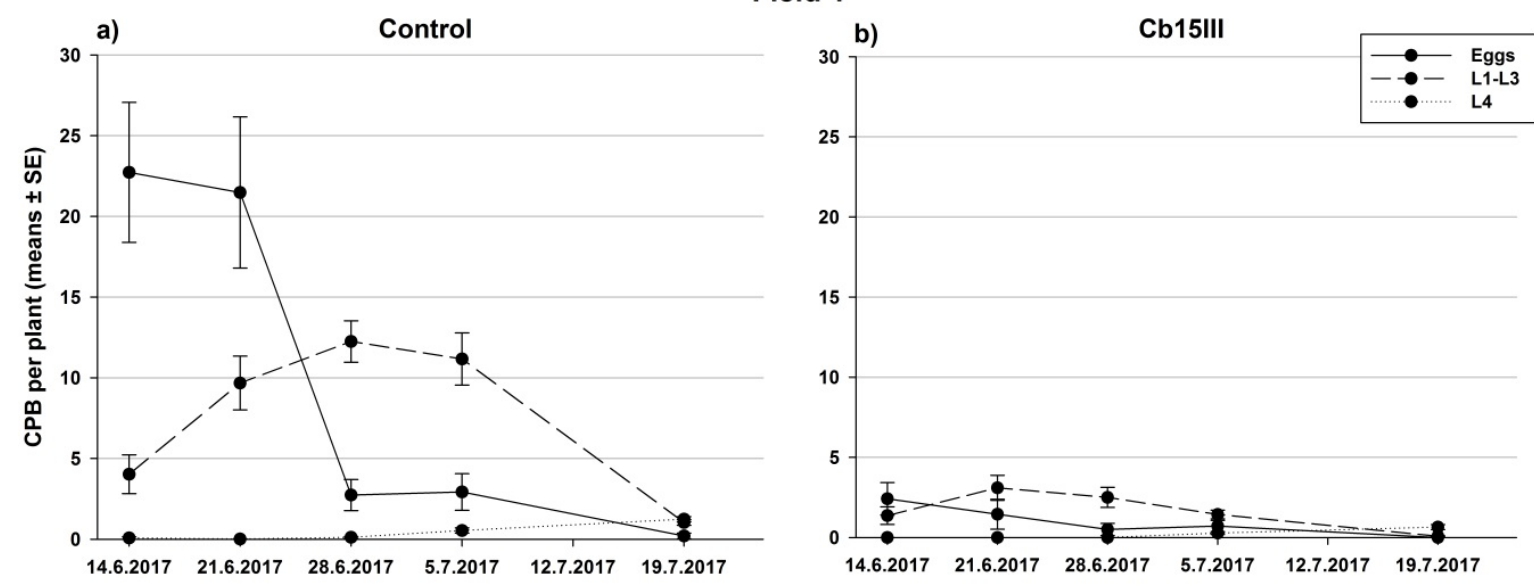

Field 2
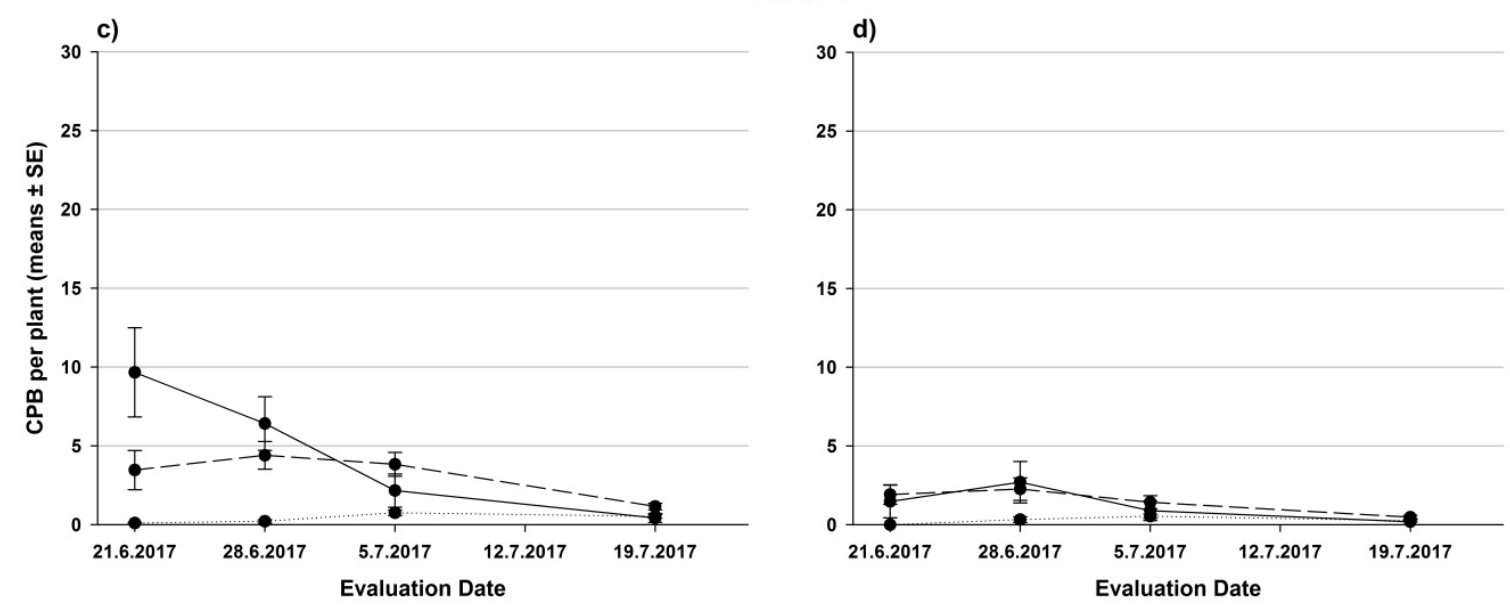

Figure 12 Average number of counted CPB eggs, $L_{1}-L_{3}$ and $L_{4}$ larvae per plant (means $\pm S E$ ) in field 1 (a) control and b) Cb15III treatment) and field 2 (c) control and d) Cb15III treatment) Counted eggs (RM-ANOVA $F_{(5,10)}=9.233, p<0.01$ ) and L1 - L3 larvae (RM-ANOVA $\left.F_{(5,10)}=11.523, p<0.001\right)$ differ significantly between treatments in field 1 . Statistical significant differences were not found between treatments in field 2 . 
Most eggs per plant were found in field 1 'Control' on $14.6 .17(22.73 \pm 4.34)$ and decreased over the evaluation period to $0.20 \pm 0.18$ at the 19.7.17. The number of $\mathrm{L}_{1}-\mathrm{L}_{3}$ larvae in the field 1 'Control' increased up to $12.25 \pm 1.28$ at the 28.6.17 and decreased thenceforth again. Similar emergence curves were observed in the field 2 'Control', however overall CPB emergence was lower in field 2 (Figure $12 \mathrm{c}$ ). Oviposition (RM-AMOVA $F_{(4,11)}=3.006, p=0.067$ ) and $L_{1}-L_{3}$ larval occurrence (RM-AMOVA $\left.F_{(4,11)}=3.122, p=0.061\right)$ in field 2 was not significantly different between treatments 'Control' and Cb15III' (Figure $12 \mathrm{c} \& \mathrm{~d}$ ). In both fields the maximum number of counted eggs in the 'Cb15III' treatments was below 5 eggs (Figure 12 b \& d). Due to the very low occurrence of $\mathrm{L}_{4}$ larvae and adults in both fields, no statistical differences were evaluated between treatments. No significant differences in tuber yield were found between treatments, neither in field 1 (t-test: $t=-0.870, D F=14, p=$ 0.399 ) nor in field 2 (t-test: $t=0.396, D F=14, p=0.698$ ). Potato yield was highest with up to $40 \mathrm{t} / \mathrm{ha}$ ('Control') from field 2, whereas, a maximum of $29 \mathrm{t} / \mathrm{ha}$ ('Cb15III') could be harvested from field 1 (Figure 13).

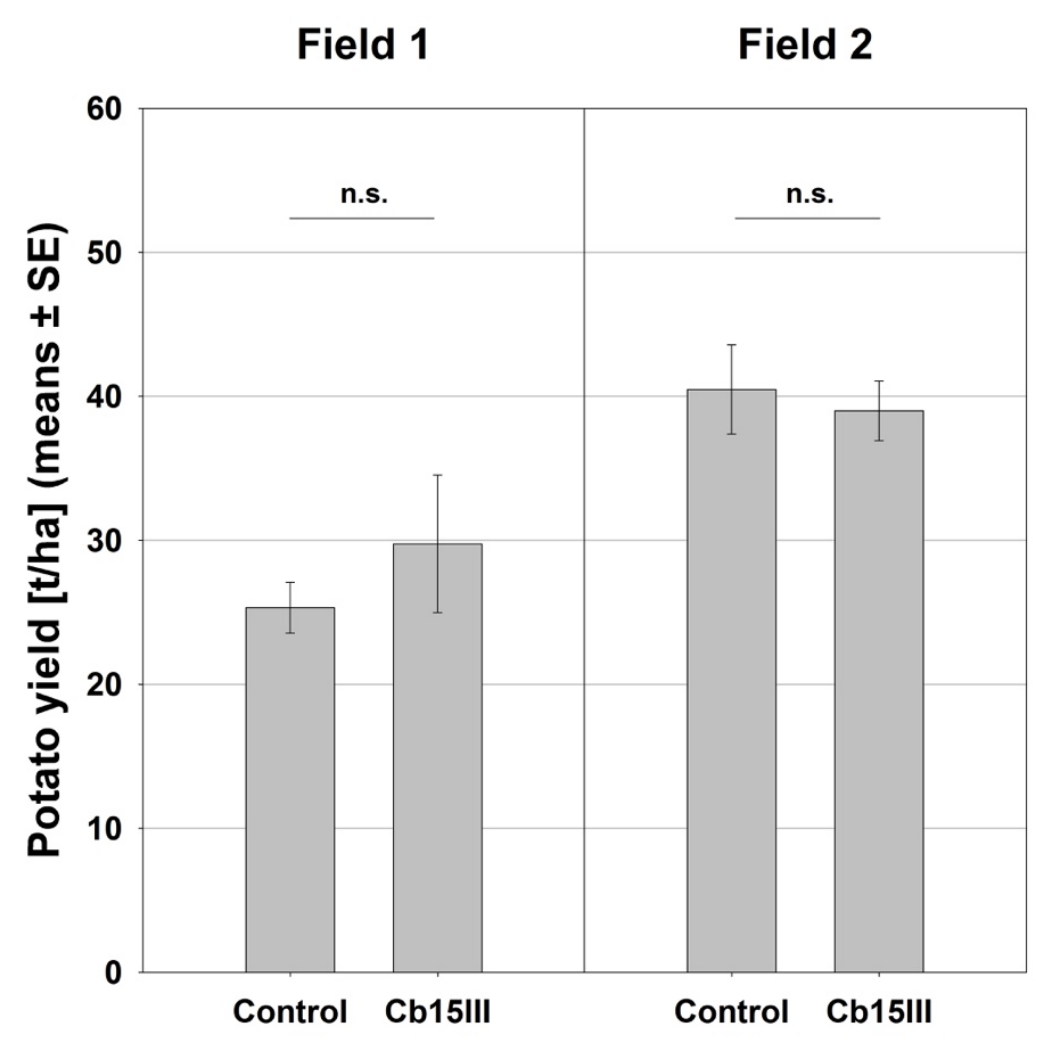

Figure 13 Tuber yield [t/ha] (means \pm standard errors (SE)) for field 1 and field 2. Yield was not significantly different between treatments (t-test $\alpha=0.05)$. 


\section{Destruxins/ Solanine}

Potato tubers from field 1 treated with $M$. brunneum strain $\mathrm{Cb} 15 \mathrm{IIl}$ revealed a statistically significant higher solanine concentration than untreated tubers from the same field (t-test: $t=-20.986$, $D F=43, p<0.00001$ ). Determined solanine concentrations in field 1 'Cb15IIl' tubers were up to three times higher than in 'Control' tubers. Solanine concentrations in tubers from field 2 were not affected by the treatments (t-test: $t=-0.021, D F=46, p<0.984$ ). These concentrations were higher than normally measured in potato tubers (20 to $100 \mathrm{mg} / \mathrm{kg}$ tuber FW) but still below the recommended limit of $200 \mathrm{mg} / \mathrm{kg}$ tuber FW (Bömer and Mattis 1924) (Figure 14). Destruxin $A$ or related destruxins were not detected in any sample.

Field 1

Field 2

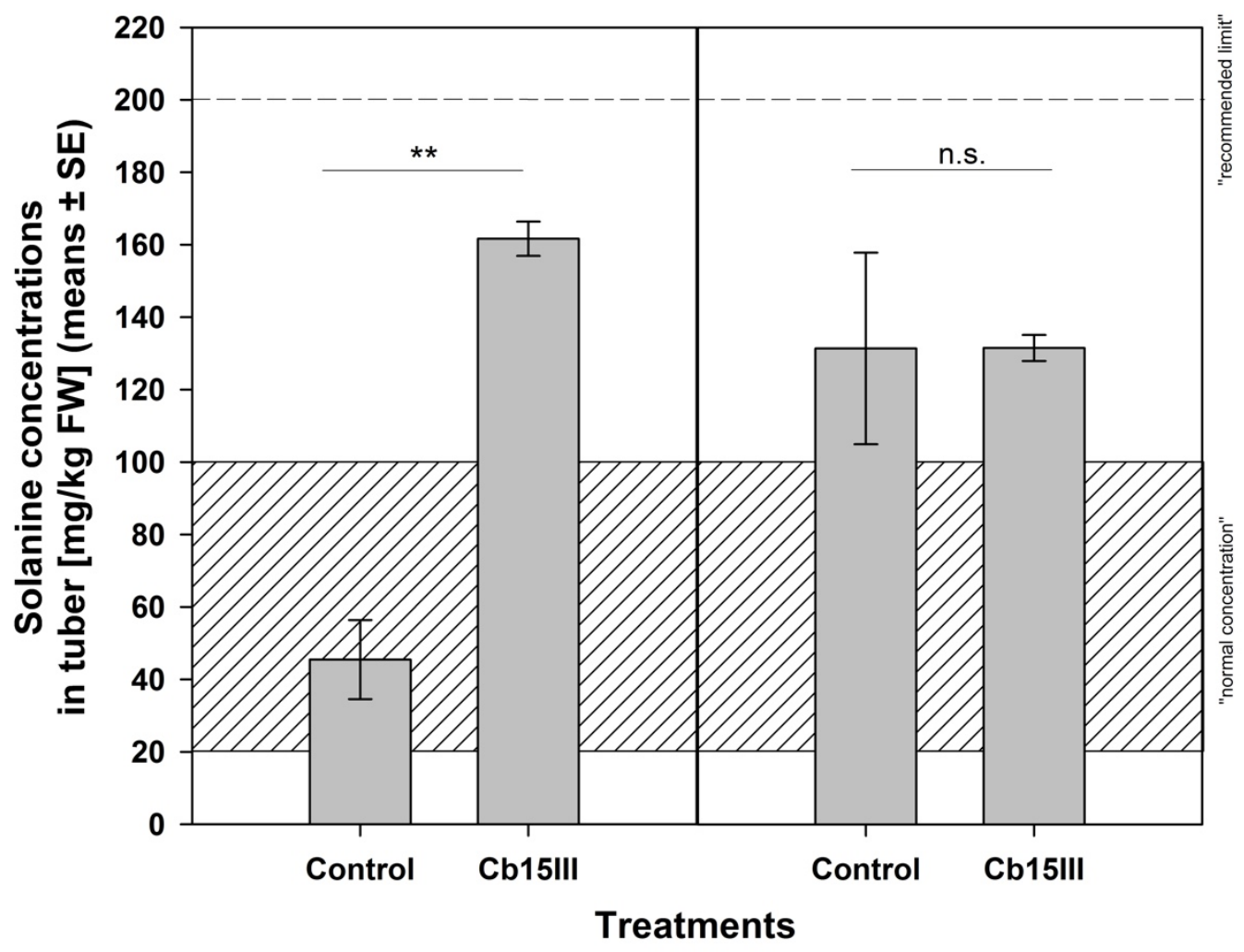

Figure 14 Solanine concentration in tubers [mg/kg fresh weight (FW)] (means \pm standard erros (SE)) of newly developed tubers from untreated potato plants ('Control') or potato plants treated with the M. brunneum strain Cb15III ('Cb15III'). Asterisks $\left({ }^{*}\right)$ indicate statistical significant differences between treatments (t-test, $\alpha=0.05$ ). Hatched area illustrates normal solanine concentrations and the dashed line indicates the highest recommended concentration in fresh potato tuber (Bömer and Mattis 1924). 


\section{Discussion}

\section{Greenhouse}

Results from the greenhouse experiments revealed an impact of the endophytic M. brunneum strain $\mathrm{Cb} 15 \mathrm{III}$ on the development of CPB. It was shown that less than $70 \%$ of the attached neonate larvae were able to develop to adult beetles when feeding on $M$. brunneum treated plants. A lower adult emergence was not observed for plants treated with a $0.1 \%$ Tween ${ }^{\circledR} 80$ solution indicating that Tween ${ }^{\circledR} 80$ do not have an effect on plants or insects in this experiment. Mycosed larvae, pupae or adults were not found throughout the experiments neither on plant nor in the soil. However, a horizontal transmission of $M$. brunneum conidia from soil to aboveground plant parts cannot be excluded for the experimental set up (Long et al. 2000). This is especially true for larvae burrowed into soil for pupation, though later larval stages are less susceptible against infections with M. brunneum (Akbarian 2012). An absence of mycosed larvae could be explained by environmental conditions in the greenhouse, which were unfavorable for the development of mycosis on infected larvae (Walstad et al. 1970). Direct infection of CPB with M. brunneum strain Cb15III seems to be possible but unlikely. The high virulence of the strain Cb15III shown in previous experiments should have had led to a higher, significant CPB mortality in this experiment in case larvae got in contact to conidia (Hettlage, data not published). Furthermore, slightly shortened tibia lengths were measured for adults emerged from 'Cb15III' treatments. This can be an indicator for a quality change in the food source instead of an infection with $M$. brunneum (Bethke et al. 1991; Urrutia C. et al. 2007). The above ground DM did not differ across treatments, though fewer adults emerged from M. brunneum treated plants. This indicates that fewer larvae in the 'Cb15III' treatment consumed an equal amount of plant DM, which would substantiate the theory of a changed food source. However, Furlong and Groden (2001) showed that CPB larvae treated with B. bassiana conidia consumed more leaf area than untreated larvae. Consequently, it is still unclear whether CPB were affected by a change in diet or an infection with $M$. brunneum. The observed effects are too small to presume a direct impact or infection of the endophytic fungus.

Even though is unclear how many potato plants very actually colonized by the $M$. brunneum strain $\mathrm{Cb} 15 \mathrm{III}$. M. brunneum could not be re-isolated from above ground plant material. Low Metarhizium re-isolation rates were reported in literature before 
especially from leaf and stem tissue (Behie et al. 2015). An additional nested-PCR analyses was able to detect Metarhizium in the plant tissue, albeit across all treatment. The primers Ma 1763 and Ma 2097 used in this study were not designed to be $M$. brunneum specific but to amplify DNA from all Metarhizium species within clade 1. (Schneider et al. 2011). Schneider et al. (2012) were able to find Metarhizium species from clade 1 in all screened habitats. Therefore, it is likely that the non-washed, organic potato tubers used in this study were contaminated or colonized by other Metarhizium species. It is not yet possible to detect $M$. brunneum specifically from plant material with a single set of primers, especially not when an untreated control is already colonized by Metarhizium clade 1 species. This seems to have been the case for potato tubers in this study.

\section{Field trail and choice test}

This is the first study indicating that a tuber treatment with $M$. brunneum can affect female oviposition behavior in field. It was shown that in field 1 the number of counted CPB eggs per plant was significantly lower compared to untreated plants. Similar observations were made in field 2, though CPB infestation were lower and effects between treatments not significantly different. Effects of lowered oviposition continued throughout larval stages. Infestation with $\mathrm{L}_{2}-\mathrm{L}_{3}$ larvae was reduced by more than 50 $\%$ in plots treated with $M$. brunneum (field 1). A tuber treatment with the endophytic $M$. brunneum strain $\mathrm{Cb} 15 \mathrm{III}$ seems to alter the chemical composition of potato plants and reduced attractiveness for CPB oviposition. A direct incorporation of fungal metabolites, such as destruxines (Ríos-Moreno et al. 2016) into the plants seems possible but destruxines and other mycotoxines were not detected or determined in tested potato tubers in this study. However, endophyte induced changes in oviposition behavior was already described by Jallow et al. (2008). They observed an enhanced oviposition by Helicoverpa armigera on tomato plants, Solanum lycopersicum, colonized by Acremonium strictum. However, development of $H$. armigera larvae feeding on A. strictum colonized plants was negatively affected. (Jaber and Vidal 2010). Slight negative effects on CPB development were also observed in the greenhouse experiment. These effects could be explained by a change in the glycoalkaloid profile, especially solanine and chaconine. It was shown that the glycoalkaloids solanine and chaconine can have negative effect on insects (Wierenga 
and Hollingworth 1992). In this study, the solanine content of untreated potato tubers from field 1 was significantly lower than in tubers treated with M. brunneum. It is possible that the increased solanine concentrations in treated potato plants must have influenced female oviposition. This conclusion, however, contradicts the literature published so far. Hufnagel et al. (2017) revealed that CPB oviposition and larval performance is not related to the overall glycoalkaloid profile and it was shown that CPB are not able to detect solanine with their antenna (Harrison and Mitchell 1988; Hollister et al. 2001). Furthermore, different solanine concentrations in tubers were only observed in field 1 . Solanine concentrations were not affected by the treatments in field 2. It has been observed that 'Control' potato plants in field 1 were already severely damaged by CPB when tubers were harvested for solanine determination (data not shown). Therefore, it is possible that tubers already started to mature, as it is known that glycoalkaloid concentrations in tubers decrease during maturing process (Papathanasiou et al. 1998). As a consequence, it is more likely that M. brunneum changed the volatiles emitted by potato plants. Schütz et al. (1997) figured out that the volatiles benzene methanol, linalool, 2-benzene-ethanol and $\beta$-caryophyllene are attractive to CPB in laboratory choice tests. However, volatiles were not measured in this study. Therefore, it is uncertain which volatiles were emitted by plants and if they were deterrent or just less attractive to CPB. Choice tests conducted in this study were not able to answer this question, as it was revealed that $M$. brunneum treated plants were slightly more attractive to CPB than control plants. This was also true when adults were allowed to feed on treated leaves. It is known that CPB are attracted by odorants emitted when potato plants are under herbivore attack (Weißbecker et al. 1997; Schütz et al. 1997; Landolt et al. 1999). Consequently, an additional aspect could be that CPB are not directly influenced by the changed volatiles bouquet caused by fungal colonization, but by other herbivore or sap sucking insects deterred by the $M$. brunneum treated plants. In field, it was observed that control plants were more likely to be infested with aphids than treated plants (personal observation). Deterrent effects of treated plants on sap sucking insects would be in accordance to findings from Menjivar et al. (2012). Therefore, it is conclusive that CPB were attracted to potato plants with a strong aphid infestation. Especially the volatiles linalool and 2-benzeneethanol were emitted by plants when under herbivore attack (Weißbecker et al. 1997; Schütz et al. 1997). Once beetles infested potato plants and start feeding, more beetles were attracted by the caused leaf injuries (Bolter et al. 1997; Schütz et al. 1997; Landolt 
et al. 1999). Furthermore, CPB females were highly attracted by male-produced aggregation pheromones (Hitchner et al. 2008). This could explain why oviposition was higher in control plants.

\section{Conclusion}

It was shown that potato plants treated with $M$. brunneum strain $\mathrm{Cb} 15 \mathrm{III}$ have an effect oviposition behavior and development of CPB. A direct infection of CPB with the fungus was not observed throughout the experiments. Therefore, it is more likely that plant volatiles bouquet was altered by the fungus. This could be exploited in future "pushpull" strategies to manage CPB in field (Cook et al. 2007). However, it is unclear which metabolic compounds are affected by $M$. brunneum in potato plants. Further research is needed to identify changes in potato plant volatiles, which could be used for "pushpull" pest management.

\section{Acknowledgements}

We would like to thank Bianca Tappe, Marie Nörthemann and Jonas Watterodt for their technical assistance and Dr. Anna Rathgeb (Georg-August-Universität Göttingen, Germany) for conducting the destruxin and solanine analysis. Furthermore, we would like to thank Wilfried Dreyer (Ökoring AG, Visselhövede, Germany) for his professional support and all farmers for providing field sites. These studies were funded by the German Federal Environmental Foundation (DBU), Germany.

\section{References}

Akbarian J (2012) Pathogenicity of some isolates of Beauveria bassiana (Bals.) Vuill. and Metarhizium anisopliae (Metsch.) Sorokin on 2nd and 4th larval instars of Colorado potato beetle, Leptinotarsa decemlineata (Say) (Col.: Chrysomelidae), under laboratory conditions. African J Microbiol Res 6:6407-6413. doi: 10.5897/AJMR12.1112

Alyokhin A, Baker M, Mota-Sanchez D, et al (2008) Colorado potato beetle resistance to insecticides. Am J Potato Res 85:395-413. doi: 10.1007/s12230-008-9052-0

Barelli L, Moonjely S, Behie SW, Bidochka MJ (2016) Fungi with multifunctional lifestyles: endophytic insect pathogenic fungi. Plant Mol Biol 90:657-664. doi: 
10.1007/s11103-015-0413-z

Batta YA (2013) Efficacy of endophytic and applied Metarhizium anisopliae (Metch.) Sorokin (Ascomycota: Hypocreales) against larvae of Plutella xylostella L. (Yponomeutidae: Lepidoptera) infesting Brassica napus plants. Crop Prot 44:128134. doi: 10.1016/j.cropro.2012.11.001

Behie SW, Jones SJ, Bidochka MJ (2015) Plant tissue localization of the endophytic insect pathogenic fungi Metarhizium and Beauveria. Fungal Ecol 13:112-119. doi: 10.1016/j.funeco.2014.08.001

Behie SW, Zelisko PM, Bidochka MJ (2012) Endophytic Insect-Parasitic Fungi Translocate Nitrogen Directly from Insects to Plants. Science (80- ) 336:15761577. doi: 10.1126/science.1222289

Bethke JA, Nuessly GS, Paine TD, Redak RA (1991) Effect of host insect-host plant associations on selected fitness components of Encarsia formosa (Gahan) (Hymenoptera: Aphelinidae). Biol Control 1:164-169. doi: 10.1016/10499644(91)90115-G

Bolter CJ, Dicke M, Van Loon JJA, et al (1997) Attraction of Colorado Potato Beetle to Herbivore-Damaged Plants During Herbivory and After Its Termination. J Chem Ecol 23:1003-1023. doi: 10.1023/B:JOEC.0000006385.70652.5e

Bömer A, Mattis H (1924) Der Solaningehalt der Kartoffeln. Zeitschr f Untersuchung d Nahr- u Genußmittel 47:97-127

Brandfass C, Karlovsky P (2008) Upscaled CTAB-Based DNA Extraction and RealTime PCR Assays for Fusarium culmorum and F. graminearum DNA in Plant Material with Reduced Sampling Error. Int J Mol Sci 9:2306-2321. doi: 10.3390/ijms9112306

Carpio A, Arroyo-Manzanares N, Ríos-Moreno A, et al (2016) Development of a QuEChERS-based extraction method for the determination of destruxins in potato plants by UHPLC-MS/MS. Talanta 146:815-822. doi: 10.1016/j.talanta.2015.06.008

Contreras J, Mendoza JE, Martínez-Aguirre MR, et al (2014) Efficacy of Enthomopathogenic Fungus Metarhizium anisopliae Against Tuta absoluta (Lepidoptera: Gelechiidae). J Econ Entomol 107:121-124. doi: 10.1603/EC13404 Cook SM, Khan ZR, Pickett JA (2007) The Use of Push-Pull Strategies in Integrated Pest Management. Annu Rev Entomol 52:375-400. doi: 10.1146/annurev.ento.52.110405.091407 
Crowder DW, Onstad DW, Gray ME, et al (2005) Analysis of the Dynamics of Adaptation to Transgenic Corn and Crop Rotation by Western Corn Rootworm (Coleoptera: Chrysomelidae) Using a Daily Time-Step Model. J Econ Entomol 98:534-551. doi: 10.1603/0022-0493-98.2.534

EPPO (2008) Leptinotarsa decemlineata. EPPO Bull 38:272-274

Ertürk Ö (2017) Effects of Various Plant Extracts on the Development of the Potato Beetle under Laboratory and Field Conditions : A Combined Study. J Entomol Res Soc 19:101-112

Ferro DN, Logan JA, Voss RH, Elkinton JS (1985) Colorado Potato Beetle (Coleoptera: Chrysomelidae) Temperature-dependent Growth and Feeding Rates. Environ Entomol 14:343-348. doi: 10.1093/ee/14.3.343

Furlong MJ, Groden E (2001) Evaluation of Synergistic Interactions Between the Colorado Potato Beetle (Coleoptera: Chrysomelidae) Pathogen <B> $<\mid>$ Beauveria bassiana $<||></ B>$ and the Insecticides, Imidacloprid, and Cyromazine. J Econ Entomol 94:344-356. doi: 10.1603/0022-0493-94.2.344

Goettel MS, Douglas Inglis G (1997) Fungi. In: Lacey LA (ed) Manual of Techniques in Insect Pathology. Elsevier, London, UK, pp 213-249

Grapputo A, Boman S, Lindström L, et al (2005) The voyage of an invasive species across continents: Genetic diversity of North American and European Colorado potato beetle populations. Mol Ecol 14:4207-4219. doi: 10.1111/j.1365294X.2005.02740.x

Hack H, Gall H, Klemke T, Klose R (1993) The BBCH scale for phenological growth stages of potato (Solanum tuberosum L.). In: 12th Triennial conference. Paris, pp 153-154

Hallsworth JE, Magan N (1999) Water and Temperature Relations of Growth of the Entomogenous Fungi Beauveria bassiana, Metarhizium anisopliae, and Paecilomyces farinosus. J Invertebr Pathol 74:261-266. doi: 10.1006/jipa.1999.4883

Hare JD (1990) Ecology and Management of the Colorado Potato Beetle. Annu Rev Entomol 35:81-100. doi: 10.1146/annurev.en.35.010190.000501

Harrison GD, Mitchell BK (1988) Host-plant acceptance by geographic populations of the colorado potato beetle, Leptinotarsa decemlineata - Role of solanaceous alkaloids as sensory deterrents. J Chem Ecol 14:777-788. doi: 10.1007/BF01018772 
Hitchner EM, Kuhar TP, Dickens JC, et al (2008) Host plant choice experiments of Colorado potato beetle (Coleoptera : Chrysomelidae) in Virginia. J Econ Entomol 101:859-865

Hollister B, Dickens JC, Perez F, Deahl KL (2001) Differential neurosensory responses of adult Colorado potato beetle, Leptinotarsa decemlineata, to glycoalkaloids. J Chem Ecol 27:1105-1118

Hufnagel M, Schilmiller AL, Ali J, Szendrei Z (2017) Choosy mothers pick challenging plants: maternal preference and larval performance of a specialist herbivore are not linked. Ecol Entomol 42:33-41. doi: 10.1111/een.12350

Hywel-Jones NL, Gillespie AT (1990) Effect of temperature on spore germination in Metarhizium anisopliae and Beauveria bassiana. Mycol Res 94:389-392. doi: 10.1016/S0953-7562(09)80363-8

Jaber LR, Vidal S (2010) Fungal endophyte negative effects on herbivory are enhanced on intact plants and maintained in a subsequent generation. Ecol Entomol 35:25-36. doi: 10.1111/j.1365-2311.2009.01152.x

Jallow MFA, Dugassa-Gobena D, Vidal S (2008) Influence of an endophytic fungus on host plant selection by a polyphagous moth via volatile spectrum changes. Arthropod Plant Interact 2:53-62. doi: 10.1007/s11829-008-9033-8

Kapsa JS (2008) Important threats in potato production and integrated pathogen/pest management. Potato Res 51:385-401. doi: 10.1007/s11540-008-9114-1

Khan AL, Hamayun M, Khan SA, et al (2012) Pure culture of Metarhizium anisopliae LHL07 reprograms soybean to higher growth and mitigates salt stress. World J Microbiol Biotechnol 28:1483-1494. doi: 10.1007/s11274-011-0950-9

Krell V, Jakobs-Schoenwandt D, Vidal S, Patel A V. (2018) Cellulase enhances endophytism of encapsulated Metarhizium brunneum in potato plants. Fungal Biol 122:373-378. doi: 10.1016/j.funbio.2018.03.002

Kryukov VY, Khodyrev VP, Yaroslavtseva ON, et al (2009) Synergistic action of entomopathogenic hyphomycetes and the bacteria Bacillus thuringiensis ssp. morrisoni in the infection of Colorado potato beetle Leptinotarsa decemlineata. Appl Biochem Microbiol 45:511-516. doi: 10.1134/S000368380905010X

Kryukov VY, Yaroslavtseva ON, Dubovskiy IM, et al (2014) Insecticidal and immunosuppressive effect of ascomycete Cordyceps militaris on the larvae of the Colorado potato beetle Leptinotarsa decemlineata. Biol Bull 41:276-283. doi: $10.1134 /$ S1062359014020046 
Landolt PJ, Tumlinson JH, Alborn DH (1999) Attraction of Colorado potato beetle (Coleoptera: Chrysomelidae) to damaged and chemically induced potato plants. Environ Entomol 28:973-978

Long DW, Groden E, Drummond F a. (2000) Horizontal transmission of Beauveria bassiana (Bals.) Vuill. Agric For Entomol 2:11-17. doi: 10.1046/j.14619563.2000.00046.x

Lovett B, St. Leger RJ (2014) Stress is the rule rather than the exception for Metarhizium. Curr Genet 253-261. doi: 10.1007/s00294-014-0447-9

Mantzoukas S, Chondrogiannis C, Grammatikopoulos G (2015) Effects of three endophytic entomopathogens on sweet sorghum and on the larvae of the stalk borer Sesamia nonagrioides. Entomol Exp Appl 154:78-87. doi: 10.1111/eea.12262

Menjivar RD, Cabrera JA, Kranz J, Sikora RA (2012) Induction of metabolite organic compounds by mutualistic endophytic fungi to reduce the greenhouse whitefly Trialeurodes vaporariorum (Westwood) infection on tomato. Plant Soil 352:233241. doi: 10.1007/s11104-011-0991-8

Mota-Sanchez D, Hollingworth RM, Grafius EJ, Moyer DD (2006) Resistance and cross-resistance to neonicotinoid insecticides and spinosad in the Colorado potato beetle,Leptinotarsa decemlineata (Say) (Coleoptera: Chrysomelidae). Pest Manag Sci 62:30-37. doi: 10.1002/ps.1120

Muvea AM, Meyhöfer R, Subramanian S, et al (2014) Colonization of Onions by Endophytic Fungi and Their Impacts on the Biology of Thrips tabaci. PLoS One 9:e108242. doi: 10.1371/journal.pone. 0108242

Ownley BH, Gwinn KD, Vega FE (2010) Endophytic fungal entomopathogens with activity against plant pathogens: Ecology and evolution. BioControl 55:113-128. doi: 10.1007/s10526-009-9241-x

Papathanasiou F, Mitchell SH, Harvey BMR (1998) Glycoalkaloid accumulation during tuber development of early potato cultivars. Potato Res 41:117-125. doi: 10.1007/BF02358434

Premachandra DWTS, Borgemeister C, Poehling H-M (2005) Effects of Neem and Spinosad on Ceratothripoides claratris (Thysanoptera: Thripidae), an Important Vegetable Pest in Thailand, Under Laboratory and Greenhouse Conditions. J Econ Entomol 98:438-448. doi: 10.1603/0022-0493-98.2.438

Ríos-Moreno A, Garrido-Jurado I, Resquín-Romero G, et al (2016) Destruxin A 
production by Metarhizium brunneum strains during transient endophytic colonisation of Solanum tuberosum. Biocontrol Sci Technol 26:1574-1585. doi: 10.1080/09583157.2016.1223274

Roush RT, Hoy CW, Ferro DN, Tingey WM (1990) Insecticide resistance in the Colorado Potato Beetle (Coleoptera: Chrysomelidae): Influence of crop rotation and insecticide use. J Econ Entomol 83:315-319

Sasan RK, Bidochka MJ (2012) The insect-pathogenic fungus Metarhizium robertsii (Clavicipitaceae) is also an endophyte that stimulates plant root development. Am J Bot 99:101-107. doi: 10.3732/ajb.1100136

Schneider S, Rehner SA, Widmer F, Enkerli J (2011) A PCR-based tool for cultivationindependent detection and quantification of Metarhizium clade 1. J Invertebr Pathol 108:106-114. doi: 10.1016/j.jip.2011.07.005

Schneider S, Widmer F, Jacot K, et al (2012) Spatial distribution of Metarhizium clade 1 in agricultural landscapes with arable land and different semi-natural habitats. Appl Soil Ecol 52:20-28. doi: 10.1016/j.apsoil.2011.10.007

Schnepf E, Crickmore N, Van Rie J, et al (1998) Bacillus thuringiensis and its pesticidal crystal proteins. Microbiol Mol Biol Rev 62:775-806. doi: 1092-2172

Schütz S, Weißbecker B, Klein A, Hummel HE (1997) Host Plant Selection of the Colorado Potato Beetle as Influenced by Damage Induced Volatiles of the Potato Plant. Naturwissenschaften 84:212-217. doi: 10.1007/s001140050381

Strasser H, Forer A, Schinner F (1996) Development of media for the selective isolation and maintenance of virulence of Beauveria brongniartii. In: Jackson TA, Glare TR (eds) Proceedings of the 3rd International Workshop on Microbial Control of Soil Dwelling Pests. Lincoln, New Zealand, pp 125-130

Trisyono A, Whalon ME (1999) Toxicity of Neem Applied Alone and in Combinations with Bacillus thuringiensis to Colorado Potato Beetle (Coleoptera: Chrysomelidae). J Econ Entomol 92:1281-1288. doi: 10.1093/jee/92.6.1281

Tyurin M V., Kryukov VY, Yaroslavtseva ON, et al (2016) Comparative analysis of immune responses in Colorado potato beetle larvae during development of mycoses caused by Metarhizium robertsii, M. brunneum, and M. pemphigi. J Evol Biochem Physiol 52:252-260. doi: 10.1134/S002209301603008X

Urrutia C. MA, Wade MR, Phillips CB, Wratten SD (2007) Influence of host diet on parasitoid fitness: unravelling the complexity of a temperate pastoral agroecosystem. Entomol Exp Appl 123:63-71. doi: 10.1111/j.1570- 
7458.2007.00526.x

Walstad JD, Anderson RF, Stambaugh WJ (1970) Effects of environmental conditions on two species of muscardine fungi (Beauveria bassiana and Metarrhizium anisopliae). J Invertebr Pathol 16:221-226. doi: 10.1016/0022-2011(70)90063-7

Weißbecker B, Schütz S, Klein A, Hummel HE (1997) Analysis of volatiles emitted by potato plants by means of a Colorado beetle electroantennographic detector. Talanta 44:2217-2224. doi: 10.1016/S0039-9140(97)00037-4

Whalon ME, Miller DL, Hollingworth RM, et al (1993) Selection of a Colorado Potato Beetle (Coleoptera: Chrysomelidae) Strain Resistant to Bacillus thuringiensis. J Econ Entomol 86:226-233. doi: 10.1093/jee/86.2.226

Wierenga JM, Hollingworth RM (1992) Inhibition of insect acetylcholinesterase by the potato glycoalkaloid a-chaconine. Nat Toxins 1:96-99. doi: 10.1002/nt.2620010207

Wraight S., Ramos M. (2002) Application Parameters Affecting Field Efficacy of Beauveria bassiana Foliar Treatments against Colorado Potato Beetle Leptinotarsa decemlineata. Biol Control 23:164-178. doi: 10.1006/bcon.2001.1004

Yaroslavtseva ON, Dubovskiy IM, Khodyrev VP, et al (2017) Immunological mechanisms of synergy between fungus Metarhizium robertsii and bacteria Bacillus thuringiensis ssp. morrisoni on Colorado potato beetle larvae. J Insect Physiol 96:14-20. doi: 10.1016/j.jinsphys.2016.10.004

Zehnder GW, Evanylo GK (1988) Influence of Colorado potato beetle sample counts and plant defoliation on potato tuber production. Am Potato J 65:725-736. doi: 10.1007/BF02853502 
Chapter 3 Encapsulated $M$. brunneum mycelium: a novel approach of managing wireworms in field with an endophytic M. brunneum strain Cb15III?

\section{Chapter 3}

Encapsulated Metarhizium brunneum mycelium: a novel approach to managing wireworms in field with an endophytic $M$. brunneum strain Cb15III?
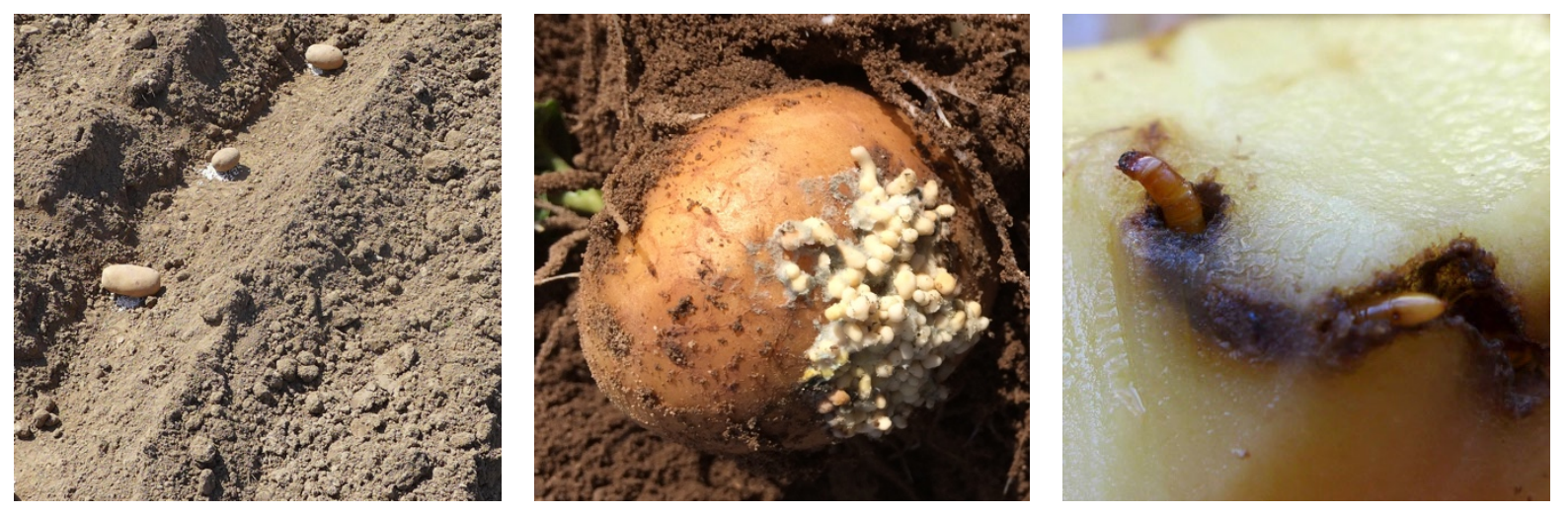

Authors: Laurenz Hettlage*, Vivien Krell, Anant Patel, Stefan Vidal

${ }^{*}$ Corresponding author 
Chapter 3 Encapsulated $M$. brunneum mycelium: a novel approach of managing wireworms in field with an endophytic M. brunneum strain Cb15III?

\section{Encapsulated Metarhizium brunneum mycelium: a novel approach to managing} wireworms in field with an endophytic M. brunneum strain Cb15III?

L. Hettlage ${ }^{1}$, V. Krell ${ }^{2}$, A. Patel ${ }^{2}$, S. Vidal ${ }^{1}$

${ }^{1}$ Georg-August University, Department of Crop Sciences, Agricultural Entomology, Grisebachstr. 6, 37077 Göttingen, Germany

Phone: +49 (0) 551-39 33732, E-mail: laurenz.hettlage@agr.uni-goettingen.de

2University of Applied Sciences Bielefeld, Department of Engineering and Mathematics, AG Fermentation and Formulation of Biologicals and Chemicals, Interaktion 1, 33619 Bielefeld, Germany

\section{Abstract}

Wireworms (Agriotes spp., Coleoptera: Elateridae) are an increasing problem in potato production in the northern hemisphere. Feeding on tubers is not only causing cosmetic wounds but can also lead to a promotion of secondary bacterial or fungal infections. Non-marketable tubers and a total yield loss can be a consequence. This study was conducted to investigate the potential of the endophytic, entomopathogenic fungus Metarhizium brunneum PETCH (Ascomycota: Hypocreales: Clavicipitaceae) strain Cb15III to reduce wireworm damage in field. Therefore, M. brunneum Cb15III mycelium was encapsulated and applied as a spot application beneath seed tubers. Mycelium was either formulated in calcium alginate/starch or calcium pectinate/starch beads. Calcium pectinate/starch beads contained additionally cellulose, inactivated baker's yeast and cellulase, latter to enhance fungal endophytism. The performance of the capsules was tested on five organic fields in Lower Saxony. Wireworm damage varied between $8-83 \%$ in the untreated control across fields. A reduction of damaged tubers was not observed for none of the tested treatments. It was revealed that a M. brunneum $\mathrm{Cb} 15 \mathrm{III}$ mycelium, encapsulated in beads, is not a suitable approach to protect potatoes from wireworm damage.

Keywords: Metarhizium brunneum, wireworm, potato, formulation, endophyte 
Chapter 3 Encapsulated $M$. brunneum mycelium: a novel approach of managing wireworms in field with an endophytic M. brunneum strain Cb15III?

\section{Introduction}

Wireworms, the larvae of click beetles (Agriotes spp., Coleoptera: Elateridae), are among the most important group of soil dwelling pests in agriculture and cause increasing problems in North America and Europe (Parker and Howard 2001; Vernon et al. 2008). In particular cereals, legumes and potatoes (Solanum tuberosum, L.) are vulnerable to wireworm infestation. Wireworm feeding causes crop losses due to stand and yield reduction and/or a decline in quality. The most abundant and destructive wireworm species in Europa are Agriotes lineatus, A. obscurus, A. sputator and in some regions $A$. ustulatus (Ritter and Richter 2013). Until the 1990s, wireworm populations were sufficiently managed using long-term, non-specific insecticides such as organochlorides, organophosphates and carbamates (Parker and Howard 2001). However, wireworms' importance raised within the last three decades and potato farmers are facing severe quality losses due to wireworm tunneling in tubers (Vernon and van Herk 2013). Reasons include changes in farmers practice, such as the conversion of permanent grassland to arable land or a reduction of tillage to a minimum. Consequently natural wireworm habitats decreased, resulting in higher population in field (Parker and Howard 2001; Vernon and van Herk 2013).

Due to potential environmental risks (Gunasekara et al. 2007), the European Food Safety Authority (2013) concluded to phase out permission for the phenylpyrazole insecticide fipronil, which was effectively controlling wireworms in potato crops (van Herk et al. 2008). Consequently, the lack of insecticides permitted on the European market in potato production exacerbates situation in wireworm management. Partially effective, non-chemical alternatives controlling wireworms are an intense tillage desiccating eggs and pupae or an incorporation of cruciferous plants (e.g. Brassica juncea) into soil (Furlan et al. 2010). Additionally, recent studies revealed that the entomopathogenic fungus Metarhizium brunneum PETCH (Ascomycota: Hypocreales: Clavicipitaceae) is a potent antagonist to Agriotes species (Reddy et al. 2014; Eckard et al. 2014; Rogge et al. 2017; Brandl et al. 2017; Razinger et al. 2018). It is reported that an "attract and kill" approach with an attractant (pheromones or $\mathrm{CO}_{2}$ (Todd Kabaluk et al. 2015; Brandl et al. 2017)) and a kill component (M. brunneum) can reduce Agriotes adults and/or larvae in field. The combination of an $\mathrm{CO}_{2}$ emitter and $M$. brunneum encapsulated in beads was able to reduce the abundance of wireworm damaged potato tubers in field trials (Brandl et al. 2017). However, reported 
Chapter 3 Encapsulated $M$. brunneum mycelium: a novel approach of managing wireworms in field with an endophytic M. brunneum strain Cb15III?

efficacies were neither consistent nor predictable, as tubers can exert a significant pull on wireworms and affect the application. The "attract and kill" could be improved by exploiting potential of Metarhizium being a naturally occurring endophyte (Khan et al. 2012; Sasan and Bidochka 2012; Behie et al. 2015). Fungal endophytes are naturally occurring in most plant species and are able to colonize plant tissue without causing apparent plant symptoms (Schulz and Boyle 2005). Furthermore, endophytes revealed to have multiple beneficial effects such as plant growth promotion (García et al. 2011; Khan et al. 2012), increased nutrient uptake (Behie et al. 2012), salt stress mitigation (Khan et al. 2012) and protection against plant pathogens (Lahlali and Hijri 2010; Sasan and Bidochka 2012; Adame-Álvarez et al. 2014). These findings open new options in biological plant protection (Vidal and Jaber 2015). Several studies revealed that entomopathogenic, endophytic fungi (EEF) protect plants from pests or alter their behavior (Batta 2013; Contreras et al. 2014; Muvea et al. 2014; Mantzoukas et al. 2015). Ríos-Moreno et al. (2016) reported that M. brunneum, virulent to Agriotes spp., is able to establish in potato plant tissue. Furthermore, Krell et al. (2018a) showed that a technical formulation and encapsulation of M. brunneum mycelium is possible and enhances endophytism in plants. In addition, encapsulated $M$. brunneum mycelium is able to penetrate potato tuber tissue and colonize them (Krell et al. 2018b). The capability of $M$. brunneum to colonize potato plants and its pathogenicity against wireworms could be used to develop a systemically acting, biological control of wireworms.

In this context we hypothesis that potato tubers, colonized by $M$. brunneum could be either deterrent to wireworms or due to dermal up take of infectious fungal/ tuber tissue lethal. In this approach not only seed tubers but also colonized plant roots would affect wireworms and consequently reduce wireworm damage on next generation tubers. In this study, Metarhizium brunneum (strain Cb15III) mycelium was encapsulated either in calcium alginate/starch or calcium pectinate/starch beads and tested under field conditions. 
Chapter 3 Encapsulated $M$. brunneum mycelium: a novel approach of managing wireworms in field with an endophytic M. brunneum strain Cb15III?

\section{Material and Method}

\section{Field sites}

Field trails were conducted during the growing seasons in the years 2016 and 2017. In 2016, treatments were tested at three locations and 2017 at two. All field sites were located in Lower Saxony, Germany and cultivated following the requirements of the organic farming association and Good Agricultural practice. Field sites were selected based on cropping history and farmers' previous experience with wireworm damage (Table 6). Weather data were recorded by weather stations within $40 \mathrm{~km}$ of field sites (Deutscher Wetterdienst, DWD, Offenbach, Germany)

Table 6 Characteristics of five field sites in Lower Saxony, Germany in 2016 and 2017 and details of potato field sites including cultivar and treatments (Control: untreated potato rows; mycelium: M. brunneum (strain: Cb15III) unformulated mycelium; CA(+)M: M. brunneum (Cb15III) mycelium in Ca-alginate beads; $C P(+) M$ : M. brunneum (Cb15III) mycelium in Capectinate bead; $C P(-) M$ : Ca-pectinate bead) and trial dimensions. $n . h$. not harvested

\begin{tabular}{|c|c|c|c|c|c|}
\hline \multirow{2}{*}{$\begin{array}{l}\text { Study year } \\
\text { Field code }\end{array}$} & \multicolumn{3}{|l|}{2016} & \multicolumn{2}{|l|}{2017} \\
\hline & 1 & 2 & 3 & 4 & 5 \\
\hline Location & Aerzen & Barnstedt & Waake & Aerzen & Bösinghausen \\
\hline Coordinates & $\begin{array}{l}\text { N } 52^{\circ} 4^{\prime} 15.875^{\prime \prime} \\
\text { E } 9^{\circ} 15^{\prime} 38.102^{\prime \prime}\end{array}$ & $\begin{array}{l}\text { N } 53^{\circ} 7^{\prime} 13.337^{\prime \prime} \\
\text { E } 10^{\circ} 23^{\prime} 10.606^{\prime \prime}\end{array}$ & $\begin{array}{l}\text { N } 51^{\circ} 33^{\prime} 0.486^{\prime \prime} \\
\text { E } 10^{\circ} 3^{\prime} 35.857^{\prime \prime}\end{array}$ & $\begin{array}{l}\text { N } 52^{\circ} 3^{\prime} 50.382^{\prime \prime} \\
\text { E } 9^{\circ} 15^{\prime} 32.388^{\prime \prime}\end{array}$ & $\begin{array}{l}\text { N } 51^{\circ} 34^{\prime} 4.337^{\prime \prime} \\
\text { E } 10^{\circ} 4^{\prime} 12.566^{\prime \prime}\end{array}$ \\
\hline Elevation (m) & 62 & 70 & 275 & 98 & 284 \\
\hline $\begin{array}{l}\text { Temperature }\left({ }^{\circ} \mathrm{C}\right) \\
\text { Mean year } \\
\text { April/ May } \\
\text { July/ Aug./ Sep. } \\
\text { Rainfall (mm) }\end{array}$ & $\begin{array}{l}10.3 \\
8.6 / 14.4 \\
19.2 / 18.1 / 17.5\end{array}$ & $\begin{array}{l}9.5 \\
7.5 / 14.1 \\
18.3 / 17.1 / 16.6\end{array}$ & $\begin{array}{l}9.9 \\
8.1 / 13.8 \\
18.6 / 17.9 / 17.2\end{array}$ & $\begin{array}{l}10.3 \\
7.7 / 14.6 \\
18.2 / 17.6 / 13.4\end{array}$ & $\begin{array}{l}9.9 \\
7.3 / 14.4 \\
18.1 / 17.6 / 13.0\end{array}$ \\
\hline $\begin{array}{l}\text { Sum year } \\
\text { April/ May } \\
\text { July/ Aug./ Sep. }\end{array}$ & $\begin{array}{l}555.6 \\
32.7 / 21.0 \\
45.7 / 23.4 / 13.3\end{array}$ & $\begin{array}{l}589.0 \\
42.5 / 53.0 \\
44.7 / 43.4 / 14.0\end{array}$ & $\begin{array}{l}543.6 \\
28.4 / 41.4 \\
43.0 / 40.5 / 34.7\end{array}$ & $\begin{array}{l}875.0 \\
20.1 / 33.9 \\
203.1 / 84.0 / 79.1\end{array}$ & $\begin{array}{l}776.6 \\
27.3 / 28.8 \\
202.1 / 87.2 / 40.5\end{array}$ \\
\hline Trial size (ha) & 0,067 & 0,067 & 0,067 & 0,067 & 0,067 \\
\hline Field size (ha) & 12,57 & 12,01 & 5,88 & 14,82 & 3,44 \\
\hline Soil type & Silt loam & Loamy sand & Sandy loam & Silt loam & Sandy loam \\
\hline Cultivar & Ditta & Ditta & Belana & Ditta & Bernina \\
\hline Tuber pre-treatment & Warming & Warming & Warming & Warming & Warming \\
\hline Previous crop & Cereal & Cereal & Cereal & Cereal & Cereal \\
\hline Irrigation & No & Yes & No & No & No \\
\hline Row-spacing (m) & 0,75 & 0,75 & 0,75 & 0,75 & 0,75 \\
\hline Tuber-spacing (m) & 0.30 & 0.30 & 0.30 & 0.30 & 0.30 \\
\hline Planting (BBCH 01) & 17. Apr. & 11. May & 27. Apr. & 15. Apr. & 07. Apr. \\
\hline Harvest (BBCH 99) & 06. Sep. & 30. Aug. & 07. Sep. & 10. Sep. & n.h. \\
\hline Plot size $\left(\mathrm{m}^{2}\right)$ & 21 & 21 & 21 & 21 & 21 \\
\hline Blocks & 8 & 8 & 8 & 8 & 8 \\
\hline Treatments & $\begin{array}{l}\text { Control } \\
\text { mycelium } \\
C A(+) M\end{array}$ & $\begin{array}{l}\text { Control } \\
\text { mycelium } \\
C A(+) M\end{array}$ & $\begin{array}{l}\text { Control } \\
\text { mycelium } \\
C A(+) M\end{array}$ & $\begin{array}{l}\text { Control } \\
C A(+) M \\
C P(+) M \\
C P(-) M\end{array}$ & $\begin{array}{l}\text { Control } \\
C A(+) M \\
C P(+) M \\
C P(-) M\end{array}$ \\
\hline
\end{tabular}


Chapter 3 Encapsulated $M$. brunneum mycelium: a novel approach of managing wireworms in field with an endophytic M. brunneum strain Cb15III?

\section{Experimental design}

Three treatments were tested in 2016 and four in 2017 to evaluate effects of encapsulated $M$. brunneum mycelium (strain Cb15III) on wireworm damage. Treatments were arranged in a randomized complete block design with eight replications. Each plot had a length of $7 \mathrm{~m}$ and a width of $3 \mathrm{~m}$ (equivalent to 4 potato rows à $0.75 \mathrm{~m}$ ). Treatments were applied as a "spot" application underneath seed potatoes within three days after surrounded potatoes had been planted by farmers. Wireworm damage was evaluated according to the European and Mediterranean Plant Protection Organization (EPPO) standards PP1/46(3) (EPPO 2005) by randomly sampling 100 tubers per plot (BBCH 99, (Hack et al. 1993)

\section{Treatments}

"mycelium": an aqueous suspension with $1.5 \%$ mycelium fragments $(50-250 \mu \mathrm{m}$ length) (M. brunneum $\mathrm{Cb} 15 \mathrm{III})$ was prepared one day before treatment application (Krell et al. 2018a).

"CA(+)M": mycelium fragments (1.5\% final concentration) were encapsulated in dried spherical calcium alginate/starch beads (diameter $2.0 \pm 0.2 \mathrm{~mm}$ ) based on Na-alginate solution, $20 \%$ maize starch and demineralized water, according to Krell et al. (2018b).

"CP(+)M": mycelium fragments (1.5\% final concentration) were encapsulated in dried spherical calcium pectinate/ starch beads (diameter $2.0 \pm 0.2 \mathrm{~mm}$ ) containing: $2 \%$ amidated pectin $20 \%$, maize starch, $2 \%$ cellulose, $2 \%$ autoclaved baker's yeast and $1 \mathrm{U} / \mathrm{g}$ cellulase in $1 \mathrm{~g}$ of moist beads based on the protocol of (Krell et al. 2018b). Autoclaved baker's yeast served as an energy source for rapid $M$. brunneum conidia germination. Cellusase enhanced endophytism in potato tubers.

“CP(-)M": dried spherical calcium pectinate/ starch beads (diameter $2.0 \pm 0.2 \mathrm{~mm}$ ) based in formulation of $C P(+) M$ but without mycelium biomass.

\section{Treatment preparation and application}

In 2016, the treatments mycelium and $C A(+) M$ were tested. Seed potatoes were planted at all fields between the end of April and beginning of May. Treatments were applied to fields within three days after seed potatoes had been planted by farmers. 
Chapter 3 Encapsulated $M$. brunneum mycelium: a novel approach of managing wireworms in field with an endophytic M. brunneum strain Cb15III?

Therefore, potato rows, set up by the farmers before, were opened with a two-wheel tractor with plowshare (Honda F560 \& F220, Honda Motor Europe Ltd., Berkshire, England). Treatments were applied in the furrow with a distance of $30 \mathrm{~cm}$ to each other. Therefore, $15 \mathrm{ml}$ mycelium suspension and $3 \mathrm{~g}$ of $C A(+) M$ were applied in the soil as "spot" applications. The mycelium treatment was applied in a $15 \mathrm{ml}$ centrifuge tube (Sarstedt AG \& Co., Nümbrecht, Germany). For the $C A(+) M$ treatment a $50 \mathrm{ml}$ centrifuge tube (Sarstedt AG \& Co., Nümbrecht, Germany) was so cut into shape that just $3 \mathrm{~g}$ of beads fit inside. Potato tubers were subsequently placed on applied treatments. Dams were covered with soil after all tubers were placed in the furrow by the use of the two-wheel tractor. In 2017, the treatments $C A(+) M, C P(+) M$ and $C P(-) M$ were applied into the planting furrows as described for $C A(+) M$ in 2016. In both years an additional untreated control was conducted without any tuber treatment.

\section{Metarhizium brunneum quality and persistence}

The quality of treatments beads was assessed with five replicates on water agar $(C A(+) M, C P(+) M$ and $C P(-) M)$ or potato dextrose agar (Carl Roth $\mathrm{GmbH} \&$ Co. KG, Karlsruhe, Germany) (mycelium). $100 \mu$ l of the mycelium suspension (mycelium) or 5 beads $(C A(+) M, C P(+) M$ and $C P(-) M)$ were plated on each Petri dish $(\varnothing 9 \mathrm{~cm}$, Sarstedt AG \& Co., Nümbrecht, Germany) and incubated in the dark at $22^{\circ} \mathrm{C}$ and $70 \%$ relative humidity. Fungal growth was assessed with light microscopy (500 x magnifications, BH2- HLSH, Olympus Corporation, Tokyo, Japan). Quality of beads and suspension was optimal as $M$. brunneum growth was observed with the suspension and the beads $(C A(+) M, C P(+) M)$ in all replications. No fungal growth was observed for $C P(-) M$ beads, indicating that beads were free of contaminations.

\section{Metarhizium brunneum persistence in soil}

M. brunneum establishment and persistence was determined based on the protocol of Brandl et al. (2017). Four soil samples were taken at four locations diagonally across each plot within the core of potato dams in a depth of $15 \mathrm{~cm}$ with a cylindrical soil core sampler (diameter $5.0 \mathrm{~cm}$ ). Samples were taken from replicates 1, 3, 5 and 7 of all treatments and locations were marked with a colored plastic bar to retrieve sample locations later. The four soil samples from one plot were poled to one sample, 
Chapter 3 Encapsulated $M$. brunneum mycelium: a novel approach of managing wireworms in field with an endophytic M. brunneum strain Cb15III?

transferred in a Zip-lock ${ }^{\mathrm{TM}}$ plastic bag and stored at $6^{\circ} \mathrm{C}$ until further processing. Soil sampling was conducted at tuber planting (April/May) and harvesting (August). In August, soil probes were taken at locations marked previously. Colony forming units (CFU) extraction from soil and counting was conducted following the protocol of Brandl et al. (2017) step by step.

\section{Assessment of wireworm damage}

In August, 100 randomly chosen potato tubers were manually harvested (BBCH 99, Hack et al. 1993) from each plot. Therefore, the two central potato dams were opened with the two-wheel tractor on a length of $5 \mathrm{~m}$ leaving $1 \mathrm{~m}$ unopened to each plot's end. In 2017, all tubers in an area of $1.5 \mathrm{~m}$ (= two rows at a length of $1 \mathrm{~m}$ ) were additionally harvested from plots center in order to determine the potato yield. Tuber damage was categorized in accordance with EPPO guideline s PP1/46(3) by differentiating wireworm damage per tuber by classes (class 1: $1-2$ holes, class 2: $3-5$ holes and class 3: > 5 holes). Wireworm damage was defined as $\geq 5 \mathrm{~mm}$ tunnels burrowed in tuber flesh and wireworm damage was only recorded if it was clearly identifiable. Beside wireworm damage, Rhizoctonia solani sclerotia and drycore symptoms as well as the overall damage (=all but wireworm holes) were determined per tuber (Keiser et al. 2012).

\section{Metarhizium brunneum molecular detection (nested-PCR)}

Potato plants from the fields 1, 2 and 5 were excavated $(\mathrm{BBCH} 13)$, separately transferred to Zip-lock ${ }^{\mathrm{TM}}$ plastic bags and cooled down in an icebox until further processing in the laboratory. One randomly chosen potato plant was excavated from each treatment and replication. In the laboratory, plants were washed with sterile tap water and intersected in root, stem and leaves with a sterile scalpel. Samples were surface sterilized by successive immersion in $2 \%(\mathrm{v} / \mathrm{v})$ sodium hypochlorite solution (2 $\mathrm{min}), 70 \%(\mathrm{v} / \mathrm{v})$ ethanol $(2 \mathrm{~min})$ and three rinses in sterile water. One hundred $\mu \mathrm{l}$ of the last watering step was plated on PDA-Media and incubated for 4 days at $25^{\circ} \mathrm{C}$ to prove the success of the surface sterilization. Surface sterilized roots, stems and leaves of each treatment were frozen at $-20^{\circ} \mathrm{C}$ for $24 \mathrm{~h}$ and afterwards lyophilized (VaCo 5, Zirbus - technology GmbH, Bad Grund (Harz), Germany) for 72 h. Genomic DNA was 
Chapter 3 Encapsulated $M$. brunneum mycelium: a novel approach of managing wireworms in field with an endophytic M. brunneum strain Cb15III?

extracted according to the cetyltrimethylammonium bromide (CTAB) protocol described by Brandfass and Karlovsky (2008). Extraction performance was tested via gel electrophoresis in a $0.8 \%(w / v)$ agarose gel (Biozym Scientific GmbH, Hessisch Oldendorf, Germany) running at $60 \mathrm{~V}$ for $60 \mathrm{~min}$. Gel was documented with a digital imaging system.

The primers used for amplification were 'Ma 1763' (forward primer: 5'-CCAACTCCCAACCCCTGTGAAT) and 'Ma 2079' (reverse primer: 5'-AAAACCAGCCTCGCCGAT) specific for Metarhizium clade 1 (Schneider et al. 2012). A volume of $14 \mu$ was used for PCR amplification consisting of $0.3 \mu \mathrm{l}$ 'Ma 1763' (10 $\mu \mathrm{M}$, Thermo Fisher Scientific Inc., Waltham, USA), $0.3 \mu \mathrm{l}$ 'Ma 2079' (10 $\mathrm{M}$, Thermo Fisher Scientific Inc., USA), $0.09 \mu \mathrm{l}$ BIOTaq DNA polymerase ( $5 \mathrm{U} / \mu \mathrm{l}$, Bioline $\mathrm{GmbH}$, Luckenwalde, Germany), $1.2 \mu \mathrm{d}$ dNTP (Bioline GmbH, Luckenwalde, Germany), $0.3 \mu \mathrm{l} \mathrm{MgCl} 2(50 \mathrm{mM}), 1.5 \mu \mathrm{l}$ reaction buffer (10 x, Bioline $\mathrm{GmbH}$, Luckenwalde, Germany), $10.3 \mu$ l sterile purified water and $1 \mu \mathrm{l}$ of the DNA extract. The PCR was performed an PCR cycler (PEQLAB Biotechnologie $\mathrm{GmbH}$, Erlangen, Germany) according to the following protocol: Initial denaturation for $1 \mathrm{~min}$ at $94^{\circ} \mathrm{C}$, followed by 35 cycles with $30 \mathrm{~s}$ at $94^{\circ} \mathrm{C}, 30 \mathrm{~s}$ at $63^{\circ}$ $\mathrm{C}$ and $30 \mathrm{~s}$ at $68^{\circ} \mathrm{C}$. The final elongation was performed for $5 \mathrm{~min}$ at $68^{\circ} \mathrm{C}$.

A second, nested-PCR amplification was performed under the same conditions as in the initial PCR but with the nested-primers MetarhL1 (forward primer: 5'-ATCTCTTGGTTCTGGCATCG) and MetarhR1 (reverse primer: 5'-CCCAACACCAAGTCCACAG) (Thermo Fisher Scientific Inc., Waltham, USA). Nested PCR performance was tested via gel electrophoresis in a $2.0 \%$ (w/v) agarose gel (Biozym Scientific GmbH, Hessisch Oldendorf,Germany) running at $60 \mathrm{~V}$ for $60 \mathrm{~min}$. Gel was documented with a digital imaging system.

\section{Destruxins extraction and determination}

Tubers were harvested at the beginning of July (ca. BBCH 45) for destruxins extraction and determination. Four randomly chosen plants from each plot were dug up, bagged plant by plant and stored in an ice box at $5^{\circ} \mathrm{C}$ for transportation. Samples were finally stored in the dark at $5^{\circ} \mathrm{C}$ in a cooled storage room until further processing. Four tubers from each plot, one from each plant, were poled to one sample. Destruxins were extracted from tubers following the protocol of Carpio et al. (2016) step by step. Identification and quantification of destruxins was implemented by the workgroup of 
Chapter 3 Encapsulated $M$. brunneum mycelium: a novel approach of managing wireworms in field with an endophytic M. brunneum strain Cb15III?

Prof. Karlsovsky (Molecular Phytopathology and Mycotoxin Research, Georg-August University, Göttingen, Germany).

\section{Statistical analysis}

Values are given as mean \pm standard error (SE), unless otherwise stated. Data was tested for normal distribution and variances homogeneity using Shapiro-Wilk test and Levene's-test, respectively. Where appropriate, data was square-root transformed and analyzed with one-way ANOVA followed by Tukey HSD post hoc test $(\alpha=0.05)$. Percentage of wireworm damaged tubers was calculated by comparing the number of wireworm damaged tubers and the number of all tested tubers.

$$
\% \text { wireworm damage }=\frac{\text { no. of wireworm damaged tubers }}{\text { no. of all tubers }} * 100
$$

Wireworm damage classes distribution (low, medium and high) was calculated by comparing tubers low, medium or high wireworm damage to the of overall wireworm damaged tubers.

$\%$ damage class distr. (low, medium or high) $=\frac{\text { no. of tubers in damage class (low, medium or high) }}{\text { no. of all wireworm damaged tubers }} * 100$

Percentages of wireworm damage classes (low, medium or high) were analyzed with Kruskal-Wallis test $(\alpha=0.05)$. Formula for calculating wireworm damage was also used for the calculation of percentage tubers with drycore symptoms or Rhizoctonia solani sclerotia. Multiple regression analysis was used to identify whether wireworm damage or Rhizoctonia solani sclerotia having a significant effect on drycore symptoms. All statistical analyses were carried out with the software STATISTICA, version 13 (StatSoft Inc., Tulsa, OK, USA). 
Chapter 3 Encapsulated $M$. brunneum mycelium: a novel approach of managing wireworms in field with an endophytic M. brunneum strain Cb15III?

\section{Results}

\section{Metarhizium brunneum persistence in soil}

Metarhizium spp. abundance was low in all fields and years when tested April/ May (BBCH01). Most CFU were found in soil samples from field 2 with $43.8 \pm 31.3$ (control ) to $50.0 \pm 33.9(C A(+) M) C F U / g$ soil. In this field, an increase of CFU in September (BBCH 99) was observed regardless of the treatments (Table 7). The only significant increase of CFU during growing season was observed for field 3 (Kruskal-Wallis test: $\left.\mathrm{H}_{(3,30)}=25.64, \mathrm{p}<0.0001\right)$. An application with $C A(+) M$ beads $(33375.0 \mathrm{CFU} / \mathrm{g})$ in field 3 significantly increased Metarhizium spp. abundance to the control (<1 CFU/g) (Dunnett test: $p<0.0001$ ). In most cased, Metarhizium spp. abundance was below detection level with less than $1 \mathrm{CFU} / \mathrm{g}$ soil. CFU in field 5 could not be determined in September $(\mathrm{BBCH} 99)$ due to a total field loss caused by a Phytophtora infestans infestation.

Table 7 Number of colony forming units (CFU) (mean \pm standard error (SE)) of Metarhizium spp. field sites (1-5) before $($ April $=\mathrm{BBCH}$ 01) and after (August/September $=$ $\mathrm{BBCH}$ 99) treatment application of mycelium, $C A(+) M, C P(+) M$ or $C P(-) M$ compared to an untreated control (four replicates/ field); $<1 \mathrm{CFU} / \mathrm{g}$ soil refers to an undetectable level of Metarhizium spp.; asterisk $\left({ }^{*}\right)$ indicates significant differences between treatments and control (Dunnet-test, $\alpha=0.05$ )

\begin{tabular}{|c|c|c|c|c|c|c|}
\hline \multirow[t]{2}{*}{$\begin{array}{l}\text { Fiel } \\
\text { d }\end{array}$} & \multirow[t]{2}{*}{ Date } & \multicolumn{5}{|c|}{ No. CFU/g soil $\pm S E$} \\
\hline & & control & mycelium & $C A(+) M$ & $C P(+) M$ & $C P(-) M$ \\
\hline \multirow[t]{2}{*}{1} & April/ BBCH 01 & $<1$ & $<1$ & $<1$ & n.t. & n.t. \\
\hline & Sep./ BBCH 99 & $<1$ & $12.5 \pm 12.5$ & $<1$ & n.t. & n.t. \\
\hline \multirow[t]{2}{*}{2} & May/ BBCH 01 & $43.8 \pm 31.3$ & $43.8 \pm 31.9$ & $50.0 \pm 33.9$ & n.t. & n.t. \\
\hline & Sep./ BBCH 99 & $106.3 \pm 63.7$ & $25.0 \pm 13.4$ & $183.3 \pm 101.4$ & n.t. & n.t. \\
\hline \multirow[t]{2}{*}{3} & April/ BBCH 01 & $3.13 \pm 3.1$ & $<1$ & $31.3 \pm 31.3$ & n.t. & n.t. \\
\hline & Aug./ BBCH 99 & $<1$ & $<1$ & $3375.0 \pm 1016.5^{\star}$ & n.t. & n.t. \\
\hline \multirow[t]{2}{*}{4} & April/ BBCH 01 & $<1$ & n.t. & $6.3 \pm 6.3$ & $6.3 \pm 6.3$ & $6.3 \pm 6.3$ \\
\hline & Sep./ BBCH 99 & $<1$ & n.t. & $<1$ & $<1$ & $<1$ \\
\hline \multirow[t]{2}{*}{5} & April/ BBCH 01 & $<1$ & n.t. & $<1$ & $<1$ & $<1$ \\
\hline & Sep./ BBCH 99 & n.t. & n.t. & n.t. & n.t. & n.t. \\
\hline
\end{tabular}


Chapter 3 Encapsulated $M$. brunneum mycelium: a novel approach of managing wireworms in field with an endophytic M. brunneum strain Cb15III?

\section{Assessment of wireworm damage}

Wireworm damage varied from 8 to $83 \%$ percent across fields in both years (Figure 1). Lowest wireworm damage was observed in field 1 and highest in field 2 with $7-10 \%$ and 83 to $86 \%$ damaged tubers, respectively. In 2016, tuber damage was neither significantly reduced in field $1\left(F_{(2,21)}=0.47, p=0.63\right)$, field $2\left(F_{(2,17)}=0.17, p=0.84\right)$ nor in field $3\left(F_{(2,21)}=0.46, p=0.64\right)$. Tuber damage was significantly increased by treatments in field $4\left(F_{(3,28)}=4,94, p<0,01\right)$ in 2017. Therefore, wireworm damaged tubers were significantly more often found in the field 4 treatments $C A(+) M$ (46.8\% \pm 5.3$)$ and $C P(-) M(46.0 \% \pm 3.9)$ compared to the control $(25.9 \% \pm 2.2)$ (Tukey HSD test: $\alpha=0.05$ ). None of the tested treatments was able to reduce wire worm damage below the economical threshold of $5 \%$.
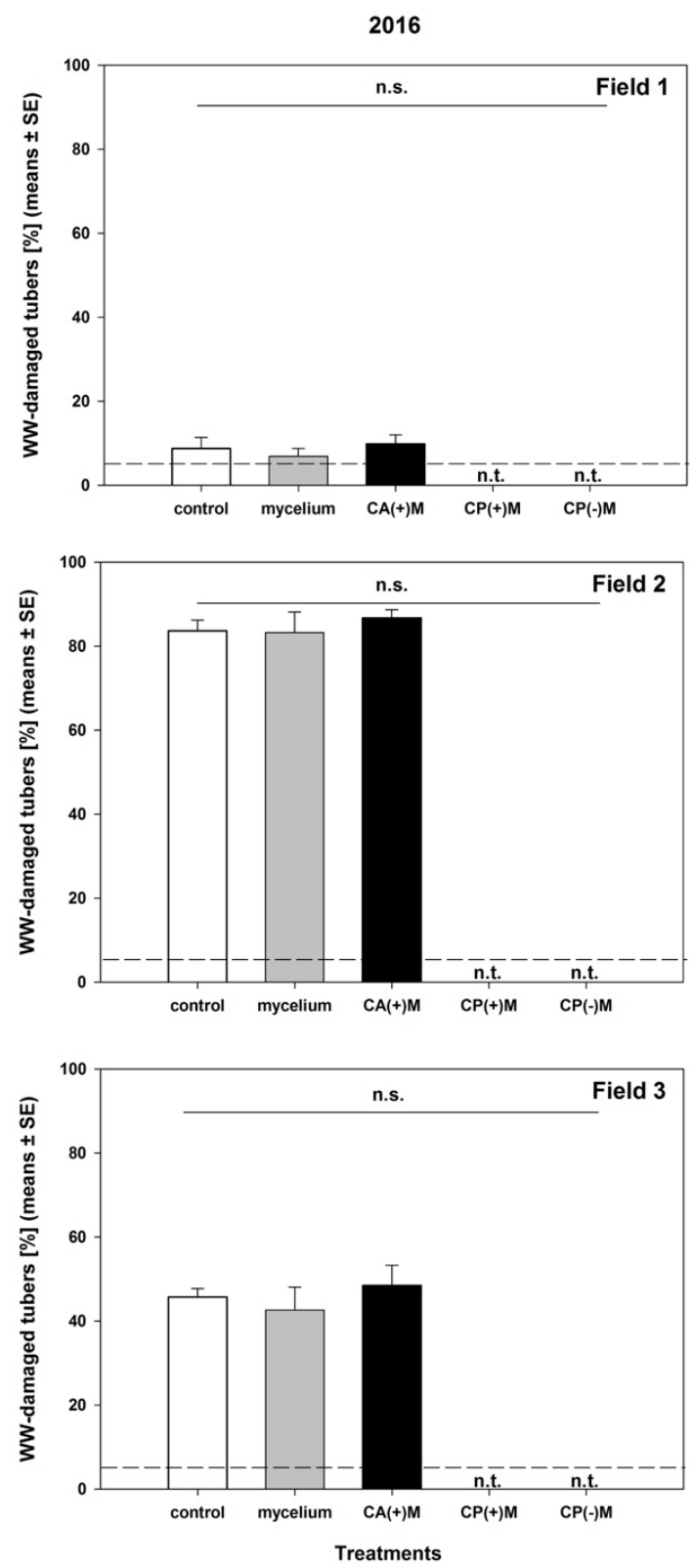

2017

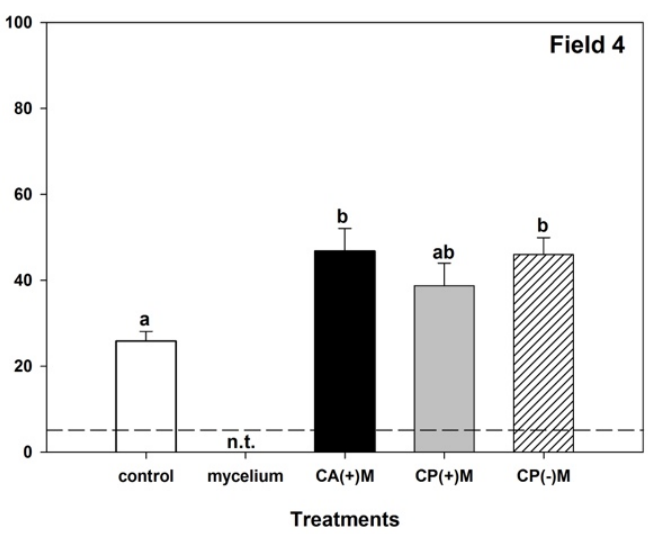

Figure 15 Percentage of wireworm (WW)damaged potato tubers (mean \pm standard error (SE)) at four field sites (2016: fields 1-3; 2017 field 4) with treatments applied as spot application underneath potato tubers. Control: untreated potato dams; mycelium: $\quad$ M. brunneum (Cb15III) mycelium suspension; $C A(+) M \& C P(+) M$ : $M$. brunneum mycelium beads; $C P(-) M$ : Beads without fungal mycelium. Different lower letters indicate significant differences between groups (One-way ANONVA followed by Tukey HSD test $(\alpha=$ 0.05). Dashed line indicates economic threshold level (= $5 \%)$; n.t. not tested) 
Chapter 3 Encapsulated $M$. brunneum mycelium: a novel approach of managing wireworms in field with an endophytic M. brunneum strain Cb15III?
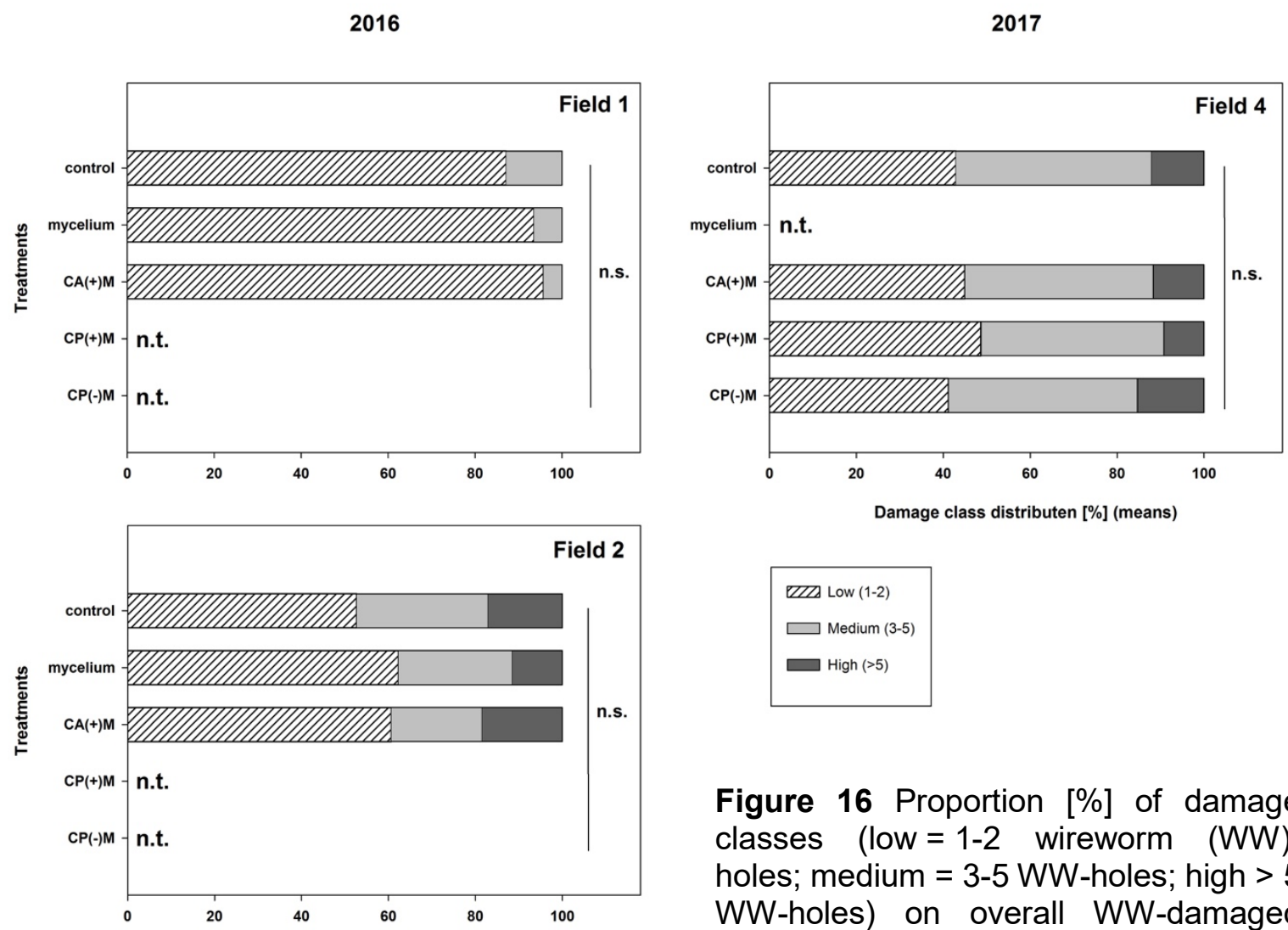

Figure 16 Proportion [\%] of damage classes (low $=1-2$ wireworm (WW)holes; medium $=3-5 \mathrm{WW}$-holes; high $>5$ WW-holes) on overall WW-damaged potato tubers at four field sites (2016: fields 1-3; 2017 field 4) with treatments applied as spot application underneath potato tubers. Control: untreated potato dams; mycelium: $M$. brunneum (Cb15III) mycelium suspension; $C A(+) M \quad \&$ $C P(+) M: M$. brunneum mycelium beads; $C P(-) M$ : Beads without fungal mycelium. Different lower letters indicate significant differences between groups (KruskalWallis test $(\alpha=0.05)$. n.t. not tested

The proportion of damage classes (low = 1 - 2 wireworm (WW)-holes; medium = 3 $5 \mathrm{WW}$-holes; high > $5 \mathrm{WW}$-holes) on overall wireworm damaged potato tubers was not affected by treatments across fields and both year (Kruskal-Wallis test $(\alpha=0.05)$ ). The highest proportion of tubers damaged with more than five wireworm holes was found in field 2 with percentages between 10 to $15 \%$ on the overall wireworm damage. Adittionally, the highest overall wireworm damage (up to $83 \%$ damaged tubers) was observed in field 2 (Figure 2). In field 1, the level of wireworm damage was low and 93 to $97 \%$ of damaged tubers revealed a low damage with $1-2$ wireworm holes per tuber. Treatments mycelium and $C A(+) M$ in field $1\left(\mathrm{H}_{(2,23)}=0.19, \mathrm{p}=0.91\right)$ and field 2 
Chapter 3 Encapsulated $M$. brunneum mycelium: a novel approach of managing wireworms in field with an endophytic M. brunneum strain Cb15III?

$\left(\mathrm{H}_{(2,23)}=0.09, \mathrm{p}=0.96\right)$ slightly increased the proportion of lowly damaged tubers compared to the untreated control indicating that severity of wireworm damage was reduced. However, the opposite was true in field $3\left(\mathrm{H}_{(2,23)}=3.89, \mathrm{p}=0.14\right)$ where the control revealed the highest proportion of low damage $(89.5 \% \pm 3.4)$ compared to mycelium $(70.0 \% \pm 3.0)$ and $C A(+) M(88.1 \% \pm 4.0)$.

Drycore symptoms were assessed for the years 2016 and 2017 and varied in the control treatments between 5 and $28 \%$ across all fields (Table 8). No significant differences were found within treatments in 2016 neither in field $1\left(F_{(2,21)}=1.89\right.$, $p=0.18)$, field $2\left(F_{(2,17)}=0.06, p=0.93\right)$ nor in field $3\left(F_{(2,21)}=0.82, p=0.45\right)$. Treatments had a significant effect on the abundance of drycore symptoms in field 4 (2017) $\left(F_{(3,28)}=4.44, p<0.05\right)$. Compared to the control, drycore symptoms in field 4 were increased in all treatments but significantly by treatment $C P(-) M$ (Tukey HSD test: $p<0.01)$. The highest overall abundance of drycore symptoms was also found in tubers harvested from field 4 and varied between 26 (control) and $43 \%$ (CP(-)M). Rhizoctonia solani sclerotia were found on harvested tubers throughout years and fields and varied between 3 and $90 \%$ (Table 9).

Table 8 Percentage of potato tubers with drycore symptoms (mean \pm standard error (SE)) at four field sites (2016: fields 1-3; 2017 field 4) with treatments applied as spot application underneath potato tubers. Control: untreated potato dams; mycelium: M. brunneum (Cb15III) mycelium suspension; $C A(+) M \& C P(+) M$ : $M$. brunneum mycelium beads; $C P(-) M$ : Beads without fungal mycelium. Different lower letters indicate significant differences between groups (One-way ANONVA followed by Tukey HSD test $(\alpha=0.05)$ ).

\begin{tabular}{|c|c|c|c|c|}
\hline \multirow[t]{3}{*}{ Treatment } & \multicolumn{4}{|c|}{ Tubers with drycore symptom [\%] } \\
\hline & \multicolumn{3}{|l|}{2016} & \multirow{2}{*}{$\begin{array}{l}2017 \\
\text { Field } 4\end{array}$} \\
\hline & Field 1 & Field 2 & Field 3 & \\
\hline control & $5.1 \pm 1.4$ & $28.3 \pm 10.2$ & $15.0 \pm 3.8$ & $26.5 \pm 2.1 \mathrm{a}$ \\
\hline mycelium & $6.6 \pm 1.3$ & $30.3 \pm 8.0$ & $9.8 \pm 2.0$ & n.t. \\
\hline$C A(+) M$ & $9.0 \pm 1.5$ & $34.5 \pm 17.6$ & $16.4 \pm 5.1$ & $37.7 \pm 3.0 \mathrm{ab}$ \\
\hline$C P(+) M$ & n.t. & n.t. & n.t. & $39.5 \pm 3.9 a b$ \\
\hline$C P(-) M$ & n.t. & n.t. & n.t. & $43.4 \pm 4.3 b$ \\
\hline
\end{tabular}


Chapter 3 Encapsulated $M$. brunneum mycelium: a novel approach of managing wireworms in field with an endophytic M. brunneum strain Cb15III?

Percentages of tubers infested with sclerotia did not revealed significant differences neither 2016 in field $1\left(F_{(2,21)}=1.22, p=0.31\right)$, field $2\left(F_{(2,17)}=0.80, p=0.46\right)$ or field 3 $\left(F_{(2,21)}=0.42, p=0.66\right)$ nor 2017 in field $4\left(F_{(3,28)}=0.30, p=0.82\right)$. Most sclerotia adhesions were found on tubers in field 1 and varied between $81(C A(+) M)$ and $90 \%$ (control), fewest in field 2 with 3 (control) to $7 \%(C A(+) M)$ sclerotia infestation. Multiple regression analysis for field $1\left(\mathrm{~F}_{(2,21)}=3.99, \mathrm{p}<0.034\right.$; drycore/WW-damage $\mathrm{R}=0.52$, $\mathrm{p}<0.05$; drycore/sclerotia $\mathrm{R}=0.16, \mathrm{p}=0.40)$ and field $4\left(\mathrm{~F}_{(2.29)}=37.08, \mathrm{p}<0.0001\right.$; drycore/WW-damage $R=0.85, p<0.0001$; drycore/sclerotia $R=0.01, p=0.91$ ) revealed a significant associations among the abundance of drycore symptoms and wireworm damage but not among drycore and sclerotia. In field $2\left(F_{(2.17)}=1.09\right.$, $p=0.36)$ and field $3\left(F_{(2.21)}=3.49, p=0.06\right)$ no associations were found neither among drycore and wireworm damage nor drycore and sclerotia.

Table 9 Percentage of potato tubers infested with Rhizoctonia solani sclerotia (mean \pm standard error (SE)) at four field sites (2016: fields 1-3; 2017 field 4) with treatments applied as spot application underneath potato tubers. Control: untreated potato dams; mycelium: M. brunneum (Cb15III) mycelium suspension; $C A(+) M \& C P(+) M: M$. brunneum mycelium beads; $C P(-) M$ : Beads without fungal mycelium. (One-way ANONVA $(\alpha=0.05)$ ).

\begin{tabular}{|c|c|c|c|c|}
\hline \multirow[t]{3}{*}{ Treatment } & \multicolumn{4}{|c|}{ Tubers with Rhizoctonia solani sclerotia [\%] } \\
\hline & \multicolumn{3}{|l|}{2016} & \multirow{2}{*}{$\begin{array}{l}2017 \\
\text { Field } 4\end{array}$} \\
\hline & Field 1 & Field 2 & Field 3 & \\
\hline control & $90.1 \pm 2.0$ & $3.3 \pm 1.0$ & $31.5 \pm 4.2$ & $46.1 \pm 3.6$ \\
\hline mycelium & $86.9 \pm 3.1$ & $5.1 \pm 2.3$ & $26.0 \pm 6.0$ & n.t. \\
\hline$C A(+) M$ & $81.6 \pm 5.6$ & $7.5 \pm 3.8$ & $25.1 \pm 5.7$ & $52.4 \pm 8.9$ \\
\hline$C P(+) M$ & n.t. & n.t. & n.t. & $54.0 \pm 5.5$ \\
\hline$C P(-) M$ & n.t. & n.t. & n.t. & $54.6 \pm 8.9$ \\
\hline
\end{tabular}

\section{Metarhizium molecular detection (nested-PCR)}

In 2016, Metarhizium spp. was exclusively detected in root, shoot and leaf samples of the control treatment with a frequency up to $80 \%$ (Table 10). Detection levels of Metarhizium spp. in 2017 varied between 0 and $40 \%$ across fields and analyzed plant tissue. Metarhizium DNA was neither found in plant tissue from CP(-)M treatments nor in field 4 control. In 2017, most samples with Metarhizium DNA were found in leaf tissue from field 5 control (40\%). 
Chapter 3 Encapsulated $M$. brunneum mycelium: a novel approach of managing wireworms in field with an endophytic M. brunneum strain Cb15III?

Table 10 Percentage of positiv Metarhizium spp. DNA amplification after nested-PCR in potato plant tissue (root, shoot and stem) at three field sites (2016: field 1; 2017 fields 4 and 5) with treatments applied as spot application underneath potato tubers. Control: untreated potato dams; mycelium: M. brunneum (Cb15III) mycelium suspension; $C A(+) M$ \& $C P(+) M$ : $M$. brunneum mycelium beads; $C P(-) M$ : Beads without fungal mycelium.

\begin{tabular}{|c|c|c|c|c|c|c|c|c|c|}
\hline \multirow{3}{*}{$\begin{array}{l}\text { Treatmen } \\
\mathrm{t}\end{array}$} & \multicolumn{9}{|c|}{ Metarhizium spp. detection [\%] after nested-PCR } \\
\hline & \multicolumn{3}{|c|}{ Field 1} & \multicolumn{3}{|c|}{ Field 4} & \multicolumn{3}{|c|}{ Field 5} \\
\hline & root & shoot & leaf & root & shoot & leaf & root & shoot & leaf \\
\hline control & $25 \%$ & $100 \%$ & $75 \%$ & $0 \%$ & $0 \%$ & $0 \%$ & $0 \%$ & $0 \%$ & $\begin{array}{l}50 \\
\%\end{array}$ \\
\hline mycelium & $0 \%$ & $0 \%$ & $0 \%$ & n.t. & n.t. & n.t. & n.t. & n.t. & n.t. \\
\hline$C A(+) M$ & $0 \%$ & $0 \%$ & $0 \%$ & $13 \%$ & $13 \%$ & $0 \%$ & $0 \%$ & $13 \%$ & $13 \%$ \\
\hline$C P(+) M$ & n.t. & n.t. & n.t. & $13 \%$ & $13 \%$ & $13 \%$ & $0 \%$ & $0 \%$ & $13 \%$ \\
\hline$C P(-) M$ & n.t. & n.t. & n.t. & $0 \%$ & $0 \%$ & $0 \%$ & $0 \%$ & $0 \%$ & $0 \%$ \\
\hline
\end{tabular}

\section{Destruxins determination}

Destruxin $A$ and related destruxins could not be detected in any tuber sample. 
Chapter 3 Encapsulated $M$. brunneum mycelium: a novel approach of managing wireworms in field with an endophytic M. brunneum strain Cb15III?

\section{Discussion}

This study was conducted to investigate the potential of encapsulated M. brunneum Cb15III mycelium to colonize potato and to protect potato tubers from wireworm damage in field trials. Formulation and encapsulation of $M$. brunneum mycelium should enhance endophytic colonization of seed tubers and consequently the entire potato plants, demonstrated by Krell et al. (2018a, b). Treatments were applied as spot application beneath planted tubers to ensure treatments getting in contact with tuber's surface.

Wireworm damage in controls varied between 8 and $83 \%$ across all harvested fields. This kind of variations was also observed by Brandl et al. (2017) and can be explained by differences in cropping history, soil type, weed density, geographical features and the number of wireworms present within specific field site (Salt and Hollick 1946; Parker and Howard 2001; Cherry and Stansly 2008; Hermann et al. 2013) However, tested agents were neither able to reduce percentage of wireworm damage on potato tubers nor its severity.

Metarhizium spp. was more frequently detected with nested-PCR in field 1 and field 5 controls than in M. brunneum Cb15III treated plants. The primers used in this study, Ma 1763 and Ma 2097, were designed to detect Metarhizium species from clade 1 but not specifically M. brunneum (Schneider et al. 2011). Metarhizium clade 1 species are omnipresent in arable soils (Schneider et al. 2012), thus a high natural colonization of control plants with Metarhizium spp. is possible. Lower colonization rates in treated plants could be explained by a low competitive capacity of the $M$. brunneum strain CB15III to the microbial soil community (St. Leger 2008; Bruck 2009). Nevertheless, M. brunneum CB15III was originally isolated from arable land and an application with $C A(+) M$ beads in field 3 increased the abundance of Metarhizium CFU in soil at potato harvest (BBCH 99). However, the abundance of Metarhizium spp. in soil can naturally vary with regard to climate (Bidochka et al. 1998), soil type (Vänninen et al. 2000; Scheepmaker and Butt 2010), vegetation (Meyling and Eilenberg 2006) and land use (Schneider et al. 2012). CFU were increased in field 3 treatment $C A(+) M$ only but showed a high variation between plots. It is unknown if CFU increment is explicable by the $C A(+) M$ treatment or natural variation due to an insect infestation event at sampling location. In addition, it is reported that the persistence of artificially introduced Metarhizium into soil can be low and degrades over time indicating that Metarhizium 
Chapter 3 Encapsulated $M$. brunneum mycelium: a novel approach of managing wireworms in field with an endophytic M. brunneum strain Cb15III?

can be outpaced by antagonistic organisms (Scheepmaker and Butt 2010; Pilz et al. 2011). This could have been of advantage for Metarhizium antagonists resulting in their propagation and consequently suppressing Metarhizium clade 1 species leading to lower colonization rates in treatments (Powell 1971; Mayerhofer et al. 2017).

In laboratory, it was observed that $M$. brunneum encapsulated in beads and placed on field collected soil was grazed by nematodes (personal observation). Therefore, it seems plausible that $M$. brunneum $\mathrm{Cb} 15 \mathrm{III}$ was not able to colonize plants under field conditions or colonization was not consistent until sampling. Some studies reported that Metarhizium spp. persistence in plant tissue over several weeks is possible, once plant tissue was colonized (Batta 2013; Greenfield et al. 2016; Jaber and Enkerli 2016). On the other hand, there are a large number of competing endophytes colonizing potato tubers with a potato-dependent composition (Sturz et al. 1999; Sessitsch et al. 2002, 2004). It is unclear, if the tested M. brunneum strain Cb15III was able to persist within this endophytic community or not (Schulz et al. 2015). As a result, it seemed not possible to introduce $M$. brunneum to a sufficient number of potato plants to establish a systemic plant protection against wireworms.

Moreover, treatments $C A(+) M, C P(+) M$ and $C P(-) M$ intensified wireworm damage in 2017. It is possible that the applied beads attracted wireworms as they were still intact when tubers were harvested in July $(\mathrm{BBCH} 45)$ for destruxins determination. Heavy rainfall between July and September 2017 could have encouraged bead decomposition by microorganism resulting in an increased $\mathrm{CO}_{2}$ production and an increased $\mathrm{CO}_{2}$ gradient towards tubers (Rovira 1953; Paul et al. 1999; Godley 2004). It is known that wireworms orientate along $\mathrm{CO}_{2}$ gradients to locate food sources (Thorpe et al. 1947; Klingler 1957; Doane et al. 1975; Doane and Klingler 1978). As a consequence, more wireworms migrated towards treated potatoes causing more damage in tubers. A further explanation for higher wireworm infestation in treated plots could be that wireworm abundance and distribution within landscape is described as patchy (Salt and Hollick 1946). Wireworm distribution in fields can vary in regard to soil type, moisture and vegetation (Salt and Hollick 1946; Hermann et al. 2013). It is highly improbable but possible that control plot distribution in field 4 coincide with wireworm abundance, even though plots were randomly distributed. Data from field 5 could help explaining effects in field 4 but complete harvest was lost due to a heavy infestation with Phytophthora infestans. 
Chapter 3 Encapsulated $M$. brunneum mycelium: a novel approach of managing wireworms in field with an endophytic M. brunneum strain Cb15III?

Observations made for the abundance of wireworm damage, drycore symptoms and $R$. solani sclerotia adherence on tubers, revealed a significantly higher correlated between wireworm damage and drycore than between $R$. solani sclerotia and drycore. Consequently, the higher abundance of tubers with drycore symptoms in treatments in field 4 can be explained by the higher wireworm damage in these treatments. A coinciding correlation was also revealed in a 3-yaer field survey by Keiser et al. (2012). Differences of $R$. solani sclerotia adherence on tubers, however, were not found within treatments across fields and years. Thus, a correlation between M. brunneum applications and sclerotia formation, as described by Brandl et al. (2017), was not observed.

\section{Conclusion}

The idea of encapsulating the endophytic M. brunneum strain Cb15III and using it to manage wireworms is ambitious and promising. However, this study revealed that the tested applications were not a functional approach to manage wireworms on field scale. This approach needs to be optimized, especially regarding fungal competitive capacity in soil and in plant. Additionally, further molecular approaches needs to be done to reliably detection $M$. brunneum Cb15III with specific primers sets to allow insights into fungal growth within plants. An implementation of this approach into biological control of wireworms without improvements is not recommended.

\section{Acknowledgements}

We would like to thank Bianca Tappe, Marie Nörthemann and Jonas Watterodt for their technical assistance, numerous students, in particular Hendrik Claus, for their contribution, and Dr. Anna Rathgeb (Georg-August-Universität Göttingen, Germany) for conducting the destruxin analysis. Furthermore, we would like to thank Wilfried Dreyer (Ökoring AG, Visselhövede, Germany) for his professional support. These studies were funded by the German Federal Environmental Foundation (DBU), Germany. 
Chapter 3 Encapsulated $M$. brunneum mycelium: a novel approach of managing wireworms in field with an endophytic M. brunneum strain Cb15III?

\section{References}

Adame-Álvarez R-M, Mendiola-Soto J, Heil M (2014) Order of arrival shifts endophytepathogen interactions in bean from resistance induction to disease facilitation. FEMS Microbiol Lett 355:100-107. doi: 10.1111/1574-6968.12454

Batta YA (2013) Efficacy of endophytic and applied Metarhizium anisopliae (Metch.) Sorokin (Ascomycota: Hypocreales) against larvae of Plutella xylostella L. (Yponomeutidae: Lepidoptera) infesting Brassica napus plants. Crop Prot 44:128134. doi: 10.1016/j.cropro.2012.11.001

Behie SW, Jones SJ, Bidochka MJ (2015) Plant tissue localization of the endophytic insect pathogenic fungi Metarhizium and Beauveria. Fungal Ecol 13:112-119. doi: 10.1016/j.funeco.2014.08.001

Behie SW, Zelisko PM, Bidochka MJ (2012) Endophytic Insect-Parasitic Fungi Translocate Nitrogen Directly from Insects to Plants. Science (80- ) 336:15761577. doi: 10.1126/science.1222289

Bidochka MJ, Kasperski JE, Wild GA (1998) Occurrence of the entomopathogenic fungi Metarhizium anisopliae and Beauveria bassiana in soils from temperate and near-northern habitats. Can J Bot 76:1198-1204. doi: 10.1139/b98-115

Brandfass C, Karlovsky P (2008) Upscaled CTAB-Based DNA Extraction and RealTime PCR Assays for Fusarium culmorum and F. graminearum DNA in Plant Material with Reduced Sampling Error. Int J Mol Sci 9:2306-2321. doi: 10.3390/ijms9112306

Brandl MA, Schumann M, Przyklenk M, et al (2017) Wireworm damage reduction in potatoes with an attract-and-kill strategy using Metarhizium brunneum. J Pest Sci (2004) 90:479-493. doi: 10.1007/s10340-016-0824-X

Bruck DJ (2009) Fungal entomopathogens in the rhizosphere. In: The Ecology of Fungal Entomopathogens. Springer Netherlands, Dordrecht, pp 103-112

Carpio A, Arroyo-Manzanares N, Ríos-Moreno A, et al (2016) Development of a QUEChERS-based extraction method for the determination of destruxins in potato plants by UHPLC-MS/MS. Talanta 146:815-822. doi: 10.1016/j.talanta.2015.06.008

Cherry R, Stansly P (2008) Abundance and Spatial Distribution of Wireworms (Coleoptera: Elateridae) in Florida Sugarcane Fields on Muck Versus Sandy Soils. Florida Entomol 91:383-387. doi: 10.1653/0015- 
Chapter 3 Encapsulated $M$. brunneum mycelium: a novel approach of managing wireworms in field with an endophytic M. brunneum strain Cb15III?

4040(2008)91[383:AASDOW]2.0.CO;2

Contreras J, Mendoza JE, Martínez-Aguirre MR, et al (2014) Efficacy of Enthomopathogenic Fungus Metarhizium anisopliae Against Tuta absoluta (Lepidoptera: Gelechiidae). J Econ Entomol 107:121-124. doi: 10.1603/EC13404 Doane JF, Klingler J (1978) Location of CO2-receptive sensilla on larvae of wireworms Agriotes lineatus-obscurus and Limonus californicus. Ann Entomol Soc Am 71:357-363

Doane JF, Lee YW, Klingler J, Westcott ND (1975) THE ORIENTATION RESPONSE OF CTEMCERA DESTRUCTOR AND OTHER WIRE WORMS (COLEOPTERA: ELATERIDAE) TO GERMINATING GRAIN AND TO CARBON DIOXIDE. Can Entomol 107:1233-1252. doi: 10.4039/Ent1071233-12

Eckard S, Ansari MA, Bacher S, et al (2014) Virulence of in vivo and in vitro produced conidia of Metarhizium brunneum strains for control of wireworms. Crop Prot 64:137-142. doi: 10.1016/j.cropro.2014.06.017

EPPO (2005) Wireworms. EPPO Bull 35:179-182. doi: 10.1111/j.13652338.2005.00780.x

European Food Safety Authority (2013) COMMISSION IMPLEMENTING REGULATION (EU) No 781/2013 of 14 August 2013 amending Implementing Regulation (EU) No 540/2011, as regards the conditions of approval of the active substance fipronil, and prohibiting the use and sale of seeds treated with plant $p$. Off J Eur Union L 219:22-25. doi: 10.2903/j.efsa.2013.3158.

Furlan L, Bonetto C, Finotto A, et al (2010) The efficacy of biofumigant meals and plants to control wireworm populations. Ind Crops Prod 31:245-254. doi: 10.1016/j.indcrop.2009.10.012

García JE, Beatriz PJ, Petricari A, Lecuona RE (2011) Metarhizium anisopliae (Metschnikoff) Sorokin promotes growth and has endophytic activity in tomato plants. Adv Biol Res (Rennes) 5:22-27

Godley AR (2004) FACTORS AFFECTING THE SOIL MICROBIAL QUALITY MEASUREMENTS OF BIOMASS QUOTIENT AND RESPIRATION QUOTIENT. Water Environ J 18:73-79. doi: 10.1111/j.1747-6593.2004.tb00500.x

Greenfield M, Gómez-Jiménez MI, Ortiz V, et al (2016) Beauveria bassiana and Metarhizium anisopliae endophytically colonize cassava roots following soil drench inoculation. Biol Control 95:40-48. doi: 10.1016/j.biocontrol.2016.01.002 Gunasekara AS, Truong T, Goh KS, et al (2007) Environmental fate and toxicology of 
Chapter 3 Encapsulated $M$. brunneum mycelium: a novel approach of managing wireworms in field with an endophytic M. brunneum strain Cb15III?

fipronil. J Pestic Sci 32:189-199. doi: 10.1584/jpestics.R07-02

Hack H, Gall H, Klemke T, Klose R (1993) The BBCH scale for phenological growth stages of potato (Solanum tuberosum L.). In: 12th Triennial conference. Paris, pp 153-154

Hermann A, Brunner N, Hann P, et al (2013) Correlations between wireworm damages in potato fields and landscape structure at different scales. J Pest Sci (2004) 86:41-51. doi: 10.1007/s10340-012-0444-z

Jaber LR, Enkerli J (2016) Effect of seed treatment duration on growth and colonization of Vicia faba by endophytic Beauveria bassiana and Metarhizium brunneum. Biol Control 103:187-195. doi: 10.1016/j.biocontrol.2016.09.008

Keiser A, Häberli M, Stamp P (2012) Drycore Appears to Result from an Interaction between Rhizoctonia solani and Wireworm (Agriotes ssp.)—Evidence from a 3Year Field Survey. Potato Res 55:59-67. doi: 10.1007/s11540-012-9207-8

Khan AL, Hamayun M, Khan SA, et al (2012) Pure culture of Metarhizium anisopliae LHL07 reprograms soybean to higher growth and mitigates salt stress. World J Microbiol Biotechnol 28:1483-1494. doi: 10.1007/s11274-011-0950-9

Klingler J (1957) Über die Bedeutung des Kohlendioxyds für die Orientierung der Larven von Otiorrhynchus sulcatus F., Melolontha und Agriotes (Col.) im Boden (Vorläufige Mitteilung). Mitteilungen der Schweizerischen Entomol Gesellschaft 30:317-322

Krell V, Jakobs-Schoenwandt D, Vidal S, Patel A V. (2018a) Encapsulation of Metarhizium brunneum enhances endophytism in tomato plants. Biol Control 116:62-73. doi: 10.1016/j.biocontrol.2017.05.004

Krell V, Jakobs-Schoenwandt D, Vidal S, Patel A V. (2018b) Cellulase enhances endophytism of encapsulated Metarhizium brunneum in potato plants. Fungal Biol 122:373-378. doi: 10.1016/j.funbio.2018.03.002

Lahlali R, Hijri M (2010) Screening, identification and evaluation of potential biocontrol fungal endophytes against Rhizoctonia solani AG3 on potato plants. FEMS Microbiol Lett 311:152-159. doi: 10.1111/j.1574-6968.2010.02084.x

Mantzoukas S, Chondrogiannis C, Grammatikopoulos G (2015) Effects of three endophytic entomopathogens on sweet sorghum and on the larvae of the stalk borer Sesamia nonagrioides. Entomol Exp Appl 154:78-87. doi: 10.1111/eea.12262

Mayerhofer J, Eckard S, Hartmann M, et al (2017) Assessing effects of the 
Chapter 3 Encapsulated $M$. brunneum mycelium: a novel approach of managing wireworms in field with an endophytic M. brunneum strain Cb15III?

entomopathogenic fungus Metarhizium brunneum on soil microbial communities in Agriotes spp. biological pest control. FEMS Microbiol Ecol 93:1-15. doi: 10.1093/femsec/fix117

Meyling N V., Eilenberg J (2006) Occurrence and distribution of soil borne entomopathogenic fungi within a single organic agroecosystem. Agric Ecosyst Environ 113:336-341. doi: 10.1016/j.agee.2005.10.011

Muvea AM, Meyhöfer R, Subramanian S, et al (2014) Colonization of Onions by Endophytic Fungi and Their Impacts on the Biology of Thrips tabaci. PLoS One 9:e108242. doi: 10.1371/journal.pone. 0108242

Parker WE, Howard JJ (2001) The biology and management of wireworms (Agriotes spp.) on potato with particular reference to the U.K. Agric For Entomol 3:85-98. doi: 10.1046/j.1461-9563.2001.00094.x

Paul EA, Harris D, Collins HP, et al (1999) Evolution of CO2 and soil carbon dynamics in biologically managed, row crop agroecosystems. Appl Soil Ecol 11:53-65

Pilz C, Enkerli J, Wegensteiner R, Keller S (2011) Establishment and persistence of the entomopathogenic fungus Metarhizium anisopliae in maize fields. J Appl Entomol 135:393-403. doi: 10.1111/j.1439-0418.2010.01566.x

Powell NT (1971) Interactions Between Nematodes and Fungi in Disease Complexes. Annu Rev Phytopathol 9:253-274. doi: 10.1146/annurev.py.09.090171.001345

Razinger J, Schroers H-J, Urek G (2018) Virulence of Metarhizium brunneum toField Collected Agriotes spp. Wireworms. J Agric Sci Technol 20:309-320

Reddy GVP, Tangtrakulwanich K, Wu S, et al (2014) Evaluation of the effectiveness of entomopathogens for the management of wireworms (Coleoptera: Elateridae) on spring wheat. J Invertebr Pathol 120:43-49. doi: 10.1016/j.jip.2014.05.005

Ríos-Moreno A, Garrido-Jurado I, Resquín-Romero G, et al (2016) Destruxin A production by Metarhizium brunneum strains during transient endophytic colonisation of Solanum tuberosum. Biocontrol Sci Technol 26:1574-1585. doi: 10.1080/09583157.2016.1223274

Ritter C, Richter E (2013) Control methods and monitoring of Agriotes wireworms (Coleoptera: Elateridae). J Plant Dis Prot 120:4-15. doi: 10.1007/BF03356448

Rogge SA, Mayerhofer J, Enkerli J, et al (2017) Preventive application of an entomopathogenic fungus in cover crops for wireworm control. BioControl 62:613623. doi: 10.1007/s10526-017-9816-x

Rovira AD (1953) Use of the Warburg Apparatus in Soil Metabolism Studies. Nature 
Chapter 3 Encapsulated $M$. brunneum mycelium: a novel approach of managing wireworms in field with an endophytic M. brunneum strain Cb15III?

172:29-30

Salt G, Hollick FSJ (1946) Studies of wireworm populations. 2. Spatial distribution. J Exp Biol 23:1-46

Sasan RK, Bidochka MJ (2012) The insect-pathogenic fungus Metarhizium robertsii (Clavicipitaceae) is also an endophyte that stimulates plant root development. Am J Bot 99:101-107. doi: 10.3732/ajb.1100136

Scheepmaker JWA, Butt TM (2010) Natural and released inoculum levels of entomopathogenic fungal biocontrol agents in soil in relation to risk assessment and in accordance with EU regulations. Biocontrol Sci Technol 20:503-552. doi: 10.1080/09583150903545035

Schneider S, Rehner SA, Widmer F, Enkerli J (2011) A PCR-based tool for cultivationindependent detection and quantification of Metarhizium clade 1. J Invertebr Pathol 108:106-114. doi: 10.1016/j.jip.2011.07.005

Schneider S, Widmer F, Jacot K, et al (2012) Spatial distribution of Metarhizium clade 1 in agricultural landscapes with arable land and different semi-natural habitats. Appl Soil Ecol 52:20-28. doi: 10.1016/j.apsoil.2011.10.007

Schulz B, Boyle C (2005) The endophytic continuum. Mycol Res 109:661-686. doi: 10.1017/S095375620500273X

Schulz B, Haas S, Junker C, et al (2015) Fungal endophytes are involved in multiple balanced antagonisms. Curr Sci 108:1-7

Sessitsch a, Reiter B, Pfeifer U, Wilhelm E (2002) Cultivation-independent population analysis of bacterial endophytes in three potato varieties based on eubacterial and Actinomycetes -specific PCR of 16S rRNA genes. FEMS Microbiol Ecol 39:23-32

Sessitsch A, Reiter B, Berg G (2004) Endophytic bacterial communities of field-grown potato plants and their plant-growth-promoting and antagonistic abilities. Can J Microbiol 50:239-249. doi: 10.1139/w03-118

St. Leger RJ (2008) Studies on adaptations of Metarhizium anisopliae to life in the soil. J Invertebr Pathol 98:271-276. doi: 10.1016/j.jip.2008.01.007

Sturz A V., Christie BR, Matheson BG, et al (1999) Endophytic bacterial communities in the periderm of potato tubers and their potential to improve resistance to soilborne plant pathogens. Plant Pathol 48:360-369. doi: 10.1046/j.13653059.1999.00351.x

Thorpe WH, Crombie AC, Hill R, Darrah JH (1947) The behavior of wireworms in response to. chemical stimulation. J Exp Biol 23:234-266 
Chapter 3 Encapsulated $M$. brunneum mycelium: a novel approach of managing wireworms in field with an endophytic M. brunneum strain Cb15III?

Todd Kabaluk J, Lafontaine JP, Borden JH (2015) An attract and kill tactic for click beetles based on Metarhizium brunneum and a new formulation of sex pheromone. J Pest Sci (2004) 88:707-716. doi: 10.1007/s10340-015-0661-3

van Herk WG, Vernon RS, Tolman JH, Saavedra HO (2008) Mortality of a wireworm, Agriotes obscurus (Coleoptera: Elateridae), after topical application of various insecticides. J Econ Entomol 101:375-83

Vänninen I, Tyni-Juslin J, Hokkanen H (2000) Persistence of augmented Metarhiziumanisopliae and Beauveria bassiana in Finnishagricultural soils. BioControl 45:201-222

Vernon RS, Van Herk W, Tolman J, et al (2008) Transitional sublethal and lethal effects of insecticides after dermal exposures to five economic species of wireworms (Coleoptera: Elateridae). J Econ Entomol 101:365-74. doi: 10.1603/00220493(2008)101[365:TSALEO]2.0.CO;2

Vernon RS, van Herk WG (2013) Wireworms as Pests of Potato

Vidal S, Jaber LR (2015) Entomopathogenic fungi as endophytes : plant - endophyte - herbivore interactions and prospects for use in biological control. Curr Sci 109:46-54 


\section{General discussion}

Potatoes (Solanum tuberosum, L.) are one of the most important but also sensitive crops worldwide. They are infested by many pests and diseases, which challenge organic potato farmers in particular. Beside of pathogens, wireworms, the larvae of click beetles (Agriotes spp., Coleoptera: Elateridae) (French and White 1965), and the Colorado potato beetle (CPB), Leptinotarsa decemlineata SAY, are the most prominent threads to potato causing tremendous yield and quality losses (French and White 1965; Hare 1990; Vernon and van Herk 2013). Management of both pests is difficult due to a high adaptability of CPB to insecticidal agents and the hidden habitat of wireworms. Novel control agents and strategies are urgently needed to prevent crops from damage. Studies on entomopathogenic fungi (EFP), in particular Metarhizium brunneum, revealed that they can be a promising candidates to control wireworms and CPB (Eckard et al. 2014; Tyurin et al. 2016; Razinger et al. 2018). Findings on the endophytic character of $M$. brunneum in potato plants opened new opportunities to control both pests (Ríos-Moreno et al. 2016; Krell et al. 2018b). Thus, development of a systemic plant protection with endophytic EPF can help managing potato pests and reduce application intervals and rates in field. However, interactions between endophytes, plants and pests are still poorly understood or most widely unknown. In this study, methodologies were implemented to find endophytic EPF and to determine their potential to protect potato plants from pest infestations.

\section{Isolation and identification of Metarhizium spp. strains}

Metarhizium spp. is known to be widely distributed within most agroecosystems (Meyling and Eilenberg 2007). Therefore, this study investigated the feasibility of controlling insect potato pests with entomopathogenic fungi isolated from regionally related habitat. Samples were either taken from permanent grassland or arable land. Isolated strains were identified with a microsatellite analysis, which revealed that almost all strains can be classified as Metarhizium brunneum. General entomopathogenicity was tested with a variation of the insect baiting method (Goettel and Douglas Inglis 1997), though soil was artificially enriched with the assayed M. brunneum strain. Tenebrio molitor L. (Coleoptera: Tenebrionidae) larvae were 
exposed to selected strains from permanent grassland and arable land. It was revealed that especially strain from arable land showed a higher virulence than strains isolated from permanent grassland. This observation was also made when wireworm of the species Agriotes lineatus, $A$. sputator and $A$. obscurus where exposed to isolates from both habitats. The $M$. brunneum strain $\mathrm{Cb} 15 \mathrm{III}$ revealed the highest virulence in the conducted trials against T. molitor and wireworms. M. brunneum strain $\mathrm{Cb} 15 \mathrm{III}$ was, furthermore, successfully tested against larvae of CPB.

These results substantiate findings of Bharadwaj and Stafford (2011) that T. molitor larvae are a suitable bioassay to test many different strains and predict their ability to infect further insect species. In addition, the approach of isolating entomopathogens from regional habitats and test them against insects from the same or a closely related habitat can improve the efficacy of entomopathogenic fungi (EPF) due to a coevolutionary adaptation to local pest populations (Lacey et al. 2001; Vega et al. 2009). Furthermore, balances of native microbial ecosystems are not or only little disturbed when artificially introducing native entomopathogenic control agents (Meyling and Eilenberg 2007).

The tested strain M. brunneum $\mathrm{Cb} 15 \mathrm{III}$ is the first report that one EPF strain from Central Germany can infect both wireworms and CPB. The ability of this strain not only infecting potato pests but also to colonize tubers is promising for the development of future biological approaches (Vidal and Jaber 2015; Krell et al. 2018b).

\section{Endophytic M. brunneum against CPB}

The present study is the first, investigating effects of an endophytic $M$. brunneum strain Cb15III on the development and behavior of CPB larvae and adults. Effects on CPB were tested laboratory (choice test), greenhouse (non-choice test) and field experiments. The greenhouse experiment was conducted to evaluate effects of M. brunneum inoculated plants on the development from neonate larvae to emerged adults. In the non-choice laboratory trial behavior and plant preference of CPB adults were observed in 'arenas' (Schütz et al. 1997). In a first set up adults were separated from potato leaves with gauze to evaluate the impact of leaf volatiles on adults' behavior. Gauze was removed in second set up to observe, if adults' leaf preferences change when in direct contact to leaves. In both set up, plants were either inoculated with M. brunneum $\mathrm{Cb} 15 \mathrm{III}, 0.1 \%$ Tween $^{\circledR} 80$ or not treated at all. Final field trials were 
conducted to observed effects of $M$. brunneum inoculated seed tubers on CPB behavior and development under field conditions.

A treatment with $M$. brunneum Cb15III revealed partially significant effects in CPB. In the conducted greenhouse trial CPB development was slightly depressed when larvae fed on $M$. brunneum inoculated plants, consequently adult emergence was reduce by an average of $33 \%$ and tibia length was slightly shortened. Mycosed larvae, pupae or adults were not found throughout the experiment, thus a direct infection with the endophytic EPF was not proven. It is possible that M. brunneum induced changes in plant metabolism or introduced own secondary metabolites into plant tissue (Jallow et al. 2008; Ríos-Moreno et al. 2016). Fungal induced changes in food source could have negatively influenced larval development. However, it unclear if $M$. brunneum was able to colonize potato plants successfully because it could neither been re-isolated from plant tissue nor explicitly detected with a nested-PCR. In addition, a direct contact and infection of CPB larvae with the EPF cannot be excluded as seed tubers were placed soaking wet into planting soil after dipping in spore suspension.

To improve chances of fungal colonization, tubers in the laboratory and field trials were inoculated via injection into tuber tissue. In field, a M. brunneum $\mathrm{Cb} 15 \mathrm{III}$ treatment had significant effects on CPB oviposition and thus on abundance of $L_{1}-L_{3}$ larvae on plants. These effects are hardly explainable, in particular because deterrent effects of M. brunneum treated plants have not been observed in the laboratory choice experiment. Effects of solanine or destruxin contents in plants are unlikely, since destruxins were not detected in tuber tissue and solanine is not known to influence CBP host plant location or oviposition (Harrison and Mitchell 1988; Hollister et al. 2001; Hufnagel et al. 2017). Volatiles were not measured in the experiments, though a measurement could help explain effects of $M$. brunneum on plant metabolism and therefor CPB host plant localization (Visser et al. 1979; Bolter et al. 1997; Schütz et al. 1997). A further determination of volatiles emitted by M. brunneum treated plants could also help to evaluate the potential of this approach to be used in a "push pull" strategy (Cook et al. 2007). Advantages of such an approach would be a more targeted and overall reduced application of insecticidal agents. 


\section{Encapsulated mycelium against wireworms}

The management of wireworms with an application of encapsulated mycelium of the fungus $M$. brunneum $\mathrm{Cb} 15 \mathrm{III}$ in calcium alginate/starch or calcium pectinate/starch beads was evaluated in field trials in 2016 and 2017. Treatments were applied as spot applications beneath seed tubers during potato planting. Quality samples from each treatment were evaluated in laboratory and revealed M. brunneum outgrow from all beads containing mycelium $(C A(+) M, C P(+) M)$. Fungal outgrow was not observed from beads without formulated fungal biomass $(C P(-) M)$. Under sterile conditions, encapsulation of $M$. brunneum mycelium enhanced endophytism in plants (Krell et al. 2018a, b). In field, an increased colonization of potato plants treated with mycelium capsules could not be detected with a nested-PCR. Furthermore, colonization was partially higher in control plants. To date, it is not possible to detect $M$. brunneum with one set of primers, thus primers for detecting Metarhizium clade 1 ('Ma 1763' and 'Ma 2079') were used in this study (Schneider et al. 2011). As a consequence, it can be assumed that potato plants were colonized by Metarhizium spp. but not exclusively M. brunneum. A more frequent colonization of control plants is hardly explainable and further research must reveal how competitive $M$. brunneum $\mathrm{Cb} 15 \mathrm{III}$ is within the soil and endophytic communities.

None of the tested treatments was able to reduce wireworm damage compared to the control, thus bead performance left behind expectations. An encapsulation formulation of $M$. brunneum mycelium should not just have enhance endophytism but also protect the sensitive mycelium from biotic and abiotic influences (Vemmer and Patel 2013). In preliminary experiments, beads were solely tested under sterile conditions (Krell et al. 2018a; Vivien Krell, personal communication). Hence, it is unknown, if M. brunneum Cb15III was able to grow from applied beads or outpaced by antagonistic microorganisms. Consequently, the tested agents are not a feasible approach to protect potatoes from wireworm damage. 


\section{References (General introduction and discussion)}

Akbarian J (2012) Pathogenicity of some isolates of Beauveria bassiana (Bals.) Vuill. and Metarhizium anisopliae (Metsch.) Sorokin on 2nd and 4th larval instars of Colorado potato beetle, Leptinotarsa decemlineata (Say) (Col.: Chrysomelidae), under laboratory conditions. African J Microbiol Res 6:6407-6413. doi: 10.5897/AJMR12.1112

Alyokhin A, Baker M, Mota-Sanchez D, et al (2008) Colorado potato beetle resistance to insecticides. Am J Potato Res 85:395-413. doi: 10.1007/s12230-008-9052-0

Anonymous (2008) Commission regulation (EC) no 889/2008 of 5 September 2008 laying down detailed rules for the implementation of council regulation $(E C)$ no $834 / 2007$ on organic production and labelling of organic products with regard to organic production, labelling and co. Off J Eur Union L 250:1-84

Batta YA (2013) Efficacy of endophytic and applied Metarhizium anisopliae (Metch.) Sorokin (Ascomycota: Hypocreales) against larvae of Plutella xylostella L. (Yponomeutidae: Lepidoptera) infesting Brassica napus plants. Crop Prot 44:128134. doi: 10.1016/j.cropro.2012.11.001

Behie SW, Zelisko PM, Bidochka MJ (2012) Endophytic Insect-Parasitic Fungi Translocate Nitrogen Directly from Insects to Plants. Science (80- ) 336:15761577. doi: 10.1126/science.1222289

Bharadwaj A, Stafford KC (2011) Potential of Tenebrio molitor (Coleoptera: Tenebrionidae) as a Bioassay Probe for Metarhizium brunneum (Hypocreales: Clavicipitaceae) Activity Against Ixodes scapularis (Acari: Ixodidae). J Econ Entomol 104:2095-2098. doi: 10.1603/EC11170

Bolter CJ, Dicke M, Van Loon JJA, et al (1997) Attraction of Colorado Potato Beetle to Herbivore-Damaged Plants During Herbivory and After Its Termination. J Chem Ecol 23:1003-1023. doi: 10.1023/B:JOEC.0000006385.70652.5e

Brandl MA, Schumann M, Przyklenk M, et al (2017) Wireworm damage reduction in potatoes with an attract-and-kill strategy using Metarhizium brunneum. J Pest Sci (2004) 90:479-493. doi: 10.1007/s10340-016-0824-x

Contreras J, Mendoza JE, Martínez-Aguirre MR, et al (2014) Efficacy of Enthomopathogenic Fungus Metarhizium anisopliae Against Tuta absoluta (Lepidoptera: Gelechiidae). J Econ Entomol 107:121-124. doi: 10.1603/EC13404 
Cook SM, Khan ZR, Pickett JA (2007) The Use of Push-Pull Strategies in Integrated Pest Management. Annu Rev Entomol 52:375-400. doi: 10.1146/annurev.ento.52.110405.091407

Cooke LR, Schepers HTAM, Hermansen A, et al (2011) Epidemiology and Integrated Control of Potato Late Blight in Europe. Potato Res 54:183-222. doi: 10.1007/s11540-011-9187-0

Crowder DW, Onstad DW, Gray ME, et al (2005) Analysis of the Dynamics of Adaptation to Transgenic Corn and Crop Rotation by Western Corn Rootworm (Coleoptera: Chrysomelidae) Using a Daily Time-Step Model. J Econ Entomol 98:534-551. doi: 10.1603/0022-0493-98.2.534

Eckard S, Ansari MA, Bacher S, et al (2014) Virulence of in vivo and in vitro produced conidia of Metarhizium brunneum strains for control of wireworms. Crop Prot 64:137-142. doi: 10.1016/j.cropro.2014.06.017

Ertürk Ö (2017) Effects of Various Plant Extracts on the Development of the Potato Beetle under Laboratory and Field Conditions : A Combined Study. J Entomol Res Soc 19:101-112

FAO (2016) World Production Potatos. http://www.fao.org/faostat/en/\#compare. Accessed 2 Jun 2018

Faria MR de, Wraight SP (2007) Mycoinsecticides and Mycoacaricides: A comprehensive list with worldwide coverage and international classification of formulation types. Biol Control 43:237-256. doi: 10.1016/j.biocontrol.2007.08.001 Ferro DN, Logan JA, Voss RH, Elkinton JS (1985) Colorado Potato Beetle (Coleoptera: Chrysomelidae) Temperature-dependent Growth and Feeding Rates. Environ Entomol 14:343-348. doi: 10.1093/ee/14.3.343

French N, White JH (1965) OBSERVATIONS ON WIREWORM POPULATIONS CAUSING DAMAGE TO WARE POTATOES. Plant Pathol 14:41-43. doi: 10.1111/j.1365-3059.1965.tb00620.x

Furlan L (1998) The biology of Agriotes ustulatus Schaller (Col., Elateridae). II. Larval development, pupation, whole cycle description and practical implications. J Appl Entomol Fur Angew Entomol 122:71-78. doi: 10.1111/j.14390418.1998.tb01464.x

Furlan L, Bonetto C, Finotto A, et al (2010) The efficacy of biofumigant meals and plants to control wireworm populations. Ind Crops Prod 31:245-254. doi: 10.1016/j.indcrop.2009.10.012 
Goettel MS, Douglas Inglis G (1997) Fungi. In: Lacey LA (ed) Manual of Techniques in Insect Pathology. Elsevier, London, UK, pp 213-249

Grapputo A, Boman S, Lindström L, et al (2005) The voyage of an invasive species across continents: Genetic diversity of North American and European Colorado potato beetle populations. Mol Ecol 14:4207-4219. doi: 10.1111/j.1365294X.2005.02740.x

Hajek AE, McManus ML, Delalibera I (2007) A review of introductions of pathogens and nematodes for classical biological control of insects and mites. Biol Control 41:1-13. doi: 10.1016/j.biocontrol.2006.11.003

Hajek AE, St. Leger RJ (1994) Interactions Between Fungal Pathogens and Insect Hosts. Annu Rev Entomol 39:293-322. doi: 10.1146/annurev.en.39.010194.001453

Hallsworth JE, Magan N (1999) Water and Temperature Relations of Growth of the Entomogenous Fungi Beauveria bassiana, Metarhizium anisopliae, and Paecilomyces farinosus. J Invertebr Pathol 74:261-266. doi: 10.1006/jipa.1999.4883

Hare JD (1990) Ecology and Management of the Colorado Potato Beetle. Annu Rev Entomol 35:81-100. doi: 10.1146/annurev.en.35.010190.000501

Harrison GD, Mitchell BK (1988) Host-plant acceptance by geographic populations of the colorado potato beetle, Leptinotarsa decemlineata - Role of solanaceous alkaloids as sensory deterrents. J Chem Ecol 14:777-788. doi: 10.1007/BF01018772

Hollister B, Dickens JC, Perez F, Deahl KL (2001) Differential neurosensory responses of adult Colorado potato beetle, Leptinotarsa decemlineata, to glycoalkaloids. J Chem Ecol 27:1105-1118

Hufnagel M, Schilmiller AL, Ali J, Szendrei Z (2017) Choosy mothers pick challenging plants: maternal preference and larval performance of a specialist herbivore are not linked. Ecol Entomol 42:33-41. doi: 10.1111/een.12350

Hywel-Jones NL, Gillespie AT (1990) Effect of temperature on spore germination in Metarhizium anisopliae and Beauveria bassiana. Mycol Res 94:389-392. doi: 10.1016/S0953-7562(09)80363-8

Jallow MFA, Dugassa-Gobena D, Vidal S (2008) Influence of an endophytic fungus on host plant selection by a polyphagous moth via volatile spectrum changes. Arthropod Plant Interact 2:53-62. doi: 10.1007/s11829-008-9033-8 
Kabaluk JT, Ericsson JD (2007) Environmental and behavioral constraints on the infection of wireworms by Metarhizium anisopliae. Environ Entomol 36:1415-20. doi: 10.1603/0046-225X(2007)36[1415:EABCOT]2.0.CO;2

Kabaluk JT, Vernon RS, Goettel MS (2007) Mortality and infection of wireworm, Agriotes obscurus [Coleoptera: Elateridae], with inundative field applications of Metarhizium anisopliae. Phytoprotection 88:51. doi: 10.7202/018055ar

Kapsa JS (2008) Important threats in potato production and integrated pathogen/pest management. Potato Res 51:385-401. doi: 10.1007/s11540-008-9114-1

Keiser A, Häberli M, Stamp P (2012) Drycore Appears to Result from an Interaction between Rhizoctonia solani and Wireworm (Agriotes ssp.)—Evidence from a 3Year Field Survey. Potato Res 55:59-67. doi: 10.1007/s11540-012-9207-8

Khan AL, Hamayun M, Khan SA, et al (2012) Pure culture of Metarhizium anisopliae LHL07 reprograms soybean to higher growth and mitigates salt stress. World J Microbiol Biotechnol 28:1483-1494. doi: 10.1007/s11274-011-0950-9

Krell V, Jakobs-Schoenwandt D, Vidal S, Patel A V. (2018b) Cellulase enhances endophytism of encapsulated Metarhizium brunneum in potato plants. Fungal Biol 122:373-378. doi: 10.1016/j.funbio.2018.03.002

Krell V, Jakobs-Schoenwandt D, Vidal S, Patel A V. (2018a) Encapsulation of Metarhizium brunneum enhances endophytism in tomato plants. Biol Control 116:62-73. doi: 10.1016/j.biocontrol.2017.05.004

Kremen C, Williams NM, Thorp RW (2002) Crop pollination from native bees at risk from agricultural intensification. Proc Natl Acad Sci 99:16812-16816. doi: 10.1073/pnas.262413599

Kryukov VY, Khodyrev VP, Yaroslavtseva ON, et al (2009) Synergistic action of entomopathogenic hyphomycetes and the bacteria Bacillus thuringiensis ssp. morrisoni in the infection of Colorado potato beetle Leptinotarsa decemlineata. Appl Biochem Microbiol 45:511-516. doi: 10.1134/S000368380905010X

Kryukov VY, Yaroslavtseva ON, Dubovskiy IM, et al (2014) Insecticidal and immunosuppressive effect of ascomycete Cordyceps militaris on the larvae of the Colorado potato beetle Leptinotarsa decemlineata. Biol Bull 41:276-283. doi: 10.1134/S1062359014020046

Lacey L., Frutos R, Kaya H., Vail P (2001) Insect Pathogens as Biological Control Agents: Do They Have a Future? Biol Control 21:230-248. doi: 10.1006/bcon.2001.0938 
Lovett B, St. Leger RJ (2014) Stress is the rule rather than the exception for Metarhizium. Curr Genet 253-261. doi: 10.1007/s00294-014-0447-9

Mantzoukas S, Chondrogiannis C, Grammatikopoulos G (2015) Effects of three endophytic entomopathogens on sweet sorghum and on the larvae of the stalk borer Sesamia nonagrioides. Entomol Exp Appl 154:78-87. doi: 10.1111/eea.12262

Matson PA a, Parton WJJ, Power AGG, Swift MJJ (1997) Agricultural intensification and ecosystem properties. Science 277:504-509. doi: 10.1126/science. 277.5325 .504

Meyling N V., Eilenberg J (2007) Ecology of the entomopathogenic fungi Beauveria bassiana and Metarhizium anisopliae in temperate agroecosystems: Potential for conservation biological control. Biol Control 43:145-155. doi: 10.1016/j.biocontrol.2007.07.007

Moonjely S, Barelli L, Bidochka MJ (2016) Insect Pathogenic Fungi as Endophytes. In: Advances in Genetics. pp 107-135

Mota-Sanchez D, Hollingworth RM, Grafius EJ, Moyer DD (2006) Resistance and cross-resistance to neonicotinoid insecticides and spinosad in the Colorado potato beetle,Leptinotarsa decemlineata (Say) (Coleoptera: Chrysomelidae). Pest Manag Sci 62:30-37. doi: 10.1002/ps.1120

Muvea AM, Meyhöfer R, Subramanian S, et al (2014) Colonization of Onions by Endophytic Fungi and Their Impacts on the Biology of Thrips tabaci. PLoS One 9:e108242. doi: 10.1371/journal.pone. 0108242

Ownley BH, Gwinn KD, Vega FE (2010) Endophytic fungal entomopathogens with activity against plant pathogens: Ecology and evolution. BioControl 55:113-128. doi: 10.1007/s10526-009-9241-x

Parker WE, Howard JJ (2001) The biology and management of wireworms (Agriotes spp.) on potato with particular reference to the U.K. Agric For Entomol 3:85-98. doi: 10.1046/j.1461-9563.2001.00094.x

Pawelzik E, Möller K (2014) Sustainable Potato Production Worldwide: the Challenge to Assess Conventional and Organic Production Systems. Potato Res 57:273290. doi: 10.1007/s11540-015-9288-2

Pilz C, Enkerli J, Wegensteiner R, Keller S (2011) Establishment and persistence of the entomopathogenic fungus Metarhizium anisopliae in maize fields. J Appl Entomol 135:393-403. doi: 10.1111/j.1439-0418.2010.01566.x 
Premachandra DWTS, Borgemeister C, Poehling H-M (2005) Effects of Neem and Spinosad on Ceratothripoides claratris (Thysanoptera: Thripidae), an Important Vegetable Pest in Thailand, Under Laboratory and Greenhouse Conditions. J Econ Entomol 98:438-448. doi: 10.1603/0022-0493-98.2.438

Quesada-Moraga E, López-Díaz C, Landa BB (2014) The Hidden Habit of the Entomopathogenic Fungus Beauveria bassiana: First Demonstration of Vertical Plant Transmission. PLoS One 9:e89278. doi: 10.1371/journal.pone.0089278

Razinger J, Schroers H-J, Urek G (2018) Virulence of Metarhizium brunneum toField Collected Agriotes spp. Wireworms. J Agric Sci Technol 20:309-320

Reddy GVP, Tangtrakulwanich K, Wu S, et al (2014) Evaluation of the effectiveness of entomopathogens for the management of wireworms (Coleoptera: Elateridae) on spring wheat. J Invertebr Pathol 120:43-49. doi: 10.1016/j.jip.2014.05.005

Ríos-Moreno A, Garrido-Jurado I, Resquín-Romero G, et al (2016) Destruxin A production by Metarhizium brunneum strains during transient endophytic colonisation of Solanum tuberosum. Biocontrol Sci Technol 26:1574-1585. doi: 10.1080/09583157.2016.1223274

Ritter C, Richter E (2013) Control methods and monitoring of Agriotes wireworms (Coleoptera: Elateridae). J Plant Dis Prot 120:4-15. doi: 10.1007/BF03356448

Rogge SA, Mayerhofer J, Enkerli J, et al (2017) Preventive application of an entomopathogenic fungus in cover crops for wireworm control. BioControl 62:613623. doi: 10.1007/s10526-017-9816-x

Roush RT, Hoy CW, Ferro DN, Tingey WM (1990) Insecticide resistance in the Colorado Potato Beetle (Coleoptera: Chrysomelidae): Influence of crop rotation and insecticide use. J Econ Entomol 83:315-319

Sasan RK, Bidochka MJ (2012) The insect-pathogenic fungus Metarhizium robertsii (Clavicipitaceae) is also an endophyte that stimulates plant root development. Am J Bot 99:101-107. doi: 10.3732/ajb.1100136

Scheepmaker JWA, Butt TM (2010) Natural and released inoculum levels of entomopathogenic fungal biocontrol agents in soil in relation to risk assessment and in accordance with EU regulations. Biocontrol Sci Technol 20:503-552. doi: 10.1080/09583150903545035

Schneider S, Rehner SA, Widmer F, Enkerli J (2011) A PCR-based tool for cultivationindependent detection and quantification of Metarhizium clade 1. J Invertebr Pathol 108:106-114. doi: 10.1016/j.jip.2011.07.005 
Schütz S, Weißbecker B, Klein A, Hummel HE (1997) Host Plant Selection of the Colorado Potato Beetle as Influenced by Damage Induced Volatiles of the Potato Plant. Naturwissenschaften 84:212-217. doi: 10.1007/s001140050381

Shah P a, Pell JK (2003) Entomopathogenic fungi as biological control agents. Appl Microbiol Biotechnol 61:413-423. doi: 10.1007/s00253-003-1240-8

Stoate C, Boatman ND, Borralho RJ, et al (2001) Ecological impacts of arable intensification in Europe. J Environ Manage 63:337-365. doi: 10.1006/jema.2001.0473

Trisyono A, Whalon ME (1999) Toxicity of Neem Applied Alone and in Combinations with Bacillus thuringiensis to Colorado Potato Beetle (Coleoptera: Chrysomelidae). J Econ Entomol 92:1281-1288. doi: 10.1093/jee/92.6.1281

Tyurin M V., Kryukov VY, Yaroslavtseva ON, et al (2016) Comparative analysis of immune responses in Colorado potato beetle larvae during development of mycoses caused by Metarhizium robertsii, M. brunneum, and M. pemphigi. J Evol Biochem Physiol 52:252-260. doi: 10.1134/S002209301603008X

Vega FE, Goettel MS, Blackwell M, et al (2009) Fungal entomopathogens: new insights on their ecology. Fungal Ecol 2:149-159. doi: 10.1016/j.funeco.2009.05.001

Vemmer M, Patel A V. (2013) Review of encapsulation methods suitable for microbial biological control agents. Biol Control 67:380-389. doi: 10.1016/j.biocontrol.2013.09.003

Vernon RS, Van Herk W, Tolman J, et al (2008) Transitional sublethal and lethal effects of insecticides after dermal exposures to five economic species of wireworms (Coleoptera: Elateridae). J Econ Entomol 101:365-74. doi: 10.1603/00220493(2008)101[365:TSALEO]2.0.CO;2

Vernon RS, van Herk WG (2013) Wireworms as Pests of Potato

Vidal S, Jaber LR (2015) Entomopathogenic fungi as endophytes : plant - endophyte - herbivore interactions and prospects for use in biological control. Curr Sci 109:46-54

Visser JH, van Straten S, Maarse H (1979) Isolation and identification of volatiles in the foliage of potato, Solanum tuberosum, a host plant of the colorado beetle, Leptinotarsa decemlineata. J Chem Ecol 5:13-25. doi: 10.1007/BF00987684

Whalon ME, Miller DL, Hollingworth RM, et al (1993) Selection of a Colorado Potato Beetle (Coleoptera: Chrysomelidae) Strain Resistant to Bacillus thuringiensis. J Econ Entomol 86:226-233. doi: 10.1093/jee/86.2.226 
Willer H, Lernoud J (2018) The World of Organic Agriculture. Statistics and Emerging Trends 2018. In: Willer H, Lernoud J (eds) Research Institute of Organic Agriculture (FiBL), Frick, and IFOAM - Organics International, Bonn. Bonn

Wraight S., Ramos M. (2002) Application Parameters Affecting Field Efficacy of Beauveria bassiana Foliar Treatments against Colorado Potato Beetle Leptinotarsa decemlineata. Biol Control 23:164-178. doi: 10.1006/bcon.2001.1004

Yaroslavtseva ON, Dubovskiy IM, Khodyrev VP, et al (2017) Immunological mechanisms of synergy between fungus Metarhizium robertsii and bacteria Bacillus thuringiensis ssp. morrisoni on Colorado potato beetle larvae. J Insect Physiol 96:14-20. doi: 10.1016/j.jinsphys.2016.10.004

Zehnder G, Gurr GM, Kühne S, et al (2007) Arthropod pest management in organic crops. Annu Rev Entomol 52:57-80. doi: 10.1146/annurev.ento.52.110405.091337

Zehnder GW, Evanylo GK (1988) Influence of Colorado potato beetle sample counts and plant defoliation on potato tuber production. Am Potato J 65:725-736. doi: 10.1007/BF02853502 


\section{Publications}

\section{Presentations at conferences and workshops}

Hettlage, L., S. Vidal (2017)

New insight in the endophytic behavior of Metarhizium brunneum and the effects on Solanum tuberosum and their pests, DGaaE-Tagung, Freising

Hettlage, L., S. Vidal (2017)

Metarhizium behandelte Kartoffelknollen - eine neue Möglichkeit des Kartoffelkäfer Managements?, DPG-Arbeitskreis Kartoffel, Braunschweig

Fischer M.-E., L. Hettlage, S. Vidal (2018)

Einsatz von mit Metarhizium brunnuem beimpften Kartoffelknollen zur Bekämpfung von Leptinotarsa decemlineata im Freiland, DPG-Arbeitskreis Kartoffel, Braunschweig

\section{Posters at conferences}

Hettlage, L., V. Krell, D. J. Jakobs-Schönwandt, S. Vidal und A. V. Patel (2017) Mit Metarhizium brunneum behandelte Saatknollen als neue Bekämpfungsstrategie gegen den Kartoffelkäfer (Leptinotarsa decemlineata SAY), 60. Deutsche Pflanzenschutztagung, Halle-Wittenberg 


\section{Acknowledgements}

Herrn Prof. Dr. Stefan Vidal danke ich für die Vergabe des interessanten Themas, für den Freiraum zur Umsetzung eigener Ideen, das Vertrauen und die Unterstützung, für die anregenden Diskussionen und für die hilfreiche Durchsicht der Manuskripte.

Herrn Dr. Mario Schumann danke ich für die immer wieder guten Ideen, die Zusammenarbeit, die vielen hilfreichen Diskussionen und wertvolle Hilfe auf dem Feld.

Mein Dank gilt dem gesamten Bielefelder Team für die gute Zusammenarbeit. Ich danke insbesondere Frau Vivien Krell für die Produktion und der Mycelkapseln für die Feldversuche. Herrn Prof. Dr. Anant Patel möchte ich zudem für die bereitwillige Übernahme des Korreferats danken.

Herrn Dr. Rainer Meyhöfer danke ich für die Mitgliedschaft im Prüfungskomitee.

Frau Bianca Tappe möchte ich für ihre unermüdliche Hilfe sowohl im Labor als auch auf dem Feld, die guten Gespräche und ihre bereichernde Art danken.

Ich danke Frau Marie Nörthemann, unseren Auszubildenden Sarah und Jonas, sowie allen Hiwis, die mir bei den Versuchsanstellungen geholfen.

Herrn Wilfried Dreyer danke ich für die gute Zusammenarbeit bei der Durchführung der Feldversuche.

Ich danke allen Landwirten die ihre Flächen zur Verfügung gestellt habe.

Ich danke Dr. Jürg Enkerli für die Identifikation der Metarhizium Isolate.

Ich danke Frau Dr. Anna Rathgeb für die Analysen der Destruxin und Solanin Gehalte.

Meinen Kollegen der Agrarentomologie danke ich für die gute und freundliche Zusammenarbeit, sowie vielen schönen Stunden.

Mein herzlichster Dank gilt dem Technikerteam: Frank Gremmes, Holger Heitmüller, Mark Fiebrich, Hubertus Reintke sowie Maik Knobel.

Ich danke meiner Familie und Freunden, besonders meiner Freundin, die mich stets unterstützt hat! 


\section{E rk I äru nge n}

1. Hiermit erkläre ich, dass diese Arbeit weder in gleicher noch in ähnlicher Form bereits anderen Prüfungsbehörden vorgelegen hat.

Weiter erkläre ich, dass ich mich an keiner anderen Hochschule um einen Doktorgrad beworben habe.

Göttingen, den

(Unterschrift)

2. Hiermit erkläre ich eidesstattlich, dass diese Dissertation selbständig und ohne unerlaubte Hilfe angefertigt wurde.

Göttingen, den

(Unterschrift) 